\title{
Recent advances in open cycle MHD electrical power generation
}

\author{
V K ROHATGI and N VENKATRAMANI \\ MHD Project, Bhabha Atomic Research Centre, Trombay, Bombay 400085
}

MS received 14 November 1983; revised 1 March 1984

\begin{abstract}
The report attempts to summarise the recent developments in the field of MHD electric power generation and identify the problem areas needing further $R$ and $D$ efforts to achieve commercial acceptance of the process. During the last two decades there has been active interest in the development of this technology. A large volume of literature is available in published form, apart from the unpublished information of commercial value. Judging from this standpoint this report cannot be considered exhaustive. Nevertheless it integrates the scattered information in a condensed volume which would be useful in extrapolating the future trends of development while assessing the present status of the technology. To make this report self-contained and complete, the fundamental principles of MHD power generation have also been included.
\end{abstract}

Keywords. MHD; electrical power generation; power generation; fuel selection and evaluation; combustor; air preheater; MHD generator; magnet system; inverter system; steam generator.

\section{Introduction}

The growth of civilisations all over the world is the history of the growth of energy. An energy-deficient society is weak and cannot make economic advancement; and it is primarily the electrical energy that keeps the wheels of progress moving at ever accelerating pace. The main sources of electrical energy have been fossil fuels, hydel and nuclear even though solar energy, geothermal energy, wind power, tidal power and fusion power offer hopeful technological alternatives. However, for most of the nations, the main burden of rapid growth rate of electrical power production for the next few decades have to be borne by power stations using fossil fuels.

At present the fossil-fuel-fired power plants have low energy conversion efficiencies, not more than $40 \%$. Hence, there has been intense research spread over a number of countries to improve thermal efficiency of fossil fuel fired steam turbine units which will not only conserve the known fuel reserves but reduce environmental pollution. In this context, the advent of direct conversion of thermal energy to electrical energy by means of a magnetohydrodynamic converter has received considerable attention. Even with the present level of knowledge and engineering technology, the first generation open cycle MHD-steam plants are expected to have overall efficiencies of $46-50 \%$ and with improvements in technology and experience this figure can be further increased to $60 \%$.

When a conducting fluid moves in a magnetic field, electrical fields are induced in the fluid which in turn result in the flow of electric currents. The interaction of the currents with the magnetic field results in forces which affect the fluid flow pattern and modifications in the magnetic field distribution. The study of this complicated

A list of symbols appears at the end of the paper 
interaction of moving conducting fluid with the magnetic field is the science of MHD (magnetohydrodynamics) which is described by the electromagnetic field equations of Maxwell along with the equations of fluid dynamics. In the literature the terms MGD (magneto gas dynamics), MPD (magneto plasma dynamics) and MFD (magneto fluid dynamics) have also been used sometimes in place of MHD.

\subsection{MHD applications}

Today MHD has many recognised applications in science and industry (Ali Kettani \& Hoyaux 1973). To name a few, geophysics, cosmic physics, controlled thermonuclear fusion and direct energy conversion are some of the areas where MHD plays an important role. In these cases the working fluid may be a conducting liquid (electromagnetic pump; steel making, earth's core) a weakly ionised gas (MHD generators, arc thrustors or accelerators, atmospheric plasmas) or a highly ionised gas (high temperature thermonuclear fusion plasma). In the examples cited above, the phenomena of MHD is manifested in different fashions and require different sets of conditions for analysis. Invariably the general solution of the fluid equations are so complicated that each problem demands a different approximation. In the present manuscript attention is devoted to the progress in the field of MHD electric power generation only and other aspects of MHD are considered beyond the scope of the present discussion.

\subsection{Historical perspective}

Historically MHD power generation was first attempted by Michael Faraday in 1831 using salt water in the Thames River under the action of earth's magnetic field. Though the experiment of Faraday did not succeed, the basic concept of MHD power generation remained unchallenged. After a lapse of hundred years, attempts to demonstrate the principles of MHD power were made by Karlovitz and Halacz in 1942. However, the first successful MHD generator based on argon plasma was tested only in 1959 at Avco in the USA. Since 1960 MHD power generation has drawn considerable attention in several countries.

In 1965 the first model MHD plant (U-02) was commissioned by the Institute of High Temperature in Moscow, USSR. The success of this experiment and continued efforts of Soviet scientists culminated in the first MHD pilot plant (U-25) in 1971 in UsSR. Today this is the biggest working MHD installation in the world which has contributed significantly to the development of MHD power technology. At the same time, many experiments have been conducted in different countries of the world which lend support to the physical concepts as well as the technological feasibility of the MHD power generation process. The overall progress of MHD power generation has been summarised in several publications (see Status Report 1972, 1976, 1980; Petschek 1965; Rosa 1968; Way 1971; Bunde 1975; Rohatgi \& Venkatramani 1980) which conclusively show that the process is now ready for commercialisation. This will be further substantiated, when the first commercial MHD pilot plant goes into operation in the USSR in mid eighties. According to Kirillin \& Shiendlin (1980) several MHD power plants operating on natural gas or oil will be constructed in the USSR in the late eighties followed by the coal-fired MHD plant by early nineties. 


\subsection{Advantages of MHD}

In the MHD generator the thermal energy of the high temperature gas (plasma) is directly converted into electrical energy: hence the MHD power generation is termed as the direct energy conversion process. As a consequence of high temperature direct conversion operation, the MHD power plants are potentially more efficient than the conventional steam power plants. Another important aspect is that basically MHD conversion is a volume process. Thus as the size of the MHD generator increases, the ratio of the MHD power conversion to the surface losses through the walls of the channel becomes more favourable. Consequently for large capacity base load applications, MHD generators are ideally suited. The following advantages of MHD power generation have now been fully established:

(i) The MHD process has a potential to increase the energy conversion efficiencies to $50-60 \%$.

(ii) The MHD process is industrially attractive because of the reduced cooling water requirements and atmospheric pollution.

(iii) MHD generation process is applicable to all kinds of heat sources such as, oil, coal, gas, nuclear, solar and thermonuclear fusion.

(iv) MHD generation offers the flexibility of operation in different modes such as baseload, peak load or semi-peak load.

(v) Studies indicate that MHD power would cost less than the conventional power. The economic benefits of MHD power over the thermal power would become increasingly more favourable as the cost of coal increases.

(vi) Encouraging progress has been made in all the essential nonstandard components of MHD plant. No fundamental technical problems have been identified which could interfere with the ultimate commercialisation of the MHD process, and as it appears today the commercialisation of the process depends on the continuing modifications of the already tested components and sub system designs.

\subsection{Scope of the report}

During the last few years, a large volume of literature on MHD is available in published form and this report attempts to integrate the scattered information in a form which will be useful in assessing the present status and predicting future trends of development. Bulk of the material reviewed here comes from proceedings of international and national conferences, technical reports prepared by leading groups and published accounts of various scientists engaged in the development of this technology in different parts of the world (International Conferences 1962, 1964, 1966, 1968, 1971, 1975, 1980; Status Reports 1972, 1976, 1980; Symposia on Engineering Aspects 1960 to 1971,1973 to 1976,1978 to 1981 ; National Symposia 1975, 1977, 1979; Joint US-USSR colloquia 1974-1976, 1978).

After a detailed review on the principle of MHD power generation in $\$ 2$, the MHD power plant cycles are dealt with in $\$ 3$. The major developmental efforts in the nonstandard equipment and special materials are covered in $\$ 4$. Section 5 covers certain independent areas which are useful in the MHD power plant technology. Considerable knowhow in these areas already exists and only marginal improvements will be necessary to adapt them to MHD plants. The technoeconomic impact of MHD power generation including cogeneration is discussed in $\$ 6$ followed by the concluding 
remarks of the authors on the present status of MHD power plant technology in $\S 7$. The authors are of the view that the short note on the fundamentals of MHD power generation contained in $\$ 2$ will make the report self-contained and complete.

\section{Principle of MHD power generation}

Plasma is a mixture of various species, both charged and neutral. The behaviour of the plasma in an MHD generator can be adequately described by the equations based on the conservation of mass, momentum and energy and Maxwell's equations. However, the problem is complex and certain simplifying approximations are made: the plasma is considered as a single fluid and the flow is said to occur under MHD approximation. This results in using only global equations and neglecting the displacement currents, excess charges and electrostatic body forces.

\subsection{MHD equations}

Under these conditions the complete set of equations (in sI units), which describe the MHD power generator in totality, can be written as follows (Pai 1959; Sutton \& Sherman 1965).

I. Continuity equation (scalar)

$$
(\partial \rho / \partial t)+\nabla \cdot(\rho \bar{v})=0
$$

II. Equation of force (vector)

$$
\rho \frac{D \bar{v}}{D t}=-\nabla p+\overline{\mathrm{J}} \times \bar{B} .
$$

III. Conservation of energy (scalar)

$$
\rho \frac{D}{D t}\left(e+\frac{v^{2}}{2}\right)=-\nabla \cdot(p \bar{v})+\nabla \cdot(k \nabla T)+\bar{J} \cdot \bar{E} .
$$

IV. Ohm's law (vector)

$$
\bar{J}=\overleftrightarrow{\sigma} \cdot(E+\bar{v} \times \bar{B})
$$

V. Maxwell's equations

$$
\begin{aligned}
& \nabla \times \bar{B}=\mu_{0} \cdot \bar{J} \\
& \nabla \times \bar{E}=-\frac{\partial \bar{B}}{\partial t}, \\
& (\nabla \cdot \bar{E}=0 ; \nabla \cdot \bar{B}=0) .
\end{aligned}
$$

VI. Equation of State

$$
p=\rho R T,
$$

where $\rho$ is the density, $\bar{v}$ the velocity, $p$ the pressure, $T$ the temperature, $e$ the internal energy, $k$ the thermal conductivity and $\overleftrightarrow{\sigma}$ the electrical conductivity of the gas, $\bar{E}$ is the electrid field, $\bar{J}$ the current density, $\bar{B}$ the magnetic induction, $\mu_{0}$ the permeability and $R$ the universal gas constant. 
This set of six equations (incorporating the MHD approximations) is frequently known as the MHD equations. In all there are 15 equations containing 15 unknowns comprising of 3 components each of $\bar{B}, \bar{E}, \bar{J}$, and $\bar{v}$ and one each of $p, \rho, T$. In addition there are several constitutive relations for $e, \overleftrightarrow{\sigma}, k$ etc. In general this set of equations is very difficult to solve. One may further simplify these equations to illustrate the basic principles of MHD power generation.

\subsection{Quasi one-dimensional approximation}

The above 15 equations can be reduced to a set of 6 equations assuming the following quasi one-dimensional MHD configuration (figure 1): (i) The only significant velocity component is in the $x$ direction $(u)$. (ii) All the flow quantities like $u, p, T$ are only functions of $x$ and are approximately uniform in the cross-sectional plane $y-z$. (iii) The magnetic field $B\left(B_{x}=B_{y}=0\right)$ has only one component in the $z$ direction whereas electrostatic field $E$ is only in the $x$ and $y$ direction $\left(E_{z}=0\right)$. The induced magnetic field by flow of current is negligible so that Maxwell's equations can be dropped. Both $B$ and $E$ are uniform over the cross-section of the channel. (iv) The flow is fully developed and the transition effects at the inlet and the outlet are neglected. (v) Also assume for simplicity that the Hall parameter $\beta_{e}=\omega_{e} \tau=0$ where $\omega_{e}$ is cyclotron frequency and $\tau^{-1}$ collision frequency. This implies that the flow of current is strictly in the direction of the induced EMF. (vi) Further assume that the induced EMF and flow of current through the entire length of the channel remains constant, then the loading factor $K$ can be treated as constant. (vii) The viscous force and the heat losses are negligible, and (viii) the conductivity is predominantly electronic and other effects like ion-slip are ignored.

Under these conditions the above six equations become:

I. Continuity equation

$$
\rho u A=G,
$$

where $A$ is the area of cross-section of the channel and $G$ the total mass flow rate.

II. Equation of force

$$
\rho u \frac{\mathrm{d} u}{\mathrm{~d} x}=-\frac{\mathrm{d} p}{\mathrm{~d} x}-J B
$$

III. Conservation of energy

$$
\rho u \frac{\mathrm{d}}{\mathrm{d} x}\left(C_{p} T+\frac{u^{2}}{2}\right)=J E,
$$

where the entnalpy $C_{p} T=e+(p / \rho), C_{p}$ being the specific heat.

IV. Ohm's Law

$$
J=\sigma U B(1-K)
$$

where the loading factor $K$ is given by

$$
K=E / U B \text {. }
$$

V. Equation of state

$$
p=\rho R T \text {. }
$$


Equations (9)-(14) are referred to as quasi one-dimensional approximation of MHD equations containing 10 unknowns $(\rho, U, G, p, T, A, K, B, J$, and $E$ ). Specifying the magnetic field $B$, cross-section area $A$, loading factor $K$ and any one of the other flow parameters from $\rho, U, G, p$, and $T$, permits the solution of these six equations with six unknowns.

The principle of MHD power generation can be understood from the set of equations (9) to (14) and is illustrated in figure 1 . When the plasma flowing with a velocity $U$ along $x$ axis passes through a magnetic field $B$ along the $z$ axis an emf equal to $U B$ is induced in the $-y$ direction which is mutually perpendicular to the flow velocity and the magnetic field. If a pair of electrodes is placed along the $y$ axis it permits a current to flow through the load. The power output $P$ per unit volume in such a generator is given by

$$
\begin{aligned}
P=J E & =\sigma U B(1-K) \cdot K U B \\
& =\sigma U^{2} B^{2} K(1-K) .
\end{aligned}
$$

Thus for a large power output from an MHD generator, it is necessary to have high $\sigma$, $U$ and $B$. The above expression for $P$ indicates that the power output is directly proportional to the electrical conductivity of the plasma $\sigma$, the square of the flow velocity $U$ and the square of the magnetic induction $B$. So developing an MHD power generator involves obtaining suitable values of $\sigma, U$ and $B$, or in other words, to make a highly conducting plasma flow across a strong magnetic field $B$ at a high velocity $U$.

At high magnetic fields, for a non-zero $\beta_{e}$, the electrical conductivity of the plasma no longer remains a scalar quantity (as assumed above), but becomes a tensor quantity (Chapman \& Cowling 1958). For a magnetic field $B$ in the $z$ direction the conductivity $\sigma$ becomes

$$
\overleftrightarrow{\sigma}=\left[\begin{array}{ccc}
\frac{\sigma}{1+\beta_{e}^{2}} & -\frac{\sigma \beta_{e}}{1+\beta_{e}^{2}} & 0 \\
-\frac{\sigma \beta_{e}}{1+\beta_{e}^{2}} & \frac{\sigma}{1+\beta_{e}^{2}} & 0 \\
0 & 0 & \sigma
\end{array}\right]
$$

For $\beta_{e} \approx 0.1$, the flow of current does not confine to the direction of $E$ field, but makes an angle which significantly reduces the transverse current, and also results in the

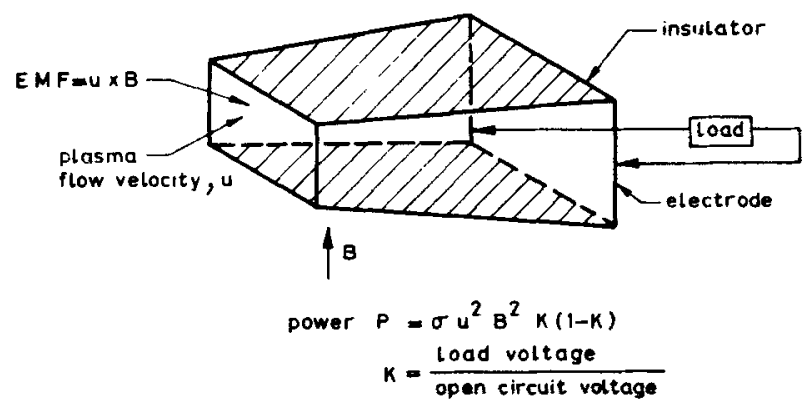

Figare 1. Schematic of MHD generator 
appearance of Hall electric field in the flow direction (Rosa 1976; Hruby et al 1983).

$$
E_{\text {Hall }}=\beta_{e} U B(1-K)
$$

The non-zero $\beta_{e}$ can also give rise to associated instabilities and nonuniformities in the flow. Experiments have been conducted at Avco by introducing a wake non-uniformity in plasma using a vane in the supersonic nozzle of Mark VII generator (Hruby et al 1983). The results indicate that qualitatively Rosa's non-uniformity factor (Rosa 1968) is valid. However, injection of a small amount of water produces a large conductivity defect whereas the injection of nitrogen did not. The consequence of this yet remains to be understood.

\subsection{Types of MHD generators}

To prevent the shorting of current due to Hall voltage, generally the electrodes in a generator are segmented along the direction normal to the flow. This configuration of the MHD generator is known as the segmented electrode Faraday generator. On the other hand, if the segmented pair of electrodes are shorted in a generator and the load current is drawn along the axial electric field (due to the Hall voltage) the generator is known to be operating as a Hall generator. Another mode of operation of a segmented electrode generator is a cross-connected or the diagonal mode of operation, which is a combination of segmented Faraday and Hall mode. The three modes of operation of a MHD generator are illustrated in figure 2. Most of the investigations thus far have been carried out on segmented Faraday generator although some experience has been reported on the diagonal MHD generator also. It is interesting to note that under the joint US-USSR collaboration extensive studies have been conducted; on the basis of which MHD generators are being designed for the commercial MHD plants.
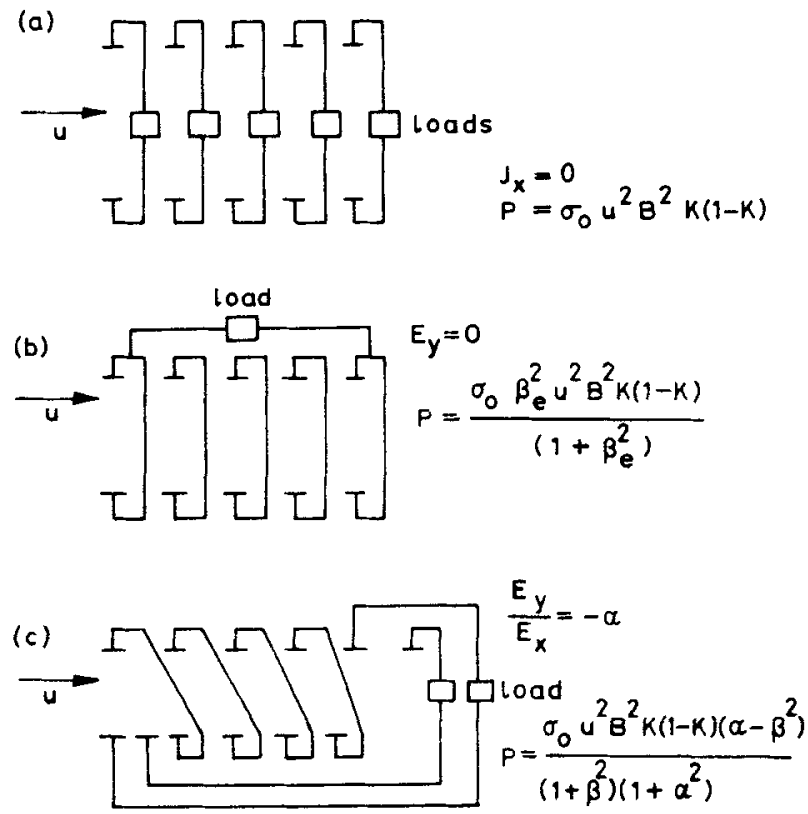

Figure 2. MHD generator configuration (a) Segmented Faraday (b) Hall (c) crossconnected. (Reference: Womack 1969) 
Though widely used for the design of MHD generators, equations (9) to (15) have many limitations when compared to a practical device. The model of MHD generator as described by simple quasi one-dimensional equations suffers from many weaknesses both as regards the physics as well as the prediction of the actual generator performance. At the same time it is very important that a reliable model be developed and evaluated by experiments so that commercial MHD generator can be designed with greater accuracy. It is for this reason that in recent years more realistic models have been considered and analysed which yield results in agreement with the experiment.

\subsection{Non-idealities in MHD generators}

A realistic model of the MHD generator should incorporate the various non-idealities of practical generators. Some of the major non-idealities in MHD generators are: (i) the profiles of temperature and velocity across the cross section leading to nonuniformity in electrical conductivity; (ii) the finite insulation resistance of the walls and the finite conductivity of electrodes; (iii) the mode of current transfer at electrodes and transition mechanisms; (iv) the effect of finite segmentation width as distinguished from infinite segmentation; (v) the entrance and exit regions with nonuniform magnetic induction.

Bityurin \& Lyubimov (1969) have analysed the flow in an MHD channel using quasione-dimensional model with friction and heat transfer at walls. A number of spatial effecis related to the inhomogeneity of flow and imperfection of insulation of the walls of the channel have also been taken into account. The effects of various non-idealities on the generator performance utilizing the quasi-one dimensional model have been studied by Sheindlin et al (1977) and the results presented in table 1. The table clearly shows that the actual output power is only $30 \%$ of the ideal power, as a result of these factors. A method of the comparison of gas dynamic flow calculations with experimental results obtained at U-25 is presented by Bityurin et al (1978). These comparisons help in establishing a number of empirical quantities like correction factors for coefficients of friction, heat transfer, electrical conductivity, near electrode

Table 1. Effect of various non-idealities on generator performance

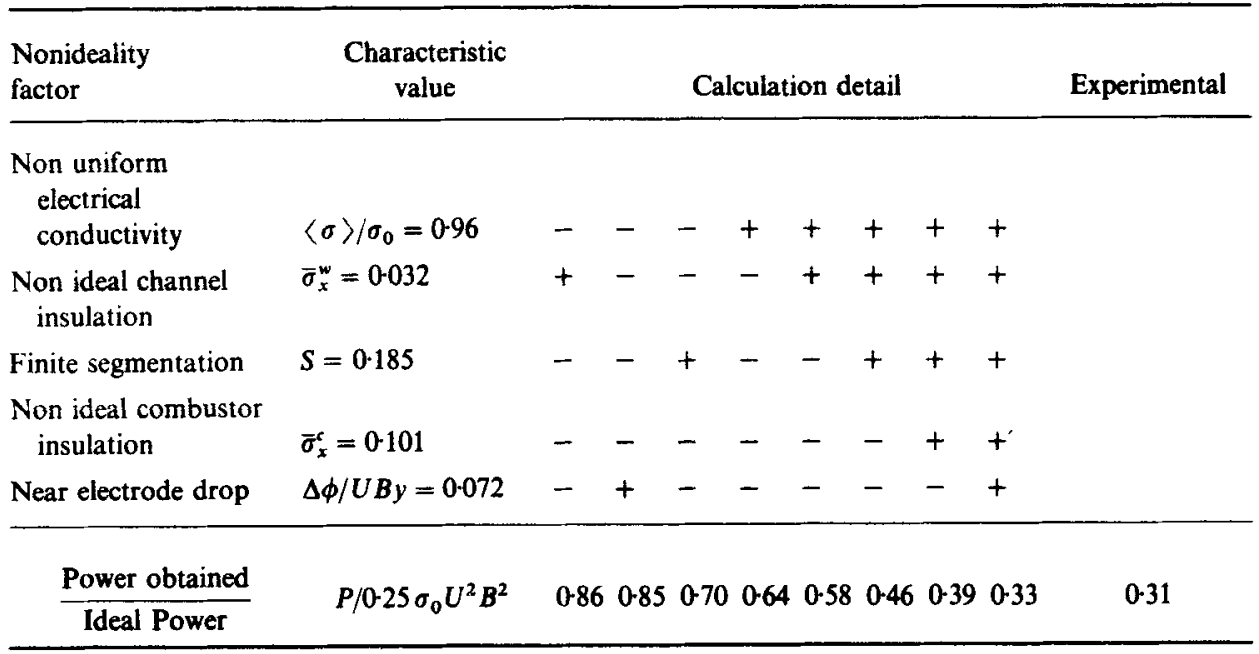

Ref. Sheindlin et al (1977) 
drops, wall conductivity etc. The empirical coefficients for friction, which are used as multiplying factors of the non-MHD values, range from 1-4. A formal technique has been suggested recently by Bityurin et al (1983) to evaluate these coefficients for friction and heat transfer. Similar studies have been reported for Avco Mark VI facility also (Kessler et al 1980).

\subsection{Two-dimensional models}

Following quasi-one-dimensional designs, a number of two-dimensional MHD channel design codes have been developed. A two-dimensional model in three design modes viz pressure, velocity and Mach No. has been described by Doss et al (1980) which has the additional advantage of predicting flow separation due to adverse pressure gradients. The effect of non-idealities on the electrical performance of Faraday MHD generators has been investigated using two-dimensional analysis by Jayakumar et al (1978) and Yoshikawa \& Hattori (1975). These studies deal with the effect of temperature profile along the Faraday direction in plasma and current bunching at the electrode surfaces due to the presence of arc spots. There is an attempt to relieve the current concentration by modifying the electrode configuration. Due to the complexity of the models, the fluid dynamic effects have not been fully incorporated. Also non-uniformity in plasma boundary layer near the electrodes needs to be considered to assess the full merit of such calculations.

The near wall regions of the MHD generator are characterised by velocity, temperature and electrostatic sheaths. It is well known that the presence of these boundary layers in a MHD generator gives rise to several losses of MHD generators, notably voltage drops at the electrode walls, also $\beta_{e}$ does not remain uniform throughout the cross-section of the generator. Messerle \& Manglick (1978) have analysed the electrostatic sheath near the cathode wall and shown that the sheath is approximately $0.06-0.1 \mathrm{~mm}$ wide. In a recent study, Gupta \& Rohatgi (1981) have tried to estimate the electrode voltage drop in Faraday MHD generator taking into account the gas dynamic and electrical sheath drop near the electrodes. Also the effect of variable $\beta_{e}$ on the voltage drop has been analysed in these studies. It is found that the assumption of uniform $\beta_{e}$ across the channel, which is generally made, is only justified when $\beta_{e}$ is near unity and the electrode wall temperature is greater than $1600 \mathrm{~K}$. Otherwise the effect of nonuniform Hall parameter (nonuniformity arising due to the temperature gradients near the electrode walls) on the electrode voltage drop is considerable and should be accounted for.

The inhomogeneity of the transverse current in an MHD channel and its effect on the generator characteristics have been studied by Kirillov (1979). The non-ideal insulation of the walls of the generator, will have negligible effects if the wall conductivities are less than $1 \%$ of the plasma conductivity. The secondary flow effects due to Hall currents in the compressible boundary layers near the insulation walls of a MHD generator have been investigated by Satyamurthy et al (1984). These cross flows are seen to have little effect on the heat transfer and wall friction but tend to homogenize the axial current density. Kruger \& Girshik (1983) have suggested that the experimental data on boundary layer voltage drops, electrode wall temperature profiles and entropy wave decay rates indicate the presence of three-dimensional effects and a programme to measure secondary flows is being pursued at Stanford University. Doss \& Ahluwalia (1983) have carried out investigations on the three-dimensional behaviour of flow patterns. The role of MHD body forces in generating secondary flows are expected to be 
stronger at off design conditions. It is conducive for the flow to separate on the anode wall in open circuit and on cathode wall in short circuit.

A mathematical model for MHD generator electrodes in the arc regime of operation has been investigated by Poberezhskii (1978). The studies indicate that the diffuse current can shunt and extinguish the arc current and in its turn the arc current can suppress the diffuse current. In the presence of arcs on the electrodes, the distributions of electrodynamic parameters are essentially three-dimensional. Bityurin \& Lyubimov (1979a,b) have used a special averaging technique of Ohm's Law to obtain a quantitative voltage-current characteristics in the arcing mode with the experimental data being used to establish the relationships. Nedospasov \& Poberezhskii (1979) have proposed approximate mathematical models for describing the configuration of an arc in a flow past an electrode. The models predict the arc dimensions, temperature distribution in the arc and voltage drops as a function of current and parameters of flow which are then compared with experimental data. Rosa (1983) has studied the boundary layer arc behaviour by dividing the arc into a column region and a spreading region. He however assumes that the column region has constant conductivity of $1000 \mathrm{mho} / \mathrm{m}$ and the spreading region of $\mathbf{4 0} \mathrm{mho} / \mathrm{m}$. Under these assumptions and stipulating that the arc will adjust itself to a minimum voltage drop, it is possible to predict the arc current and voltage as a complex function of flow parameters: velocity, wall temperature, boundary layer thickness, transverse current density etc. The theory agrees well with the experimental data on critical current density for arc initiation.

A simplified model for electrode voltage drop in the arc mode of MHD generator operation has been developed by Satyamurthy et al (1983). Arcs are simulated by freezing the electron temperature, and hence the electrical conductivity to a temperature called $T_{\text {arc }}$ when the gas in the boundary layer is less than $T_{\text {arc }}$. The $T_{\text {arc }}$ is empirically determined from the experimental data and is a function of current density and the linear distance. The two-dimensional calculations using this model yield satisfactory data on near-electrode drops, joule heating, potential distribution etc.

Recently Prusova (1979) has proposed a kinetic model for engineering calculations which includes the effects of chemical and electron kinetics during supersonic expansion. These calculations reveal a departure from equilibrium values for combustion chambers operating below $1.2 \mathrm{MPa}$. At $0.4 \mathrm{MPa}$, the enthalpy at channel outlet increases by approximately $20 \%$ and electrical conductivity 7-8 times.

The effect of modifying the magnetic field configurations on the flow to achieve higher conversion efficiency has been studied by Ozawa \& Kayukawa $(1975,1980)$. These analyses show an increase in the conversion efficiency by about $10 \%$ due to optimum field design. In principle, the approach consists of sharply reducing the magnetic induction near the electrodes in order to minimize the electrical losses caused by Hall effect and conductivity non-uniformity in the boundary layer. This improves the apparent conductivity, output power and internal impedance by a factor of about 1.5-2. The actual electrical characteristics have been experimentally investigated (Kayukawa et al 1983).

Another important phenomena frequently observed, is the electrical breakdown between the adjacent pairs of segmented electrodes in a Faraday MHD generator. This leads to shorting of Hall current and also the reduction of life of the generator due to erosion at the arc roots. Oliver (1975) has attempted to study the conditions leading to such breakdown in terms of thermal and electromagnetic interaction of the arcs for electrode walls parallel and inclined to the external magnetic field. The theory predicts 
the occurrence of electrical breakdown in anode as well as cathode walls as indeed has been the observations in many cases. Unkel and coworkers (Unkel \& Kruger 1983; Unkel et al 1983) have established through cinephotographic records that the axial Hall breakdown could be initiated either in the plasma or in the interelectrode insulator. The breakdown occurred only when a threshold voltage was exceeded with the voltage increasing with insulator gap size. For normal electrode configurations, the voltage for plasma initiated breakdown was considerably higher than insulator initiated breakdown. The insulator initiated breakdown voltages were $100 \mathrm{~V}$ for $7.5 \mathrm{~mm}$ gap and $175 \mathrm{~V}$ for $19 \mathrm{~mm}$ gap with plasma initiated breakdown voltages about $50 \mathrm{~V}$ higher than corresponding values. No qualitative difference between anode and cathode wall was observed. Similar studies have been carried out at the Institute of High Temperatures, USSR (Zalkind et al 1982).

The velocity and current distribution and the efficiency of the MHD generator in the inlet region of the channel has been studied by Mittal et al (1979) for a case when the conducting fluid enters the duct with a uniform velocity. It is found that the Hall ionslip current produces fluctuations in the current component thus affecting the efficiency in the inlet region of the generator.

\subsection{Three-dimensional effects}

The three-dimensional effects in a diagonal MHD generator were investigated by Gubarev \& Ovchinnikov (1980) and Unkel (1980) using three-dimensional electrical fields and currents assuming the velocity field and distribution of flow parameters. $A$ coupled core boundary layer model based on Patankar-Spalding technique has been formulated and used by Satyamurthy et al (1982a, b). This model predicts performance analysis of MHD channels.

Three-dimensional current calculations for diagonal wall and Faraday MHD generator using finite difference methods have been attempted by Shamma et al (1980). Also available now are the three-dimensional computer codes developed by the STD Corporation (Vetler et al 1980) which permit complete simulation and understanding of mHD channel test data. Though the details are not located, it is believed that extensive work has been done on the development of models of MHD generator in terms of computer codes which have been duly evaluated by the direct experiments on U- 25 .

Transient responses to start-up, shut-down and load charges have been calculated by Yoshikawa et al (1979) using unsteady MHD equations. The results indicate that MHD generator can attain another steady state within 10 times the gas residence time for most of the load charges. The most dangerous transient characteristics are found to be due to very large transient Hall fields at the start up. Bityurin et al (1983) have analysed the transient regimes of MHD generator operating in combination with other equipment in a power plant. It has been shown that MHD generator and the power plant admit an efficient and good regulation for the change in mass flow rate. The supersonic Faraday generator shows highest efficiency in the entire range of flow rate variation as compared to subsonic Faraday or supersonic diagonal generators. As regards the propagating acoustic and entropy waves, measurements were carried out by Simons et al (1982) at Stanford facility. The pressure pulses seemed to be unaffected by MHD phenomena whereas the convected temperature fluctuations are affected by magnetic field and currents. The equivalent circuit approach to the analysis of MHD generators has been 
made by Blitshtein et al (1979). This approach is useful in planning and operation of the electrode part of the generator. Normally, the parameters of the equivalent circuit are obtained from complete fluid dynamic calculations.

\subsection{Summary}

In summary, it is concluded that in spite of complex fluid dynamics and its interaction with electromagnetic fields, there has been significant progress in the understanding of the physical processes present in an MHD generator. Most encouraging and interesting is the fact that models developed on computer have been adequately verified by direct experiments so that more confident design of MHD generators for commercial plants now becomes possible. Also, with this experience at hand, it is now possible to take up the design of more complicated and advanced MHD generator configurations which will yield results of higher quality.

\section{MHD power cycles}

MHD generator applications have been identified in two modes of operations, namely (i) short duration (a few seconds to minutes), and (ii) continuous or long term operations.

\subsection{Short duration MHD generators}

The short duration applications in general prefer the simplicity and reliability of the generator to economy or thermal efficiency. Such devices are very attractive for aerospace and defence applications. Again because of the special requirements, the efficiency of energy conversion (about 15-35\%) and economy assume secondary importance when compared to the uniqueness of the application. In early sixties, the short duration MHD generators received considerable attention in the USA (Grundy 1978). Avco Everett Research Laboratory in the USA has been doing pioneering work in this field and demonstrated the first generator (identified as Mark V) which produced electrical power of $32 \mathrm{Mw}$ for a few seconds. The thrust in the development of short duration MHD generator in the USA has been mostly for military applications. Consequently relatively little information is available in the literature. It is believed that the current interest is strongly directed towards the development of MHD driven laser systems, MHD acceleration of gas in supersonic wind tunnels, spacecraft accelerators (thrustors) and the possibility of coupling MHD generator with the thermonuclear reactors.

In the USSR, short duration MHD generator finds interest in geophysical studies (Velikov et al 1975). This report gives the results of investigation of a MHD generator using alkali seeded solid fuel combustion products. The generator operated for about 1.5 seconds producing a peak power of about $30 \mathrm{Mw}$, when tested in a facility identified as PAMIR-I, located in URAL Mountains. The currents produced by the MHD generators have been used to study the earth's structure as far away as $70 \mathrm{~km}$ from the source and $30-40 \mathrm{~km}$ deep in the ground. It is suggested that such experiments can give useful information regarding the locations of mineral deposits and ore-bearing regions. Also such devices may be used to modify the flow of water currents in the sea and rivers. 


\subsection{Central power station applications}

Compared to the short duration applications, the interest in central power stations with MHD generator is much more. In this case the MHD generator operates as a topping unit of a binary cycle. The reason for this is that for an MHD generator the fuel is heated to a high temperature (about $3000 \mathrm{~K}$ ) to achieve high electrical conductivity. However, after passing through the MHD generator the temperature of the working media is lower only by a few hundred degrees resulting in substantial drop in its electrical conductivity. The fluid is then no longer useful for MHD generation purposes, but is still at a high temperature to produce steam to drive steam turbine in a conventional manner. The operation of a binary cycle therefore results in a higher energy conversion efficiency of the plant. The efficiency of a binary cycle $\eta$ in a simplified form is given by Pericart (1966)

$$
\eta=\eta_{\mathrm{MHD}}+\varepsilon\left(1-\eta_{\mathrm{MHD}}\right) \eta_{\mathrm{th}}
$$

where $\eta_{\text {MHD }}$ and $\eta_{\text {th }}$ represent the efficiency of MHD generator (topping cycle) and steam turbine unit (bottoming cycle) respectively. The quantity $\varepsilon$ is the relative efficiency of the topping unit, ( $\varepsilon=1$ for a perfectly reversible cycle). Thus, for example with typical values of $\eta_{\text {MHD }}$ of about $20 \%$ and $\eta_{\text {th }}$ of $40 \%$, one can achieve a conversion efficiency of the order of $52 \%$. It is this possibility of obtaining high conversion efficiency which has been the strong motivation in the development of MHD steam combined cycles. Further if $\eta_{\mathrm{MHD}}$ is improved as has been the expectation from the advanced cycles, still higher conversion efficiencies are possible from such systems.

Basically three types of MHD power cycles have been analysed for central power generation. They are: (i) MHD-steam open cycle using fossil fuels, (ii) MHD-steam closed cycle using nuclear reactor as the source of heat, and (iii) liquid metal MHD closed cycles.

In the open cycle the products of combustion of fossil fuel, seeded to improve the ionisation (electrical conductivity of the plasma) are released into the atmosphere after passing through the MHD generator and the rest of the bottoming cycle. In the case of closed cycles, it is understood that the working media continues to circulate through a closed loop. The liquid metal MHD system could use as a working fluid, the liquid metal from a fast neutron reactor.

The last few years have witnessed considerable progress and encouraging results in the technology of MHD-steam open cycles using fossil fuels. Consequently they are at an advanced stage of engineering and nearest to commercialisation. In view of the difficulties of operating nuclear reactors at high enough temperatures which are essential for effective operation of MHD generators, the MHD-steam closed cycle coupled with nuclear reactor has found less interest in recent years. In the liquid metal MHD cycle, the failure to attain high flow velocities of the liquid have made these systems less attractive. From both the physical and engineering stand points, however, the possibilities of MHD systems in closed or liquid metal cycles have been firmly established. For the reasons mentioned above the potential use of these closed cycles in large scale power station has not yet been developed to the same extent as that of open cycle systems.

\subsection{MHD-steam plant layout}

A typical layout of the open cycle MHD steam generator is illustrated in figure 3 . The main components (or subsystems) of such a cycle have also been identified in the 


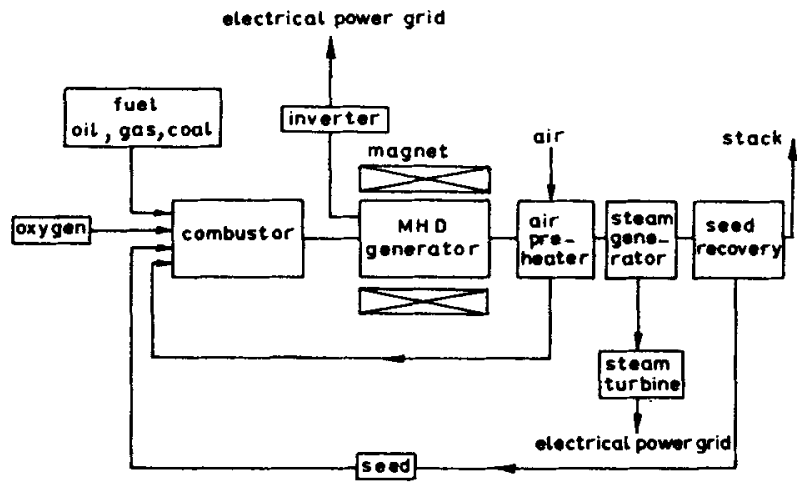

Figare 3. Typical layout of an open cycle MHD generator.

diagram. The electrical power is generated at 2 stages that is (i) the topping MHD generator, and (ii) the bottoming steam plant leading to higher conversion efficiencies (approaching 50-60\%) of the plant as a whole. The status of the recent development as regards to the individual components will be discussed in the subsequent sections of this text. It may however be interesting to see some of the practical cycles which have been in operation for sometime and also a few of the cycles which have been recently proposed.

Figure 4 shows the schematic of the first open cycle MHD-steam demonstration plant, which has been in operation since 1971 in Moscow. This plant identified as U-25 (MHD component 25 Mwe) includes all the major components of open cycle MHD steam plant. The plant has been successfully operated on natural gas generating $10-20 \mathrm{Mw}$ (electrical) MHD power for extended periods of time which has been fed to the Moscow power grid. Also as indicated, this installation has a by-pass loop for experimentation

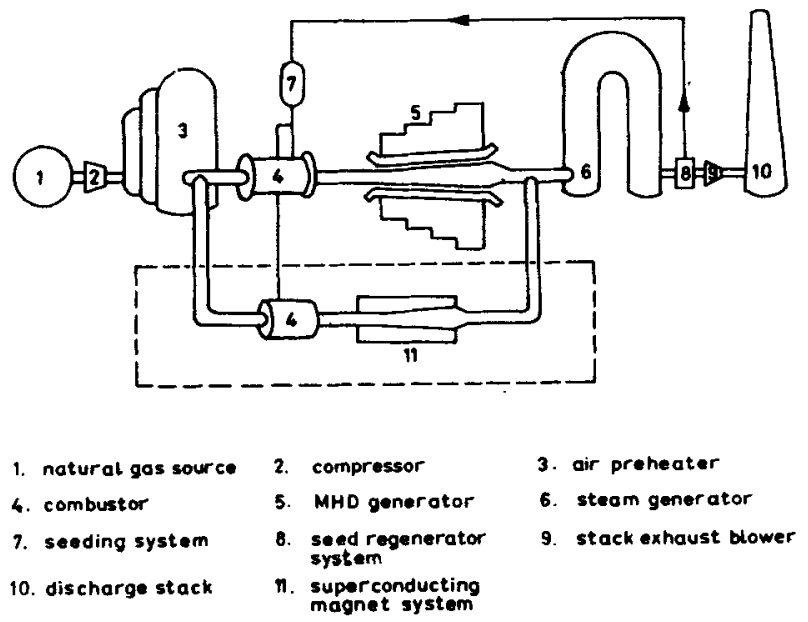

Figure 4. Schematic of U-25 MHD facility with bypass loop for superconducting magnet. 
with the American built superconducting magnet of 5 Tesla induction. The joint US-USSR experiments have yielded many interesting results thus furthering the technology of the MHD power generation. On the basis of this experience the first 500 Mwe MHD power plant is being built at RYAZAN near Moscow in USSR. The design parameters (Petrick \& Shumyatsky 1978) of this plant are given in table 2. Figure 5 is the block diagram of component development and integration facility (CDIF)-the biggest us effort in the development of MHD power generation (Lightner \& Dooley 1980). The portion in dotted lines in figure 5 is the proposed alternatives to the main scheme. The cDIF project was initiated in 1975 to provide a testing facility for MHD power train components. It is believed that the experience gained at this facility will permit the scale-up design of components and subsystems for a commercial MHD plant. The facility is dedicated to the development of coal-fired MHD power generation, although for experiments, oil-fired ash-injected combustors will also be investigated to simulate the conditions of coal-based operations. The design parameters for the

Table 2. Design parameters of $500 \mathrm{MWe}$ MHD power generation plant

\begin{tabular}{ll}
\hline Fuel & $\begin{array}{l}\text { Natural gas, seeded with } \\
\text { potassium carbonate } \\
\text { Oxygen-rich air (27\% enrichment) } \\
\text { preheated to } 1700^{\circ} \mathrm{C}\end{array}$ \\
Oxidiser & $1000 \mathrm{~m} / \mathrm{s}$ \\
Flow velocity & 5 Tesla (superconducting) \\
Magnet & $250 \mathrm{MW}$ \\
MHD generation & \\
Steam turbine & generation \\
Conversion efficiency & $48.6 \%$ \\
\hline
\end{tabular}

Ref. Kirillin and Sheindlin (1980)

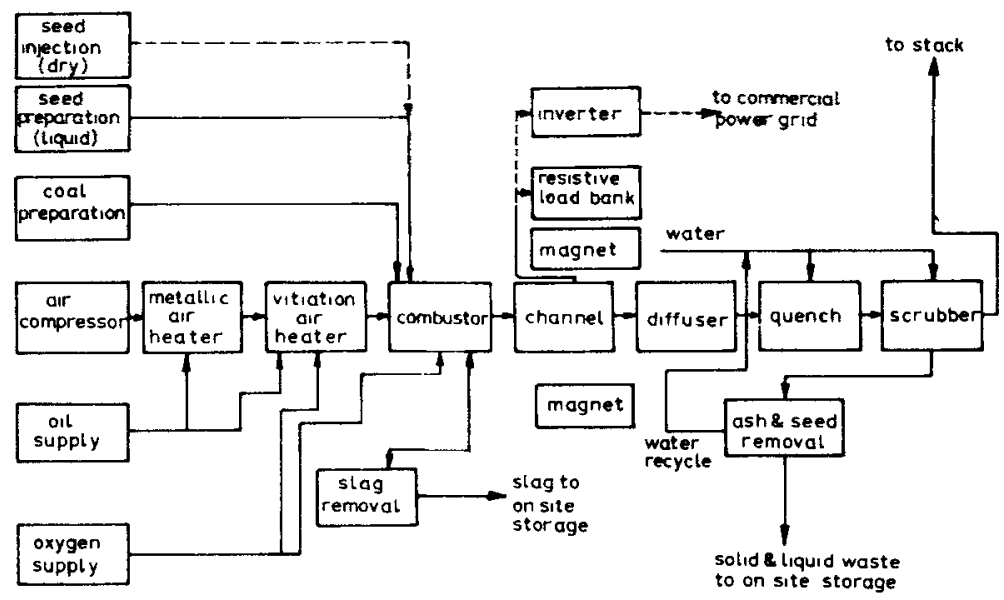

Figure 5. Functional block diagram-CDIF facility (Lightner \& Dooley 1980). 
generator are given in table 3. Installation and commissioning of equipment at site are in progress. According to the report, power generation tests will be conducted around late 1983.

Apart from these major efforts in USA and USSR, many other countries have been working in the area of MHD power generation. To name a few, Netherlands, Poland, Japan, India and China are actively engaged in the development of MHD power generation technology whereas Australia, Canada, Sweden, Israel and France have programmes of relatively smaller magnitude.

Table 3. Design parameter of the MHD generator for CDIF project

\begin{tabular}{ll}
\hline Mass flow rate & $10 \mathrm{~kg} / \mathrm{s}(50 \mathrm{MW})$ \\
Fuel & Fuel oil \\
Oxidiser & Nitrogen + oxygen \\
Seed & $\mathrm{K}_{2} \mathrm{CO}_{3}$ in aq. solution. \\
Ash carryover simulation & $5-25 \%$ \\
Magnetic field (max.) & $6 \mathrm{Tesla}$ \\
Mach number (core) & $0-7-1$ \\
Current density (core) & $0-9$ to $1 \cdot 1 \mathrm{~A} / \mathrm{cm}^{2}$ \\
Axial elec. field, $E_{x}$ & $2-3 \mathrm{kV} / \mathrm{m}$ \\
Transverse elec. field, $E_{y}$ & $3-4 \mathrm{kV} / \mathrm{m}$ \\
Hall parameter $\beta_{e}$ & $2-4$ \\
Heat fluxes to generator wall & $150-300 \mathrm{watts} / \mathrm{cm}^{2}$ \\
Enthalpy extraction & $4-8 \%$ \\
Electrical power output & $2-4 \mathrm{MW}$ \\
\hline
\end{tabular}

Ref. Lightner and Dooley (1980)

\subsection{Indian MHD plant}

The open cycle MHD Project in India (Ambasankaran et al 1975) is based on coal gasification route using blue water gas as the main fuel in the initial stages. The $R$ and $D$ facilities of $5 \mathrm{MW}$ (thermal) input with a provision to increase the capacity upto $15 \mathrm{MW}$ (thermal) is being created along with the necessary infrastructure for the development of this technology. The emphasis in the programme will be on the collection of scientific data and experience on (a) plasma flow properties, (b) thermal and electrical behaviour of the MHD ducts and (c) the development and testing of high temperature materials, components and subsystems for MHD power generation. This plant is expected to be in operation around 1984-85.

\subsection{Closed cycle MHD}

As mentioned earlier, nuclear reactor based closed cycle MHD generators at present do not appear very attractive due to the nonavailability of high temperature reactors. However, closed cycle using non-equilibrium plasma still finds considerable interest. Referring to equation (15), it is seen that the generator performance improves with higher electrcal conductivity of the plasma. In the case of monoatomic gases, assuming that most of the collisions are elastic, it is possible to show that electron can exist at a 
temperature higher than the gas/ion temperature. This results in higher electrical conductivities compared to diatomic molecular gases (such as combustion plasma) where rapid energy transfer takes place due to excitation of rotational and vibrational degrees of freedom causing the plasma to reach thermodynamical equilibrium. Figure 6 shows the comparison of electrical conductivities of seeded combustion and argon plasma. The non-equilibrium seeded argon plasma can give about 100 times higher electrical conductivity than the combustion plasma under similar conditions. The transport properties of a two-temperature argon plasma have been computed by Kannappan \& Bose (1977) using rigorous kinetic theory. The equilibrium plasma is considered as a special case and the results show good agreement and an improvement over earlier studies (Devoto 1973).

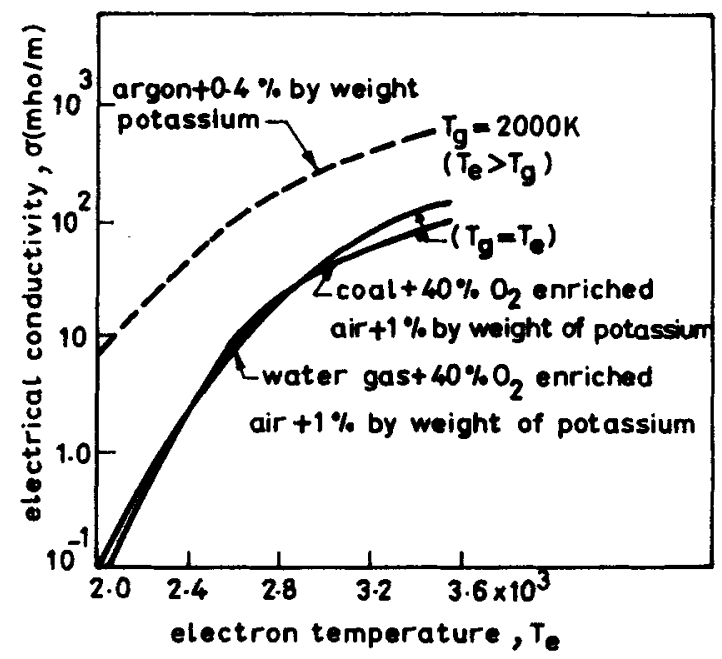

Figure 6. Comparison of electrical conductivity of equilibrium seeded combustion plasma and nonequilibrium seeded argon plasma (Pressure: 1 ata.)

Thus the closed cycle MHD using seeded noble gases as the active medium, can work in a 2 temperature region. In that case (figure 6) the minimum required gas temperature can be approximately $700^{\circ} \mathrm{K}$ lower in a closed cycle MHD plant as compared to open cycle MHD plant. Under a joint programme between the usA and the Netherlands, closed cycle MHD blow down facility of $5 \mathrm{mw}$ (thermal) is being developed at Technische Hogeschool, Eindhoven (Sluyter et al 1980). This facility incorporates a clean fuel fired ceramic matrix, regenerative heat exchanger and a pulsed cryogenically cooled magnet of 5 Tesla. The pulse duration of the magnetic induction is about 10 seconds. The schematic of a closed cycle MHD steam plant is given in figure 7. In this case a series of regenerative heat exchangers operating in a cyclic fashion, are heated by fossil fired fuel. The heat is transferred to a cesium seeded argon plasma which drives the MHD generator. The remaining heat in the argon gas produces steam. Subsequently the argon is compressed and reheated in a closed loop. In principle, cycles of this concept can be energised by any source of heat such as fossil fuel, solar or nuclear. 


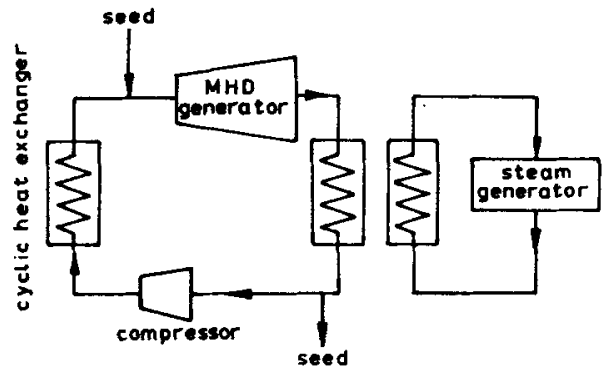

Figure 7. Schematic of a closed cycle MHD-steam plant.

\subsection{Liquid metal MHD}

Other cycles of MHD deserving mention here include solar-powered liquid metal MHD generation (Branover et al 1980) and MHD conversion systems coupled with thermonuclear fusion reactor (Status Report 1976). These cycles at present appear to be somewhat futuristic but merit consideration in view of the global energy demands for the year 2000 and beyond. The solar-powered liquid metal MHD cycle is illustrated in figure 8 . In this case, a liquid metal passes directly through a solar collector and then enters the mixer, at the same time an organic liquid is injected into the liquid metal which boils due to the heat transfer from liquid metal. The organic gas thus produced undergoes expansion, accelerating the liquid metal through the MHD generator. After that the fluid goes through a separator where liquid and gas are separated and circulated through their respective cycles as shown in figure 8 . The results of investigations of various aspects of such a system are given by Branover et al (1980). The study concludes that high efficiency of conversion of heat into mechanical energy is possible by means of injecting volatile liquid droplets into the hot metal.

\subsection{Fusion-MHD systems}

It has been mentioned earlier that the MHD generator cannot function effectively with the conventional nuclear reactors for want of high temperature operation of the reactor. However, this limitation can be removed in the case of thermonuclear fusion reactors. The possibility of coupling MHD generator with thermonuclear reactor has been gaining in interest in recent years. The conceptual schemes of coupling a closed cycle MHD generator to a fusion reactor have been analysed by Kantrowitz \& Rosa

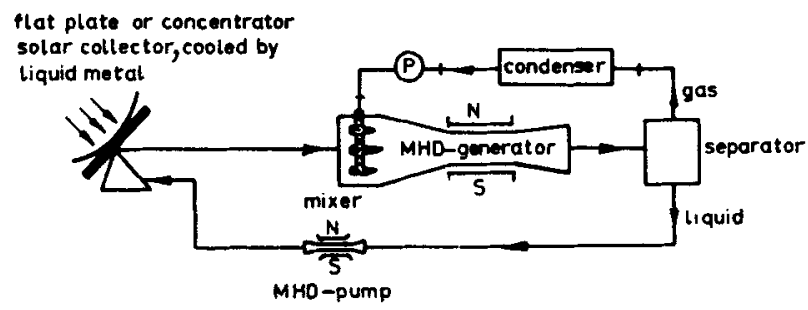

Figure 8. Solar-powered MHD system with liquid metal cooled collector (Branover et al 1980). 
(1975) and are illustrated in figure 9. Assuming a safe operating limit of graphite blanket upto $2800 \mathrm{~K}$, the preliminary estimates indicate an overall conversion efficiency of the order of $60 \%$ (Rosa \& Powell 1975). Similar studies made in the Soviet Union yield a conversion efficiency of the order of $60 \%$ for a MHD medium working in the temperature range of $2300 \mathrm{~K}$ to $2500 \mathrm{~K}$ (Shelkov et al 1975). Using more advanced concepts Breev et al (1977) of the Kurchatov Institute have shown that a Faraday MHD generator coupled to a thermonuclear power station operating at pressures of $100 \mathrm{MPa}$ and temperatures of 1-2 eV for the working fluid (water, argon, helium etc.) can yield efficiencies around $60-80 \%$.

The above discussion refers to a combination of closed cycle MHD generator with a magnetically confined fusion reactor such as the Tokamak or linear machine capable of operating in a continuous mode. For the inertially confined pulsed fusion reactors, Velikhov (Freeman 1980) has proposed a dumb-bell shaped design for MHD power generation with a fusion reactor. The concept of this scheme is illustrated in figure 10 . When the fusion reaction is ignited in chamber No. 1, the evaporating blanket of liquid (say lithium) vaporises. The expanding hot vapour pushes the metallic piston through the magnet of MHD generator towards chamber No. 2. The kinetic energy thus converted into the electrical energy is coupled to the load through the solenoid. When

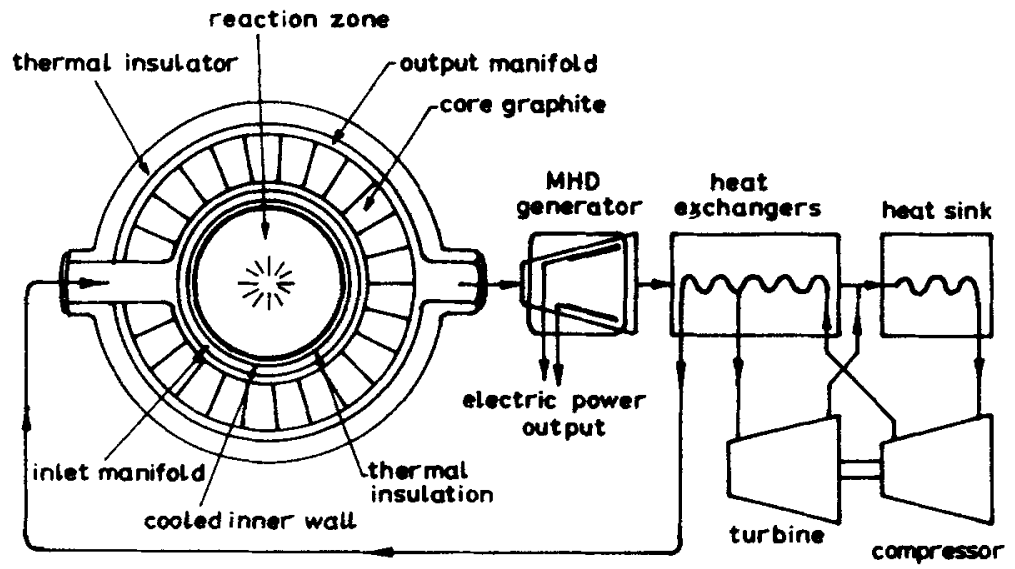

Figare 9. MHD system coupled to a fusion reactor (Kantrowitz \& Rosa 1975).

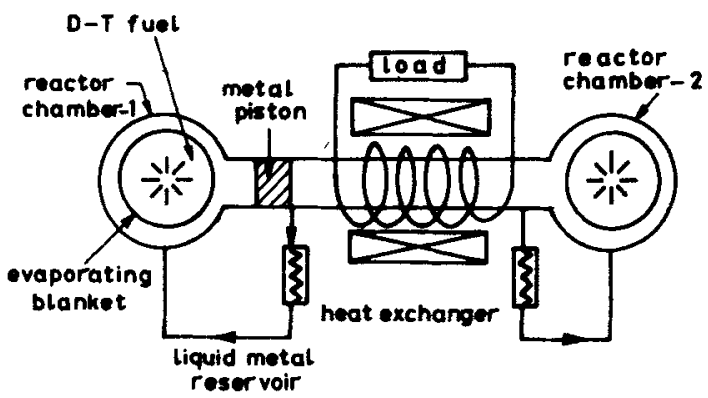

Figure 10. MHD generator for pulsed thermonuclear reactions (Status Report 1976). 
the reaction is produced in chamber No. 2 the reverse takes place sending the piston back towards chamber No. 1. Thus in a cyclic operation the piston moves back and forth between two fusion reactors whereas the liquid metal vapour recycles through the heat exchanger, to the reactor blanket.

Of what has been said so far regarding the MHD power cycles, it may be concluded that the fossil-fired open cycles of MHD are the most developed systems and nearest to commercialisation. In the USSR and the USA, open cycle MHD power generation has already entered the engineering stages. There is no doubt that natural gas based open cycle MHD-steam plant can become commercial within this decade. The remaining part of this manuscript is devoted to the review of status of components and subsystems required for the open cycle MHD-steam power generation. The areas demanding more efforts to achieve the goals at an early date are also identified in the subsequent sections of this report.

\section{Components and material development for MHD steam power plants}

The success of a commercial MHD steam plant depends strongly on the development of efficient and economic subsystems and processes. The reliability and performance characteristics of the individual components must show compatibility with the rest of the system and must meet the specifications of the industry. Having established the fundamental physical process of MHD power generation in early 1970 s the effort during the last decade has been on the development, scaling up and design of components for industrial applications. While noticeable progress has been observed in certain fields, in others it has now been possible to identify new problem areas demanding greater efforts.

The progress of technology with respect to open cycle MHD steam plant will be discussed here in terms of the following nonstandard components which are essential for the commercial acceptance and success of this process: (a) fuel; (b) combustor; (c) air preheater; (d) MHD generator; (e) magnet; (f) inverter; (g) steam generator; and (h) high temperature material.

\subsection{Fuel selection and evaluation}

The selection and conditioning of fuel is important to obtain the desired physical properties of the plasma. In the present context this refers to the chemical and thermodynamical aspects of the problem rather than the technological details. It has been mentioned earlier that any fossil fuel such as natural gas, oil or coal can be used for the open cycle MHD generation. Of the three types of fuels, extensive studies have been carried out on gas and oil in the past. Only because of the recent rise in the price of these fuels, the importance of developing coal-based MHD power generation has been realised. Thus while the technology of MHD power generation using natural gas is ready for commercial plants (Kirillin \& Sheindlin 1980) systems based on gasified coal or direct coal combustion are in the advanced stages of engineering and demonstration.

Referring back to equation (15), it is seen that higher electrical conductivity of the plasma is necessary for larger power density in the MHD generator. This in turn requires higher flame temperature of the gas. At these temperatures the electrical conductivity increases exponentially with temperature (Rose 1968). In general, the flame temperature of combustion gas is low and unsuitable for MHD applications. However, there are 
many ways in which these temperatures can be increased to suit the purpose. For instance, it is seen from simple thermodynamic calculations that the flame temperature increases with increasing (a) operating pressure, (b) oxygen enrichment of the air, and (c) the preheat air temperature (Prusova 1979). By adjusting the operating parameters it is possible to achieve fiame temperatures in the range of $3000 \mathrm{~K}$. In addition, some low ionisation potential materials like potassium $\left(V_{i}=4.34 \mathrm{eV}\right)$ or cesium $\left(V_{i}=3.89 \mathrm{eV}\right)$ are added to increase the electrical conductivity of the plasma. For assessment purposes high plasma temperature and electrical conductivity have been accepted as the main criteria for MHD power generation (Venkatramani \& Das 1975). In a practical situation this is achieved by appropriate operating conditions, i.e. oxygen enrichment, preheat, pressure conditions and seed injection. The thermodynamic and transport properties of equilibrium combustion plasma (having only gaseous phase) have been well documented in the literature (Womack 1969). Most of these calculations are based on adiabatic equilibrium conditions. As a result, these estimates can differ from the actual measured values. Both gas temperature and conductivity have been found to be lower than the predicted values. The difference has been explained due to lack of complete combustion, heat losses in the device and incomplete ionisation of the seed. More refined calculations are now under investigation. Also the paucity of data on different energy, momentum and charge transfer process in the range of interest is responsible for the discrepancies between the theory and the experiment (Gupta \& Rohatgi 1981; Rohatgi et al 1975; Stickler 1980). This poses difficulties in making better estimates of the electrical conductivity of the combustion plasma.

The typical range of combustion plasma for MHD power generation is given in table 4. Generally the operating conditions are selected on the basis of fuel and the availability of technology. In large systems, economic considerations influence the choice of parameters. For instance, in a recent study (Springmann et al 1980) it has been argued that efficient air separator plants can be developed for MHD power generation which could eliminate the need of high temperature air preheater from the MHD steam cycle. It was reported (Sluyter 1980) that this concept could lead to substantial economy in terms of money, space and time in the development of commercial MHD plants. The us programme on commercial MHD power generation is considering this option rather seriously.

4.1a Coal and coal-based fuels Of more recent interest is the development of coalbased MHD power generation. There are two possible ways of using coal for this purpose: (i) direct coal combustion, and (ii) coal gasification route. The direct coal

Table 4. Typical range of operating conditions for combustion plasma in MHD generation

\begin{tabular}{ll} 
Fuel & Natural gas \\
Seeding & Potassium $1-2 \%$ by weight \\
Injection & $50 \%$ aqueous solution of $\mathrm{K}_{2} \mathrm{CO}_{3} / \mathrm{dry}$ \\
Air preheat & $1000-2000 \mathrm{~K}$ \\
Oxygen enrichment & $20-40 \%$ \\
Pressure & $1-10$ atmosphere \\
Stoichiometry & $0.85-1 \cdot 05$ \\
Flame temperature & 2800 to $3000^{\circ} \mathrm{K}$ \\
Electrical conductivity & 5 to $30 \mathrm{mho} / \mathrm{m}$ \\
\hline
\end{tabular}


combustion implies burning of solid pulverised coal in the combustor so that the combustion products may pass through the system. However, it is possible to design combustors, where a large fraction of ash can be rejected at the first stage of the combustion in the molten slag form. Suffice it to mention here that this aspect though attractive economically has many complex problems to be solved. These problems are both of scientific and engineering nature. Considerable efforts are now being directed to understand and develop technology to cope with the problems.

Alternatively it is proposed that the coal be gasified and cleaned prior to its burning in the combustor. In principle, once the coal is gasified, the MHD plant technology becomes similar to other natural gas-fired MHD plants. In this case the problem area is shifted to the coal gasification process. Though there is a loss of net efficiency and additional cost of gasification process, this approach is advantageous especially when dealing with coals of high ash content. For the Indian MHD power generation project the coal gasification route is preferred in the initial stages (Gupta \& Rohatgi 1981).

4.1b Coal gasification Several well-established gasification processes have been considered for this application, such as the producer gas, blue water gas, Lurgi gas and Koppers-Totzek gas (Papic 1976; Vorres 1980). Several gasification processes are under development and may be suitable. It is also possible to use the hot exhaust gases from the channel for gasification. Brzozowsky et al (1983) have reported the modification and retrofitting of the Polish $4 \mathrm{mw}$ facility at Swierk for coal gasification. This configuration results in compact gasification units and can yield coal gas with calorific values around $1200 \mathrm{kcal} / \mathrm{m}^{3}$ dependent on feed rates and stoichiometric ratio. Even with the same types of coal these processes result in different composition and physical characteristics of the gas. Applying the criteria of adiabatic flame temperature and associated electrical conductivity it is concluded that except for the producer gas, the other 3 products are suitable for the MHD power generation (Das 1979). In the investigations carried out by Naidu et al (1977) and Sawhney et al (1976) the electrical conductivity of the combustion products of the water gas was simulated by a suitable mixture of LPG and acetylene in oxygen. The results have been compared with an analytical model by Amichand and Sawhney (1981).

Das (1979) also extended the single phase equilibrium combustion plasma studies to multicomponent plasma systems. This study has two-fold interest. Firstly, the coal gasification process permits one to assess the consequence of ash component present in the gasification products. From the present investigation of transport properties of multicomponent plasma one can define the limits to which the gas purification is necessary. Secondly, in the case of direct coal combustion, the results of this study are useful for designing the combustor and the MHD generator. With seeded Indian coal containing $15-20 \%$ ash the total number of species in the plasma are identified to be 130 (about 70 gas phase species and 60 condensed phase species). The individual species concentration and the thermodynamic properties have been evaluated from the solution of the equivalent multiphase multicomponent equilibrium problem. This study on coal combustion plasma resulted in two important conclusions: (a) the formation of a large amount of $\mathrm{AlO}_{2}^{-}$ions has been observed in the temperature range of interest to MHD. This reduces the free electron density and the electrical conductivity of the plasma. Thus in the design of combustor all efforts should be made to reject slag at the first stage itself, (b) also it is seen that the contribution of electron-ion collisions cannot be neglected while estimating the transport properties of the plasma. Das and 
coworkers (Das et al 1981; Das \& Rohatgi 1983) have extended the multiphase coal combustion calculations to multistage combustors and included the seed-slag compounds in the computation. The results indicate that slag tapping at the diffuser end results in the formation of only $7 \%$ potassium in the form of insoluble seed-slag compounds as compared to $15 \%$ in two-stage combustion and $80 \%$ in single-stage combustion without slag tapping. In conclusion, it is important to realise that calculations based on the chemical equilibrium can give useful guidelines in the development of MHD technology. More useful study will however be necessary on kinetics of combustion process under MHD conditions (Prusova 1979).

\subsection{Combustor}

The combustor in an MHD plant is primarily a plasma generator. Unlike a normal power plant combustor, the combustors for MHD plants operate at high specific intensity $\left(20-100 \mathrm{Mw} / \mathrm{m}^{3}\right)$, short residence time $(5-20 \mathrm{~ms})$ and low excess air coefficient (0-85-0.95) and yet should achieve good combustion efficiency, complete seed ionization and uniform velocity and electrical conductivity at the combustor outlet. The design of the combustor becomes complicated when it is expected to meet all its functional requirements, that is, (i) complete combustion of the fuel is a must for high efficiency performance. (ii) The combustor should be capable of operating under high temperature and pressure conditions continuously. (iii) The combustor should exhibit low heat losses and pressure drops. (iv) The combustor should accept dry/wet seed and result in high degree of ionisation (preferably $100 \%$ ). (v) The device should produce uniform plasma free of oscillations and instabilities. The gas composition, velocity, temperature and the electrical conductivity should be uniform both as a function of space and time. (vi) The combustor material has to be compatible with the operating conditions to give a satisfactory long life of say few thousand hours. (vii) In addition, if the fuel is coal, there should be a provision for slag rejection in liquid phase. (viii) Also the interaction of seed with slag should be minimum to reduce the loss of seed along with the slag rejection. (ix) Due to induced Hall voltage the combustor operates at a high potential (of the order of a few $\mathrm{kV}$ above the ground). This necessitates electrical insulation of all the input lines to the combustor.

With all these requirements the development of combustor for MHD is a complex problem. In the laboratory scale experiments many of these conditions are not satisfied to the full extent whereas experiments with commercial scale devices are limited at the moment.

Petrick \& Shumyatski (1978) have attempted to outline a systematic approach to the combustor design. Also included in this reference are several practical suggestions for design consideration of single stage and multistage combustors. Earlier attempts on the subject have been covered by Heywood \& Womack (1969). One of the most complex tasks is the modelling of the combustor. The computer modelling of the natural gas burning combustor has been performed by Cristea et al (1983). This model integrates several partial models viz the flow or combustion aerodynamics, combustion, thermochemistry, heat transfer, thermodynamics etc. No results have been reported.

4.2a Staged combustion According to Way (1974) combustors can be designed for liquid and gaseous fuels, by following the principles of vortex burner or by using a straight-through flow with a mixing device at the upstream end. In a recent report Bibermen et al (1980) have calculated the radiative thermal fluxes on the walls of such a 
combustion chamber of an MHD elctrical power plants based on the spectral characteristics of molecular components of the combustion product and potassium seed, and have found that the emission from potassium atoms amounts to $50 \%$ of the total thermal flux density of $200-300 \mathrm{~W} / \mathrm{cm}^{2}$ received on the wall. For coal-fired systems, to avoid the ash carry over cyclone type combustors which retain a major part of slag have been recommended. At Krzhizhanovsky Power Institute, Moscow, as a joint project along with the Institute of Nuclear Research Swierk, Poland, a single stage combustor with 75-80\% ash rejection has been developed successfully (Brozozowskii 1980). In two-stage combustor slag rejection upto $90 \%$ can be achieved. The first stage is operated around $2200 \mathrm{~K}$ to $2300 \mathrm{~K}$, where bulk of this slag is tapped in the liquid phase and the gas along with the seed is burnt at a higher temperature in the second stage. Figure 11 shows some of the conceptual designs of multi stage MHD combustors. The engineering performance of these concepts, specially at the industrial scale, remains to be demonstrated. Figure 12 shows the schematic of a 3-stage combustor with thermal capacity of $65 \mathrm{mw}$, being developed at Pittsburgh Energy Research Centre (Status Report 1976). The first two stages of this will serve as a coal-gasifier whereas the third stage will be the combustion chamber for the coal gasification products. Ash rejection of $95 \%$ and total heat loss of $5 \%$ are the predicted design features. The actual performance results from this installation have not been located in the literature.

The relative merits and demerits of the methods of coal combustion both direct and through gasification route have been studied by Gannon et al (1975). The study pointed out that problems associated with the development of large scale high temperature, high pressure combustor must be addressed. At the University of Tennessee, a direct coal burner based on liquid rocket combustor using pulverised coal with oxygen has been developed (Shanklin 1973). The device has operated successfully upto 5 Mw (thermal) input.

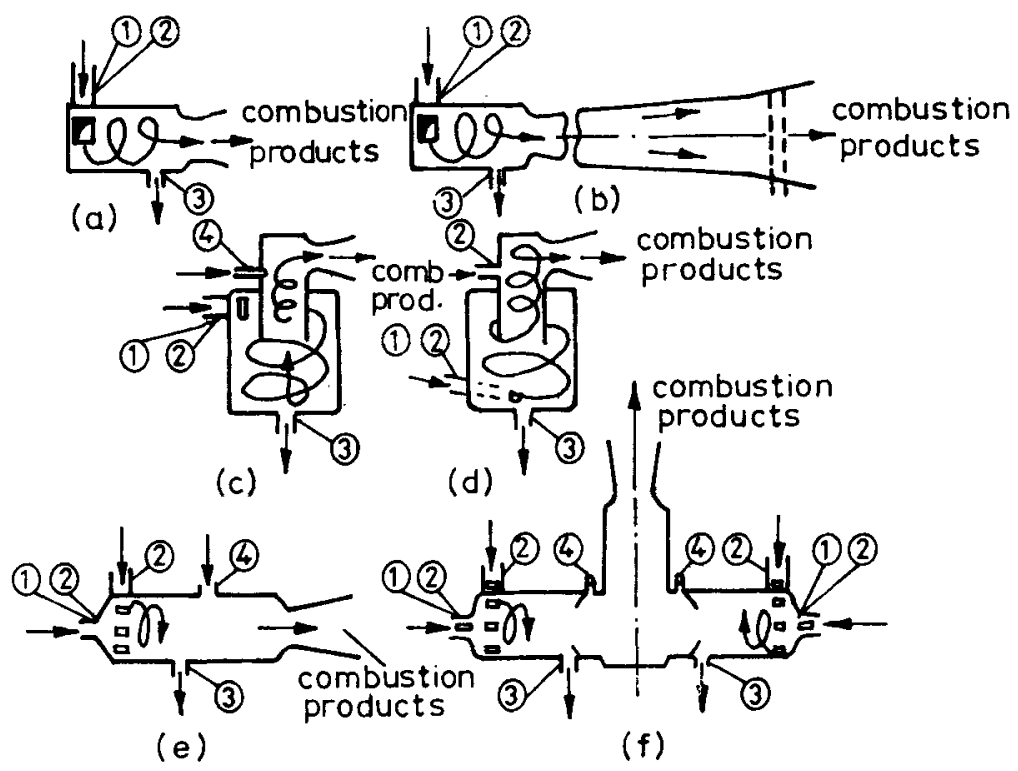

Figure 11. Conceptual designs of multistage combustors for MHD applications. (a), (b) Single stage. (c), (d), (e) Two-stage. (f) Three stage. (1) Fuel. (2) Oxidiser. (3) Slag. (4) Gas. 


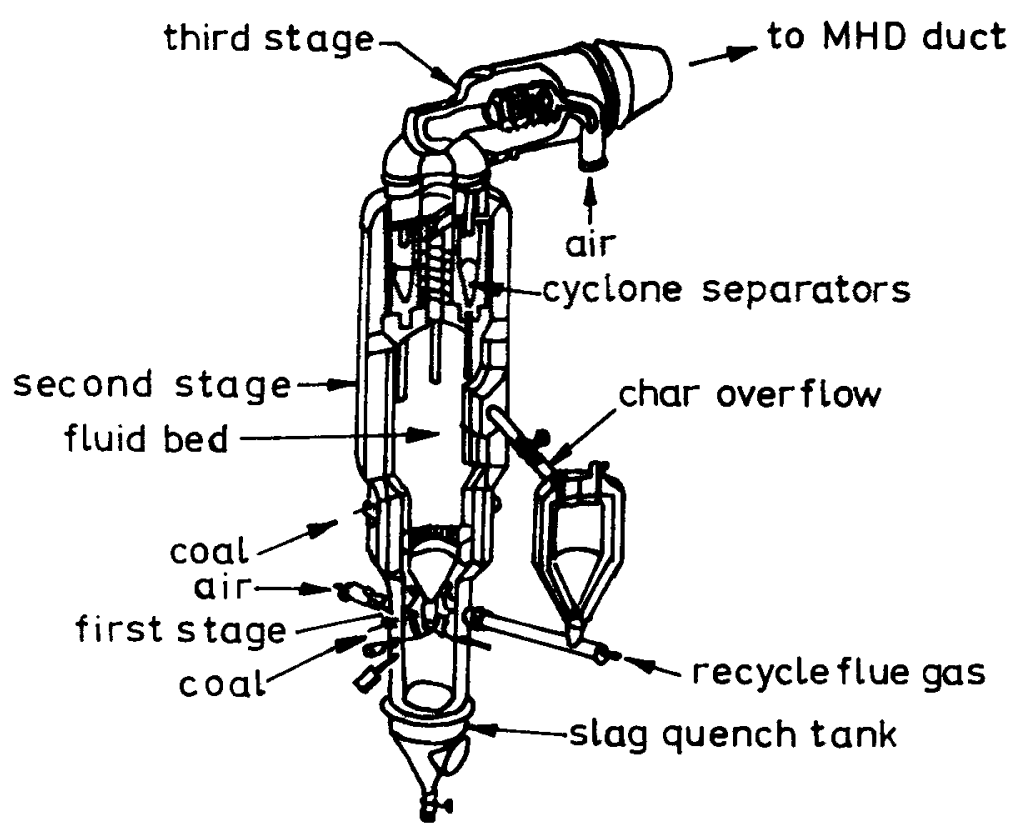

Figure 12. Three-stage coal combustor designed by Pittsburgh Energy Research Centre (Status Report 1976).

Another aspect of combustors which has received scant attention is the possibility of acoustic instabilities being sustained by the system (Petrick \& Shumayatsky 1978). Any pressure or velocity fluctuations in the combustor/channel will effectively reduce the power output from the MHD generator. Dvoinishniko (1980) has analysed the excitation of pressure oscillations in highly loaded combustors and suggested that the high frequency pressure oscillations may arise due to the breakdown of the stability of motion of combustion products with the kinetic energy of motion acting as the source of energy.

$4.2 \mathrm{~b}$ Seed droplet evaporation The problem of achieving nearly $100 \%$ seed ionisation in the combustor has not yet been fully analysed. Both the scientific understanding as well as the practical realisation of this needs more efforts. Evaporation of seed droplet (assuming liquid seed injection) and its ionisation including chemical reaction with other species present in the system is a complicated process to analyse. Coupled with this, the problem of producing controlled size of the droplet and its uniform dispersion in the flame makes it difficult to compare the results of the experiments with the theory.

Modelling of seed droplet evaporation in combustion products in the absence of seed chemistry has been studied by Sharma et al (1979). In this study, the effect of size distribution of the seed droplet depending on the type of atomiser used has been examined. In fact this analysis is an extension of the work of Golovin \& Peroschin (1976), where the earlier authors assumed all the droplets to be of the same size. Figure 13 shows the comparison of the rate of evaporation in two cases. From the figure it is seen that the evaporation of potassium takes much longer when the size of the droplet has a distribution around the mean radius. This could explain to some extent why in experiments, the conductivity is found to be lower than the predicted values 


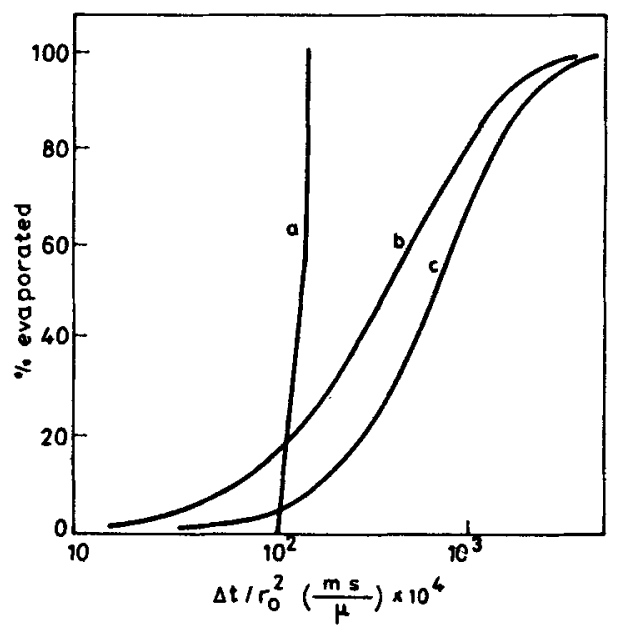

Figare 13. Comparison of rate of evaporation of seed in a combustion plasma (a) single droplet of radius $r_{0}\left(\right.$ b) droplet distribution with mean radius $r_{0}$ (c) droplet of mean radius $r_{0}$ (Sharma et al 1979).

assuming single droplet size. This information has been applied to predict the performance of the MHD generator fired by a plug flow combustor (Sharma et al 1980). A combustor of cross-section $22 \times 22 \mathrm{~cm}^{2}$ and variable length from 0.5 to 1.5 meter is coupled to a channel of 3 meter and mean cross-section of $10 \times 15 \mathrm{~cm}$ via a nozzle (dimensions representative of Indian MHD plant of $5 \mathrm{Mwt}$ input). The maximum power of $50 \mathrm{kWe}$ has been estimated for a combustor length of 0.5 meter and droplet size of one micron. Use of larger size droplets and correspondingly longer combustor to achieve complete droplet evaporation and plasma equilibration results in a drastic loss in power output to about $14 \mathrm{kWe}$.

Detailed calculations along these lines and including other effects will prove quite useful in the design and evaluation of performance characteristics of MHD combustors. Judging from the status of this technology it appears that much more effort will be required to develop suitable large scale high temperature, high pressure combustors which will satisfy the industry requirements.

\subsection{Air preheater}

The function of the air preheater is to heat the air/oxidizer to a suitably high temperature prior to its injection in the MHD combustor. This is necessary to achieve a desired high flame temperature and electrical conductivity of the plasma. The air preheaters operate in two modes: (i) Recuperators where the heat transfer is continuous from one fluid to another which are separated through solid walls, and (ii) Regenerators in which the heat transfer takes place in a cyclic fashion. In this case the refractory media is heated to a high temperature by a hot fluid and then the heat is transferred to the cooler fluid through the refractory material while the flow of hot fluid is stopped. Subsequently the cold flow is. stopped and the hot flow is started in a prescribed time cycle.

Recuperators for MHD application have not been very successful for want of engineering solutions. The efforts in the last few years have been concentrated in the 
development of regenerative type of air preheater for MHD application. Several variations such as fixed and moving bed designs have been attempted for practical systems (Petrick \& Shumayatsky 1978, Saari 1983). The development of suitable heating material which can withstand the thermal cycle, chemical corrosion and mechanical stress are some of the difficult areas because of which no satisfactory solution to the design of this component is yet available. Today the most commonly thought of materials are alumina, magnesia and zirconia for the heating media of air preheaters. The high temperature operation and chemical stability of the material dictate very high purity and unconventional technology for their preparation. This enhances the cost of fabrication of large quantity of highly specialised materials. In spite of extensive efforts devoted to evolve acceptable solutions to these problems, it appears that the problem is still open for scientific as well as technological work.

At the Institute of High Temperature, Moscow, successful operation of regenerative air preheater upto $1975^{\circ} \mathrm{K}$ has been reported using $99 \%$ alumina as the heating media. For higher temperatures yttria stabilised zirconia has been recommended. However, the long time operating experience at temperatures above $2000^{\circ} \mathrm{K}$ is not available. Preheat temperatures upto $1975^{\circ} \mathrm{K}$ have also been achieved at Avco Everett Research Laboratory in the USA. Practically no data and operating experience is available for directly coal-fired high temperature air preheater for MHD applications. Attempts to develop high temperature air preheaters for open cycle MHD with the aid of computer modelling was reported by Saari et al (1980). The authors conclude that for both directly and indirectly fired high temperature air heater systems, greater effort is needed for the development of material, operability, bed support and control systems. Dense relatively nonporous refractory appears to be needed to withstand the corrosion/erosion effects due to the attack of seed and slag.

The problem of selecting types of air preheater for commerical MHD plant has been discussed by the scientists from the Institute of High Temperature, Moscow (Agafonova et al 1980). The authors recommend that for the first commercial MHD plant, regenerative air preheater similar to those used in blast furnace may be suitable. The present air heaters of this type operate around $1700^{\circ} \mathrm{K}$ with a mass flow rate of $200 \mathrm{~kg} / \mathrm{s}$. Both the operating temperature and mass filow rates will have to be increased for which the cost may be rather high. Ultimately this will reflect on the high cost for MHD plants. The authors recommend that major emphasis should be placed on the development of means for reducing air preheater size and cost.

More or less similar opinion was expressed by the us scientists in the 1980 meeting of the International Conference on MHD (Sluyter 1980). According to them it appears that the efforts required to develop suitable material and technology for air preheater would take more time and money than had been projected earlier. The alternative route of eliminating high temperature air heater (HTAH) by higher oxygen enrichment may result in overall economy in space, time and money for the development of commercial MHD plants.

\subsection{MHD generators}

MHD generator is the single most complicated component of the entire system. The channel of an MHD generator operates under the extreme conditions of temperature, thermal flux, velocity of plasma and electric and magnetic fields. Perhaps, because of this reason it has received the maximum attention by the researchers in the field. In the 
past much work has been done on the development and testing of MHD generators in many laboratories of the world. Figure 14 summarises the experience gained thus far in the development and testing of MHD generators in different laboratories of the world. It may be mentioned here that only major experiments have been included in this figure. The data presented here is in terms of power generated versus the operating time. As seen, the study of generators falls in two categories (i) short duration high power generators, and (ii) low power long duration power generators. Also included in the right hand corner of the figure are the requirements for MHD generators to qualify for commercial applications. It is seen from the figure that only the U-25 MHD generator in Moscow is closest to the commercial requirement.

In principle MHD generator can be designed from the six equations discussed in section 2. However, these equations [equations (9) to (14)], not including the boundary effects and other microscopic and macroscopic phenomena can give only the order of magnitude calculations. The development of realistic mathematical model for generator design is still an open problem. Attempts to develop reliable and proven models for large scale generators is the current objective of many scientists working in this field. For instance, it is observed that in generators exceeding about $250 \mathrm{kWe}$ the induced voltages show nonuniform distribution in spite of the overall channel performance being in agreement with the mathematical model. It is feared that such non-uniformities could lead to instabilities and damaging effects to the channel performance. Some of these problems are being studied at present. The recent status of the progress towards this end has already been discussed in an earlier chapter (section 2). In addition to the theoretical considerations there are many other aspects which have to be considered while developing and building MHD generators. For example, the generator must show integrity against mechanical, thermal, electrical, magnetic and chemical stresses to which it is subjected during operation. It has been already mentioned that the prime interest in the development of this technology is for central power generation. The life of the device and its reliable operation becomes therefore, major requirements for the satisfactory performance of a device. At present there is no well-defined procedure to design MHD generators. Considerable effort is required in this direction. Of the three configurations of linear MHD generators, the
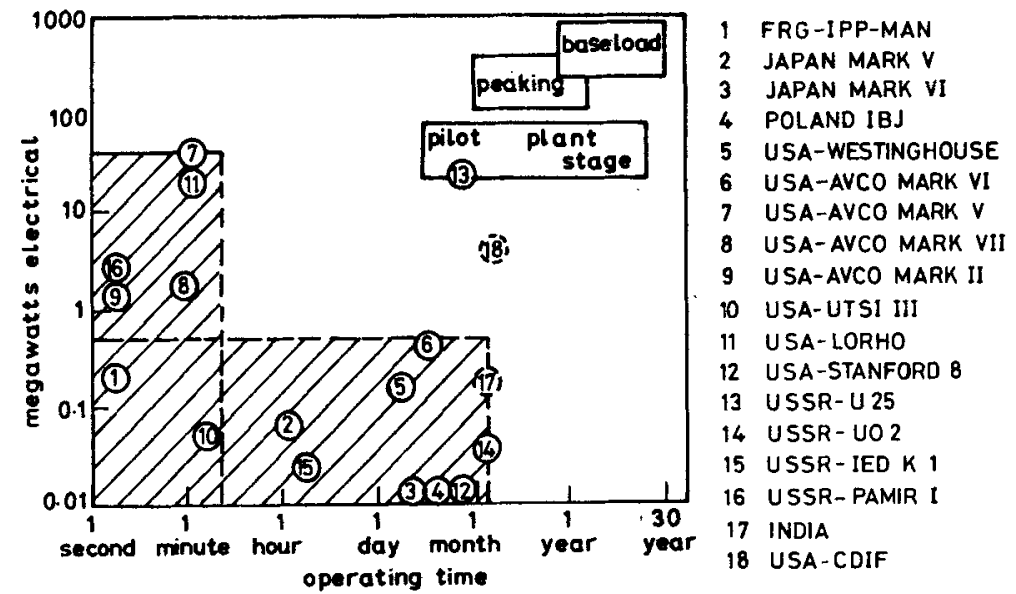

Figure 14. Summary of generator operating experience. 
segmented Faraday generator has been most widely studied. The segmentation of electrodes permits to break the induced Hall currents and offers modular construction for greater flexibility. As a consequence more confidence and experience are available at present in the design of segmented Faraday generators.

The properties of construction materials assume a very important role in the design of channel components and its performance. Specially the electrical and insulating materials in contact with the plasma demand very careful preparation and evaluation of their properties to qualify for this application. Typical electrode materials include metals (copper, stainless steel etc.) refractories (lanthanum chromite and stabilised zirconia) and cermets (chromium-lanthanum chromite). For insulators, alumina, magnesia and stabilised zirconia have been used by many investigators. In the experiments reported in figure 14 a combination of these materials has been extensively investigated with various degrees of success, but there is still no material which satisfies the requirement of MHD generator in full. Ideally these materials should demonstrate stable electrical and thermal behaviour during long time operation. Based on the Soviet experience, it is now possible to design channels for a few hundred hours of continuous operation (100 to 200 hours).

The mechanical design of channels depend strongly on the properties of the plasma and the construction materials. The problems encountered in the channel design include adequate water cooling, tightness of the device against water and gas leaks and acceptable levels of electrical insulation between various elements of the channel. Ensuring full guarantee against various leaks during operation makes the task of the channel designer very complicated. Through experience many semi-empirical guidelines have been evolved to solve these problems and yet there is scope for improvement by way of selection of suitable materials, engineering designs and fabrication techniques to achieve reliable channel construction. Computer codes have been developed which permit the calculation of temperature, heat and current flow patterns in the channel. On the basis of experience and individual judgement the designers provide enough safety margin against failure during operation. This approach tends to increase the size of the component and complexity in assembly. Also the present design philosophy includes various sophisticated instruments and a number of diagnostic ports to give forewarning of any malfunction of the channel during operationespecially with the possibility of achieving quick shutdown of the plant in case of a major catastrophy. It is also customary to subject the channel to rigorous quality control and pre-operational tests before commissioning of the channel for hot operation. Figure 15 shows the horizontal section of a long duration segmented electrode channel design for Indian MHD plant to be operated with seeded combustion products of blue water gas. The design parameters of this channel are listed in table 5. It is to be noted that the design uses hybrid structures of water cooled copper and high density high purity alumina in contact with the plasma. The physical principle as well as the engineering concepts of this design were validated by the joint Indo-ussR experiment on Indian channel at U-02 Installation in Moscow in 1980 (Rohatgi \& Shishkov 1981). The electrode current densities of 0.8 to $1 \mathrm{amp} / \mathrm{cm}^{2}$ and heat flux of the order of $100 \mathrm{~W} / \mathrm{cm}^{2}$ (simulating commercial generator conditions) were recorded during the experiment. The test channel was subjected to 65 hours of uninterrrupted hot test including start up and scheduled shutdown. With other materials the construction details will change accordingly. At the same time it will affect the operating conditions as well as the generator performance in terms of life and power output. 


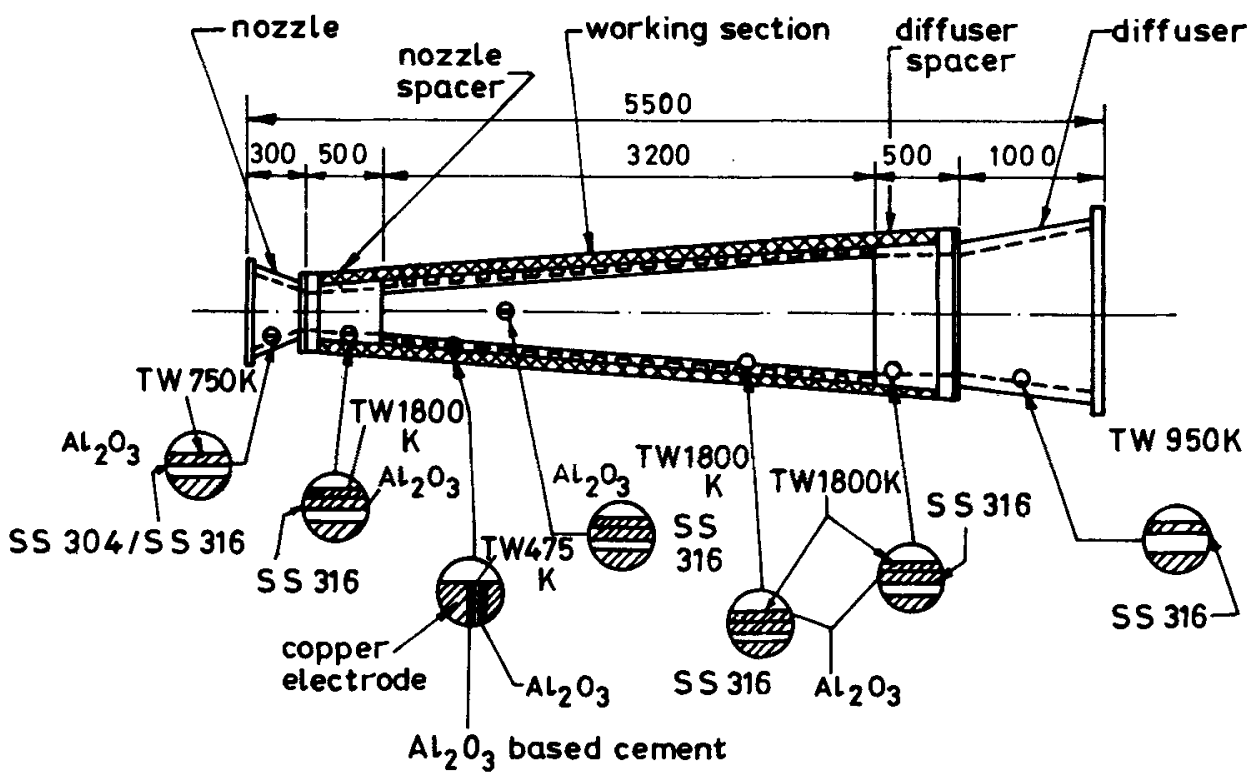

Figure 15. Horizontal section along the length of channel.

Table 5. Design parameter of the channel for Indian MHD plant

Working medium

Flow rate
Inlet stagnation temperature
Inlet stagnation pressure
Magnetic field
Maximum Hall potential
Heat flux to generator walls
Maximum current density
(under applied fields)
Type and material of construction
Electrode
Insulator
Inter-electrode insulation
Casing
Gaskets

Flow rate

Inlet stagnation temperature

Maximum Hall potential

Heat flux to generator walls

Maximum current density

(under applied fields)

ype and material of construction

Electrode

Insulator

Casing

Gaskets
Products of combustion, blue water gas with $40 \%$ enriched air and seeded with potassium (1\% by weight) in the form of $50 \%$ aqueous solution of potassium carbonate

$1 \mathrm{~kg} / \mathrm{s}$

$2750 \mathrm{~K}$

2.5 ATA

2 Tesla

$1000 \mathrm{~V}$

$(1-0.3) \times 10^{6} \mathrm{~W} / \mathrm{m}^{2}$

0-8-1 A/cm ${ }^{2}$

Segmented Faraday

Water cooled copper with $\mathrm{Al}_{2} \mathrm{O}_{3}$ insert

Peg wall type with $\mathrm{Al}_{2} \mathrm{O}_{3}$ insulating head

$\mathrm{Al}_{2} \mathrm{O}_{3}$

Fibreglass reinforced plastic

Viton

In the absence of proven materials for this application, the approach in the channel development has been shifted more towards sophisticated engineering concepts, using readily available materials. One such example is the diagonal channel known as RM channel, fully developed by the Soviet scientists and tested at U-25 facility in Moscow (Barshak et al 1976). In this case the frame is nearly oval-shaped providing better aerodynamics and more efficient current distribution to the walls. Typical MHD channel frame construction is shown in figure 16 (Tempelmeyer \& Sokolov 1978). The channel 


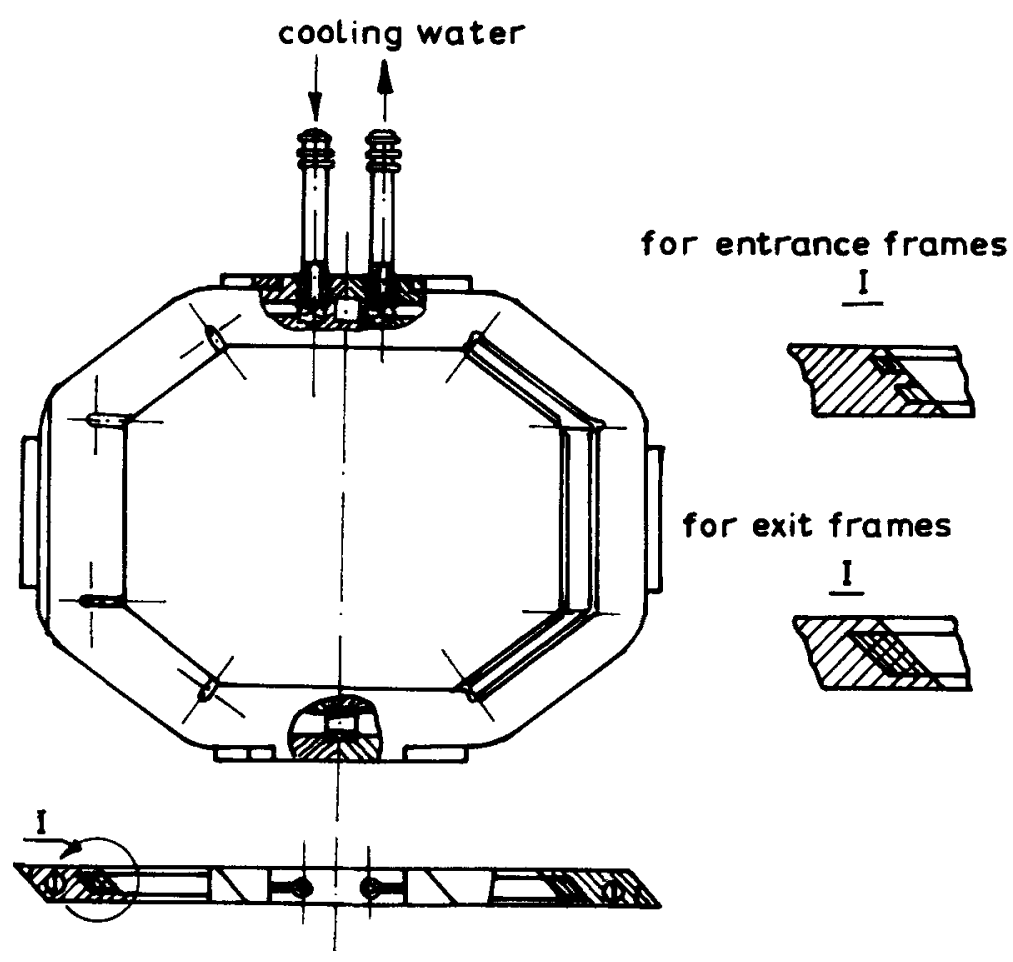

Figure 16. Typical MHD channel frame construction (Tempelmeyer \& Sokolov 1978).

consists of copper electrode with zirconia concrete in a fibreglass housing. The channel construction permits its operation in diagonal mode of operation. Recent investigations of the RM channel on the U-25 facility have been summarised by Bityurin et al (1980). Good agreement between the experiment and theory has been noticed in the case of power output, induced Hall voltage and the pressure distribution along the channel. Both quasi-one-dimensional and the two-dimensional electrodynamic calculations have been performed. The data presented here shows satisfactory agreement $(10 \%$ accuracy) between the measurements and the theoretical calculations. This channel has been operated for more than 100 hours with satisfactory results. Long duration channels operating for more than 100 hours have also been developed at Westinghouse and AvCo in the USA (Petrick \& Shumayatsky 1978). The Avco channel Mark VI (Petty et al 1975) is a diagonal generator containing electrodes of various materials. This is a supersonic channel and can operate at high Hall fields of $2-4 \mathrm{kV} / \mathrm{m}$. During the operation of the channel it has been established that substantial current flows through the diagonal bars. Zalkind et al (1983) have studied the correlation of the experimental data obtained on several MHD devices on the cathode spots and erosion of metal electrodes. The deposition of the film of alkali compounds of the seed has an exceptionally pronounced effect on the spot behaviour and electrode erosion. Raju et al (1983) have found that the deposits lower the work function and a sharp decrease in the cathode potential drop. This results in a larger current density in diffusive mode. Other factors include the nature of plasma flow surface temperature, current etc. Even though the current transfer to electrodes occurs in spots, the main cause of destruction of 
copper electrodes is not the evaporation from spots. This is due to the presence of film on the surface. Zalkind et al (1983) reports a specific erosion rate of copper as $10 \mu \mathrm{g} /$ coulomb at $600^{\circ} \mathrm{C}$ and nearly an order lower at $200^{\circ} \mathrm{C}$.

With the growing interest in the direct coal MHD plant the designer's interest has also shifted to the development of channels for slagging conditions. Prior to this the main interest was in operating the channels with high surface temperatures tgreater than $2000^{\circ} \mathrm{K}$ ) to achieve higher conversion efficiencies in MHD generator. The absence of suitable materials to operate under these conditions has caused serious limitations to this requirement. Also due to arc-mode of current flow, excessive electrode damage results which in fact reduces the useful life of the device. These problems do not appear severe in the case of operation under slagging conditions. The inorganic constituents of coal with the alkali seed form an iron-rich 'dirty' glass which coats the walls and electrodes of the MHD generator. Pollina et al (1980) have analysed the electrical conductivity of coal ash with graded amounts of $\mathrm{K}_{2} \mathrm{CO}_{3}$ and find that at high temperatures several ions contribute to conductivity whereas at lower temperature the conduction becomes complex with the presence of crystalline phases in the glass. The channel surface temperature for slagging operation can be around $1800^{\circ} \mathrm{K}$ to permit the deposition of slag layer (of the order of a few $\mathrm{mm}$ ) on the electrode surfaces which acts as a protective layer for the electrode wall. The exact mechanism of interaction of slag layer with electrode as well as with the plasma is not fully developed. However, roughly speaking, the systems work like this: The molten slag layer, as it were, connects the high temperature combustion plasma to the electrode wall in a manner that the face of the layer in contact with the electrode surface is in the condensed phase, whereas on the plasma side it is in the vapour phase. Thus current transfer from plasma to electrode is through the slag layer which when eroded is replaced by fresh layer in a dynamic mode. The electrode is thereby protected. The phenomena of charge transfer, heat conduction and the seed/slag chemical reaction need considerable attention for better understanding. Extensive experiments have been conducted at UTSI, AVCO and at U-02 Installation to gain the understanding of the MHD generator under slagging conditions. The group at the University of Tennessee Space Institute (UTSI, Tullahoma, USA) has attempted to study the current distribution in a $60^{\circ}$ diagonal cold wall channel under high slagging conditions (Scott $e t$ al 1980). The study also attempts to assess the effect of increased leakage on current and augmented voltage conditions between the adjacent pair of electrodes. Their experiment shows strong influence of leakage effects on the local electrode behaviour in the generator. Accordingly, it is concluded that leakage effects must be included in the equations describing generator behaviour.

Engineers at Avco (Hruby et al 1980) have been experimenting with watercooled copper electrode walls with boron nitride insulators. To reduce arcing damage, the copper electrodes are capped with different materials. Figure 17 shows the details of electrode construction tested at Avco. The caps of platinum, gold, palladium, cupronickel, copper, stainless steel, Inconel and Hastelloy have been investigated for their relative performance. The authors arrive at the following conclusions: (i) No gasexposed copper anodic surface can be tolerated. (ii) The least eroded non-platinum anode material is found to be stainless steel. (iii) The best anode configuration so far has been the design type 4 (figure 17) with exclusively platinum caps. (iv) Longer test times at high plasma surface concentrations are needed to accurately ascertain the platinum erosion rates. Development of nondestructive thickness measurement technique is needed. (v) The electrochemical mechanism leading to generally higher corrosion rates 


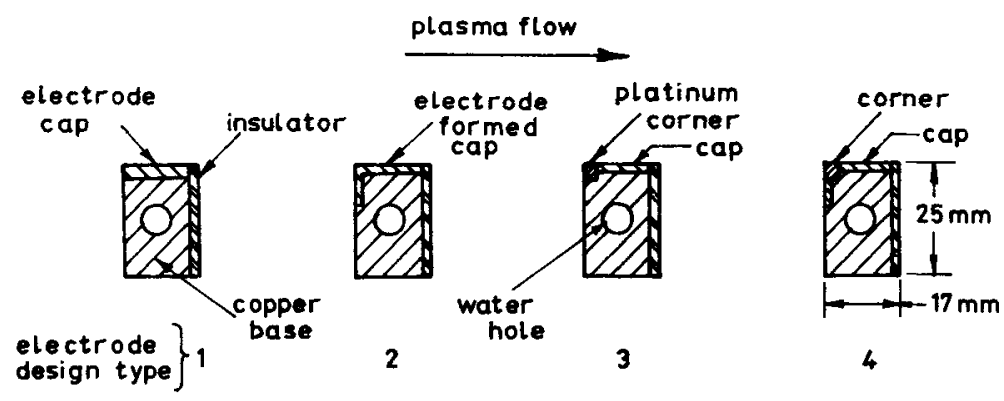

Figure 17. Schematic of four electrode designs tested at AVCO (Hruby et al 1980).

in the presence of sulphur has not been identified. (vi) Insulating walls may need local protective capping to minimise anodic type corrosion due to leakage currents. (vii) Cathode in general does not appear to be affected by sulphur rich environment. Tungsten copper continues to be the most promising cathode material. On the basis of experiments conducted at Avco, Hruby et al (1982) find that the most successful electrodes are made of copper with platinum and/or stainless steel cladding. The anode electrodes lasted for over $1000 \mathrm{hr}$, with a projected life span of $5000-8000 \mathrm{hr}$, under the same electrical, thermal and chemical stress conditions as would exist in a commercial MHD plant including sulphur and coal ash carry over.

Experiments with slagging electrodes have also been carried at the U-02 facility in Moscow, Institute of Nuclear Research, Poland, Westinghouse R and D Centre, usA and Stanford University, USA. Most of these investigations conclude longer electrode life as an advantage of slag layer, whereas the problem area needing greater research have been identified to be electrochemical effects at the electrodes and current transfer mechanisms from plasma to electrode.

4.4a Disc generators Apart from the development of linear MHD generators, scientists are also interested in the disc type MHD generators. The cylindrical disc geometry appears promising for high enthalpy extraction (Klepeis et al 1975). The advantage of disc generator over linear channel is that the electrode material problems in disc geometry are circumvented. Analytical considerations show that mechanisms which strongly influence electrical breakdown in linear devices are greatly minimised in disc geometry. These advantages are directly attributable to the absence of an electrode wall. A radial flow disc is a pure Hall effect device. However, the use of swirl can significantly reduce the dependence of disc electrical efficiency on a given degree of plasma nonuniformity. Another advantage of the disc generator is the simplicity of its magnet design. The magnet of a disc generator is a simple solenoid coil while for a linear device it has to be a saddle type construction. The authors conclude, however, that detailed investigations of the magneto acoustic instability to which disc geometry is more susceptible is necessary. The measured characteristics of a combustion driven high magnetic field disc generator are given by Jenkins et al. Figures 18 and 19 show the details of the disc device used by Jenkins at Stanford University. The operating conditions of the Stanford disc generator are listed in table 6. The measured electrical performance data yielded typical linear load line characteristics in agreement with the theoretical predictions. The short circuit current of $1.5 \mathrm{~A} / \mathrm{cm}^{2}$, open circuit electric fields of $8 \mathrm{kV} / \mathrm{m}$ and power densities of $32 \mathrm{Mw} / \mathrm{m}^{3}$ were recorded during the 


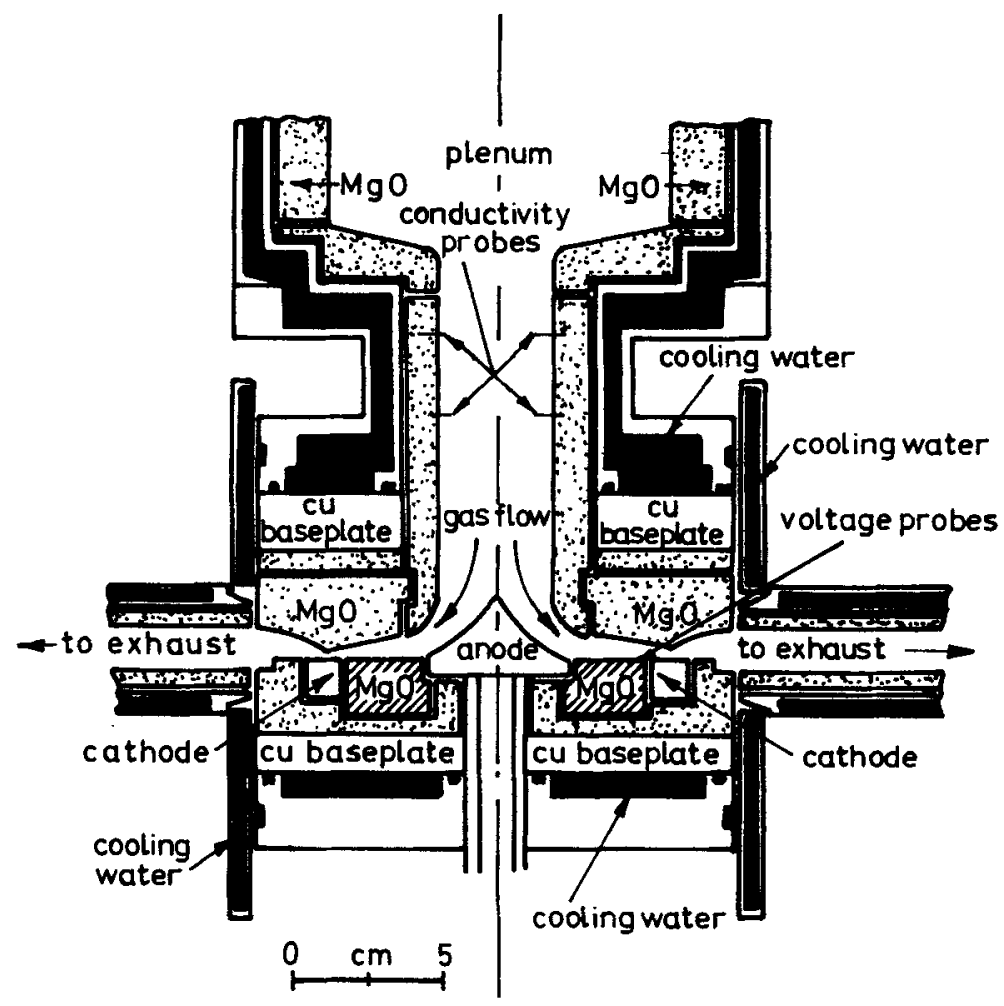

Fignre 18. Cross-section through disk generator showing cooling chamber, electrodes and insulator assembly (Jenkins et al 1980).

experiment. These results show the possible advantages of disc generator for base load open cycle MHD power generation. Analytical studies dealing with the electrodynamics and gas dynamics in the disc generator have been made by Ishikawa (1980) solving the three-dimensional flow equations by the finite element method. The author has studied the velocity nonuniformity effect on generator performance. Electrical efficiencies as high as $85 \%$ have been predicted in the large scale disc generators. The optimisation of disc generator performance for base load power plant has been attempted by Teare $e t$ al (1980). This study concludes that disc generator operating in open cycle as well as close cycle modes compare favourably with linear generators under similar conditions. Enthalpy extraction upto $23 \%$ with $71 \%$ isentropic efficiency has been predicted. Power density in the range of $70-170 \mathrm{Mw} / \mathrm{m}^{3}$ appears feasible, leading to very compact generator configuration.

\subsection{Magnetic systems for MHD generators}

The need of superconducting magnet in commercial MHD power plant cannot be overemphasised. Equation (15) shows that the power density in MHD generator increases as the square of the magnetic field. Higher magnetic fields are therefore most essential for economic MHD power. This is possible only with superconducting magnet. The economy of MHD power with superconducting magnet (SCM) is effected mainly 


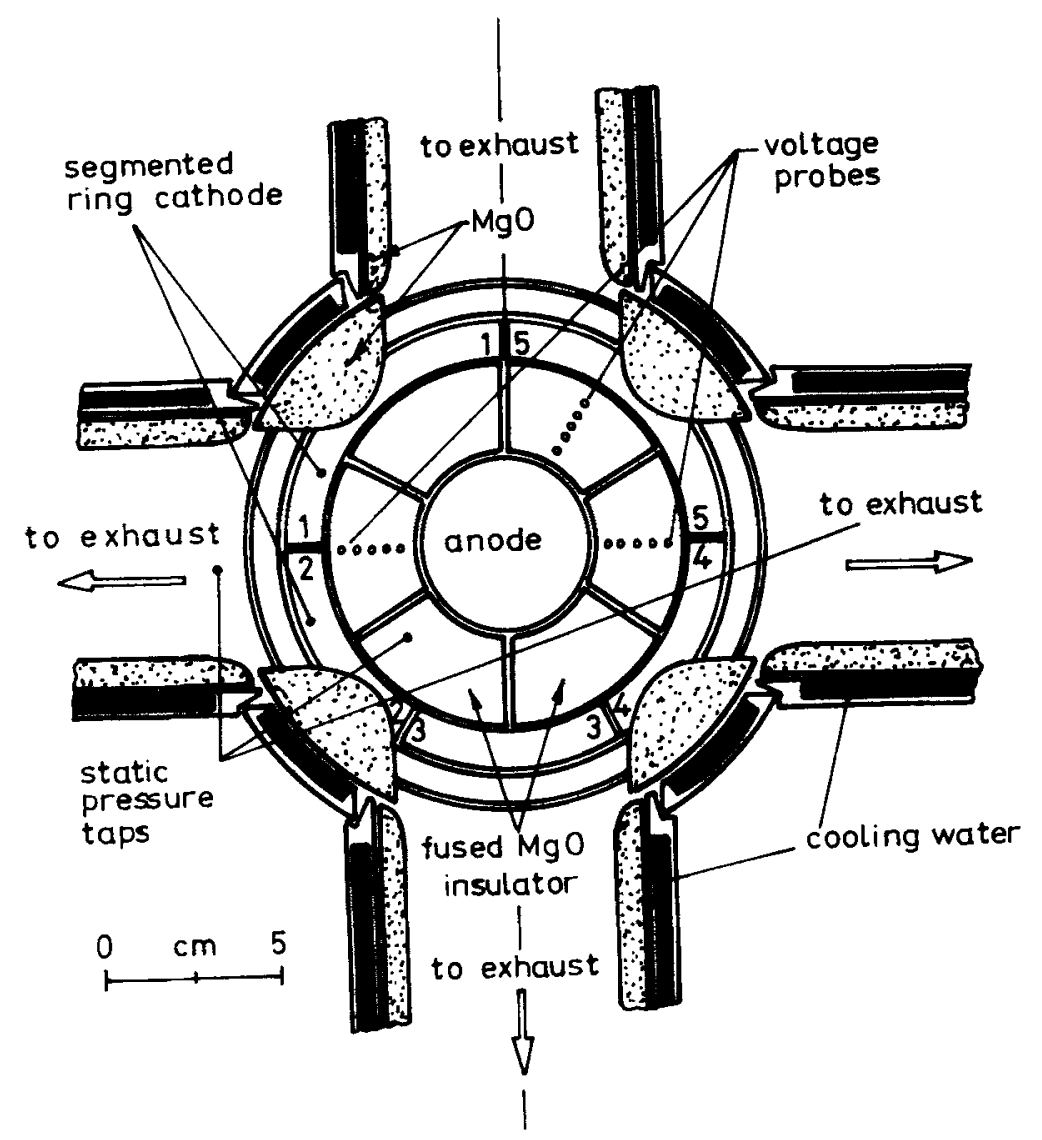

Figure 19. Section through mid-plane of disc generator (Jenkins et al 1980).

Table 6. Typical operating conditions for Standard combustion disk generator

Fuel

Oxidant

Diluent

Seed

Combustor/plenum residence time

Mass flow rate

Mach number

Channel static pressure

Plasma static temperature

Measured conductivity

Hall parameter

Channel area

Anode surface area

Cathode surface area

Anode-to-cathode distance

Heat flux

Surface temperature

Test duration

\section{Ethanol}

Oxygen

Stoichiometric conditions

Nitrogen, $\mathrm{N}_{2} / \mathrm{O}_{2}=0.25-1 \cdot 5$

$\mathrm{KOH}, 1 \%$ by weight of total reactants at $\mathrm{N}_{2} / \mathrm{O}_{2}=0.5$

$$
>10 \mathrm{~ms}
$$

$0-05-0.1 \mathrm{~kg} / \mathrm{s}$

$0.2-0.6$

$<1$ atm

$2500-2800 \mathrm{~K}$ (calculated from measured conductivity)

3-15 mho/meter at channel inlet

2.5 at 5.5 Tesla

$19 \mathrm{~cm}^{2}$ (channel 1) $12 \mathrm{~cm}^{2}$ (channel 2)

$11 \mathrm{~cm}^{2}$ (channel 1) $25 \mathrm{~cm}^{2}$ (channel 2)

$57 \mathrm{~cm}^{2}$

$3 \mathrm{~cm}$ (channel 1) $2.38 \mathrm{~cm}$ (channel 2)

$300-500 \mathrm{w} / \mathrm{cm}^{2}$ (anode); $40 \mathrm{w} / \mathrm{cm}^{2}$ (insulator)

$1000^{\circ} \mathrm{K}$ (anode); $1700 \mathrm{~K}$ (cathode); $2500 \mathrm{~K}$ (insulator) 5-8 hr

Ref. Jenkins et al (1980) 
because of negligible ohmic losses in the superconducting magnet when compared to a conventional electromagnet.

Practically no direct experience is available today in the construction and operation of SCM systems compatible with MHD plants. The largest superconducting magnet in operation is with bubble chamber which is about 10 times smaller than the magnet required for the commercial MHD installation in terms of energy handling capacity. Whereas the saddle-shaped SCM at the U-25B in Moscow (fabricated at the Argonne National Laboratory, USA under the joint US-USSR collaboration programme) is about 300 times smaller than the projected requirement for commercial MHD plant. The science and technology of superconducting magnet irrespective of MHD application, are in the developing stage. A major effort is therefore necessary to develop adequate expertise and confidence in this technology. The magnet development programme for MHD application should concentrate on the low risk, high reliability systems. The general design considerations for both conventional and superconducting magnets have been discussed by Rosa (1968) and Petrick \& Shumyatsky (1978). Typical problem areas which have been identified are as follows.

4.5a Conductor development The working limit of niobium-titanium materials allow peak field upto $8 \mathrm{~T}$ in the winding which will yield a duct field of $6 \mathrm{Tesla}$. Higher field materials are of interest so that MHD duct could be placed in fields above 6 Tesla.

Present-day magnet designs use current carrying capacity of about 1 kiloampere which will have to be increased to 10-50 kiloamperes for base load MHD power plants. The use of aluminium in place of copper for stabilisation could result in substantial economy-such developments will be of interest in future. In addition, joining of conductor and cooling systems deserve special attention in designing of sсM systems.

The conductor design should be such that in case of thermal disturbances, or local hot spots, the magnet should remain in a stable steady state condition. This is generally assured by derating the current carrying capacity of the conductor. The stability is also required against sudden rise in current and any strong interaction from the MHD channel which may cause excess helium loss. These considerations call for careful design of cooling and cryostat. Also important in this connection are the critical studies of likely sources of disturbances, their extent and their durations.

4.5b Electrical and mechanical design considerations The problems of failure mode in operating SCM have been discussed by Montgomery (1975). These failures can be classified as electrical and mechanical faults.

Short circuit between turns and turn-to-ground, occurrence of arc spots and conductor burn-out are common when operating with scM systems. Reliable cooling designs with careful selection of insulating material and safe operating voltages therefore must be established.

Mechanical fault can result due to high stresses in the coil winding, joint failure in the conductor and structural weaknesses. Suitable test schedules have yet to be evolved for testing the electrical and mechanical integrity of the magnet. According to Petrick \& Shumyatsky (1978), the risk associated with the first-time construction will continue to be high. This can be overcome by successfully experimenting with intermediate scale devices. Quality control, engineering and fabrication should be treated as separate functions and practised likewise.

The most valuable experience in this connection is the joint us-ussR experiment at the U-25B loop with the sCM system developed by the Argonne National Laboratory, 
USA. Since the incorporation of SCM into the U-25B loop in 1977, 7 runs have been conducted at this Facility todate. Figure 20 shows the sectional details of the U-25B superconducting magnet and its cryostat, whereas figure 21 gives the field configuration and its position relative to the channel. The SCM system is provided with adequate control systems for normal operation as well as diagnostics of the system parameters. The control for automatic protection to the magnetic system is also included in case of possible abnormal operating conditions. The magnet operation and its interaction with MHD channel was reported by Niemann et al (1980). Several practical suggestions regarding the design improvement and equipment protection have been suggested by the authors.

Table 7 lists the design parameter of 3 sCM systems, namely, (i) ANL built SCM which is being used for joint US-USSR experiment at U-25B (Tempelmeyer \& Sokolov 1978), (ii) the projected USSR design for the first commercial mHD plant (Petrick \& Shumyatsky 1978), and (iii) the modular CASK concept which is being developed by the General Dynamics Convair Division, San Diego, usA (Baldi 1980). The usSR design for base load application appears to be a scale-up version of the ANL magnet whereas the cASK concept of modular construction seems more functional and has a logical approach to the problem. It has been well recognised that the magnetic system being
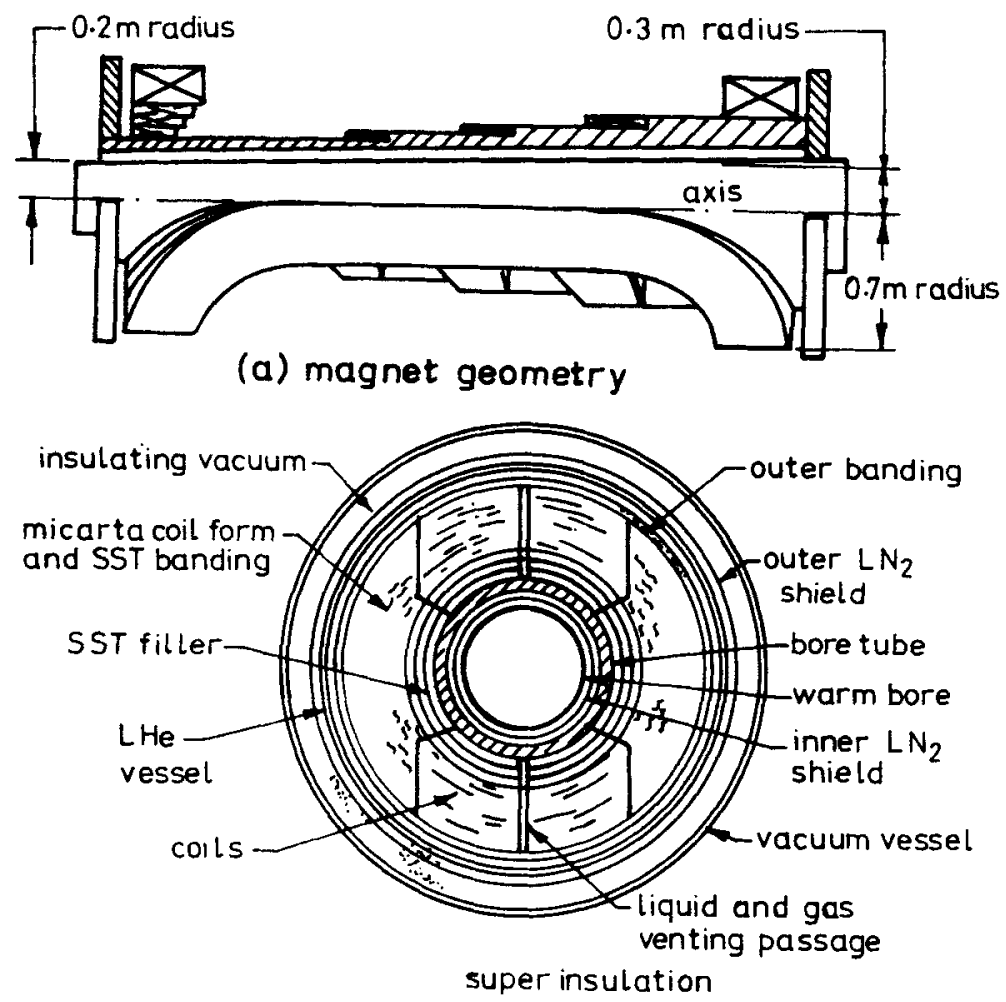

(b) cross-section normal to axis

Figure 20. Sectional diagram of ANL superconducting magnet for U-25B facility (Niemann et al 1980). 


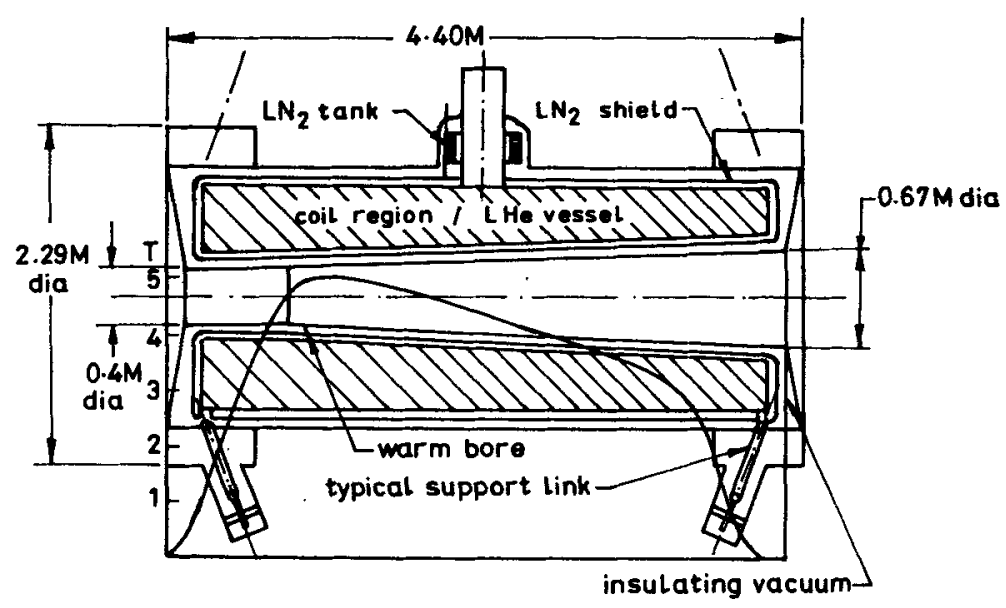

Figure 21. Cross-section of SCM cryostat at U-25B facility with the magnetic induction profile (Niemann et al 1980).

Table 7. Design parameters of large scale scM for MHD plants

\begin{tabular}{|c|c|c|c|}
\hline & $\begin{array}{l}\text { ANL magnet } \\
\mathrm{U} 25 \mathrm{~B}\end{array}$ & $\begin{array}{l}\text { USSR commercial } \\
\text { plant }\end{array}$ & $\begin{array}{l}\text { CASK concept, } \\
\text { USA }\end{array}$ \\
\hline \multicolumn{4}{|l|}{ On axis field } \\
\hline Inlet $(\mathrm{T})$ & 4 peak at $5 \mathrm{~T}$ & 6 & 6 \\
\hline Outlet (T) & $3 \cdot 2$ & $3 \cdot 3$ & \\
\hline $\begin{array}{l}\text { Field uniformity } \\
\text { on axis }(\%)\end{array}$ & \pm 5 & $\begin{array}{l}\text { Inlet } 3 \cdot 1-3 \cdot 2 \\
\text { Outlet } 4 \cdot 1-4 \cdot 4\end{array}$ & 5 \\
\hline \multicolumn{3}{|l|}{ Effective magnetic } & $14 \cdot 5$ \\
\hline \multicolumn{4}{|l|}{ Warm bore ( $\mathrm{m}$ dia) } \\
\hline Inlet & 0.4 & $2 \cdot 23 \times 2 \cdot 23$ & $2 \cdot 48$ \\
\hline Outlet & 0.6 & $4.21 \times 4 \cdot 21$ & $4 \cdot 5$ \\
\hline Operational current (A) & 892 & 10,833 & 50,000 \\
\hline Stored energy (MJ) & $34 \cdot 2$ & 7600 & 5000 \\
\hline $\begin{array}{l}\text { Conductor current } \\
\left(\mathrm{A} / \mathrm{cm}^{2}\right)\end{array}$ & 4460 & 3845 & 2000 \\
\hline Winding type & Circular saddle & Rectangular saddle & Circular saddle \\
\hline $\begin{array}{l}\text { Winding overall } \\
\text { length (m) }\end{array}$ & 3.759 & 24 & $23 \cdot 6$ \\
\hline $\begin{array}{l}\text { Ampere turns } \\
\left(\times 10^{6}\right)\end{array}$ & $6 \cdot 3$ & 3600 & - \\
\hline Peak field (T) & 6 & 8 & 7 \\
\hline $\begin{array}{l}\text { Conductor weight } \\
\left(\times 10^{3} \mathrm{~kg}\right)\end{array}$ & 10 & 500 & - \\
\hline Conductor material & $\mathrm{Nb}-\mathrm{Ti}$ in $\mathrm{Cu}$ & $\mathrm{Nb}-\mathrm{Ti}$ in $\mathrm{Cu}$ & $\mathrm{Nb}-\mathrm{Ti}$ in $\mathrm{Cu}$ \\
\hline Total magnet wt (kg) & 36,818 & $2.690 \times 10^{6}$ & $2.65 \times 10^{6}$ \\
\hline
\end{tabular}

Ref. Neimann et al (1980), Petrick \& Shumyatsky (1978) and Baldi (1980) 
large in size will have to be assembled at the plant site. To that extent the cask design offers several advantages. It is believed that this design will help in early commercialisation of MHD power plants.

Designs of relatively smaller superconducting magnet systems have also been developed by other groups. For details, the reader should refer to the work of Stekly et al (1980) and Wang (1980).

The studies of SCM for base load MHD generators by Montgomery et al conclude that a saddle-type magnet is presently the most suitable and that it should have a magnetic field of 6 Tesla. The magnet should not use iron in significant quantity, and the winding should be fully stabilised. Such a magnet should weigh around 2000 tonnes, thus necessitating construction at site. The authors strongly recommend the detailed design studies and back-up $\mathbf{R}$ and $\mathbf{D}$ to be initiated as early as possible.

In short, it is concluded that large volume superconducting magnet (about $100 \mathrm{~m}^{3}$ ) with fields of 6 Tesla and above is essential for commercial MHD plants. Limited experience in designing and building of smaller SCM system is already available. This experience will be valuable in developing bigger systems. A systematic and concentrated effort is requird to achieve the suitable SCM system by the end of this decade.

\subsection{Inverter systems}

The power produced from a MHD generator cannot be used for distribution directly. This is because the voltages induced in the generator $(V=U B d$ where $U$ is the flow velocity, $B$ is the magnetic induction and $d$ is the distance between the electrode pair) are low and vary along the length of the generator. Also the induced voltages in the present MHD generator are DC. AC MHD generation though possible in principle, is not commercially attractive at this stage due to the difficulties in producing high conductivity plasma. Likewise the maximum (short circuit) current depends on the internal impedance of the generator which also varies in a generator. There is significant variations of these parameters as a function of distance along the channel length. Typical induced voltages are about a few kilovolts and the short circuit currents are of the order of kiloamperes. The power from MHD generator also depends on the configuration of the generator itself (see figure 2 for different MHD generator configurations). On the other hand power grids (both AC and DC) transmit power at a much higher voltage 220 kilovolts and above) and demand stability of power source. This necessitates suitable conditioning of the MHD power to be fed into the power grid. The function of inverter is to condition the MHD power by suitable impedance matching. Thus the loading of each channel needs a detailed power take off analysis similar to the one carried out by Pan \& Doss (1980). The inverter function, in addition, also includes the protection of MHD generator from the disturbances which may arise from the grid.

Earlier the MHD generator performance was studied using resistive load banks. This did not permit the investigation of interaction between the active load and the generator. Power inversion systems using mercury arc controlled rectifiers were then introduced at the U-02 installation in Moscow (Kazachkov et al 1968). This provided investigation of MHD generator under continuously varying no-load to short-circuit conditions. Also experience has been gained from this test regarding the interaction between the power grid and the generator. Several problem areas in the development of inverter systems for commercial MHD plant have also become clearer. Subsequently, 
since the last 10 years SCR (silicon-controlled rectifiers) have been used in the development of inverter systems for the MHD generator.

The block diagram of a single load inverter connecting MHD generator to the transmission line is shown in figure 22. The essential elements of this circuit include DC interruptor, smoothening inductor, inverter unit, $A C$ disconnect switch, step-up transformer, high frequency harmonic filters variable VAR supply, and AC circuit breakers. The selection criteria of each component has been discussed by Ray \& Schainker (1980) along with the specific design of an inverter for the MHD Component Development and Integration Facility (CDIF) at Butte, Montana, USA. Kordus et al (1975) designed and tested the performance of an MHD generator connected to a conventional power grid through a solid state inverter system. Testing of the generator (rated at $600 \mathrm{~kW}$ ) included both Faraday as well as diagonal electrode connections. The control systems allowed the firing angle of the thyristor to be adjusted to permit the operation of MHD generator at any desired point of its external characteristics. The inverter circuit was tested on an analog model of MHD generator as well as by actual experiments. The authors draw the following conclusions from this study: (i) the development of thyristor design is ahead of the MHD generator engineering which makes it possible to design inverter systems for any MHD generator power output. (ii) Inverters with suitable transformer tapping and thyristor firing angle regulation allows full control of MHD generator loading. (iii) Over dimensioning of inverter in relation to MHD generator power output limits the controlling process. The inverter consumes reactive power and should be associated with compensating devices.

The block diagram of the inverter system for MHD generator developed at UTSI is given in figure 23 (Barnett 1975). The inverter system was designed for a $60^{\circ}$ conducting wall diagonal channel of approximately $1.05 \mathrm{~m}$. The channel had 65 electrode pairs and was located in a magnetic field of 2 Tesla. The 65 electrodes were bunched into four groups (electrode Nos: 6-28, 29-40, 41-52 and 53-63) giving approximately equal power distribution (about $26 \mathrm{~kW}$ in each section). To begin with, each section of the generator was loaded by $2 \mathrm{ohms}$ resistor until stable operation was realised. The inverter trigger circuit (figure 23) was then activated to disconnect the 2 ohms resistor and bring the inverter system in line. The inverter efficiency was measured to be $98 \%$. The other conclusions from this study were in agreement with the results of Kordus et al (1975). The analysis in the case of static inverter shows that the transfer of power from MHD generator to the transmission line has certain constraints on the current voltage relationship of the MHD generator, the inverter and the inverter angles, the power flow and the power factor characteristics (Trung \& Messerle 1981).

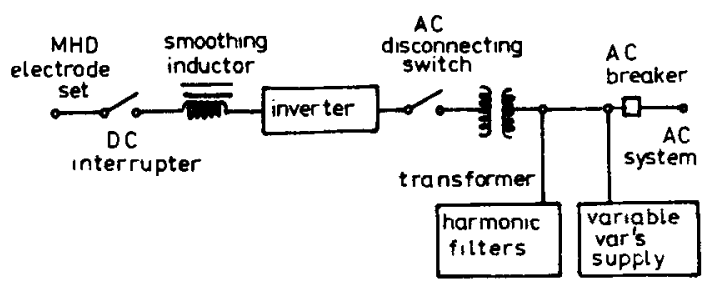

Figure 22. Block diagram of a single inverter system connecting MHD generator to transmission line (Petrick \& Shumayatsky 1978). 


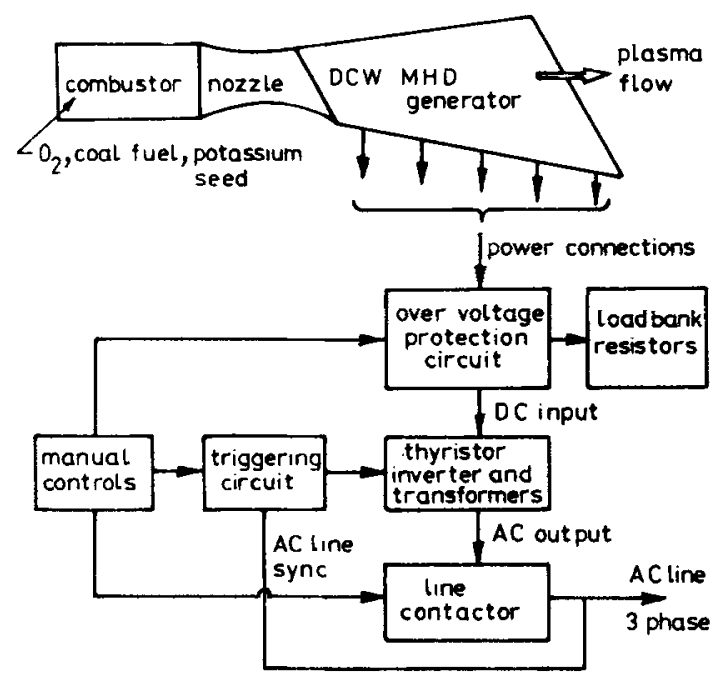

Figure 23. Block diagram of an inverter system for UTSI MHD generator (Barnett 1975).

The possibility of coupling of a multielectrode MHD generator to a rotary inverter system has been studied by Trung et al (1980). The MHD-rotary inverter link has been analysed using steady state fluid dynamic equations for the MHD generator together with the equations describing the inverter system. It is shown that by varying the field current of the parallel-connected-rotary motor (PCRM), the power extracted from the MHD generator can be varied, whereas the reactive power flow can be controlled by the field current of the synchronous generator. The power and the reactive power flow have been calculated for the $2 \mathrm{MWt}$ MHD generator with a $40 \mathrm{~kW}$ inverter system (1980).

The inverter systems remain unaltered for peak, semipeak and base load commercial MHD plants. However, the design of commercial MHD plant is governed by the type of MHD generator and its power rating. To that extent the design of an inverter system is affected by a given plant. The number of inverters required depends on the channel configuration, end effects, and load distribution along the different sections of the channel. The problems peculiar to a given generator will also be refiected in the design of the inverter systems.

Block diagrams of inverter systems of $500 \mathrm{MW}$ and $300 \mathrm{MW}$ MHD generator with segmented Faraday and diagonal connection have been developed at the Institute of High Temperature, Moscow. A typical scheme is shown in figure 24 (Petrick \& Shumyatsky 1978).

In short, though direct experience with large size inverters in conjunction with MHD generator is absent, there is enough evidence that efficient inverter systems (efficiency in excess of $95 \%$ ) can be developed for commercial mHD installations. No new technology is required in the design of inverter systems. Widespread experience with inverters in the other applications lends strong support in this direction. The problems areas affecting the design and construction of an inverter system from the generator viewpoint are (i) impedance matching of the generator to the respective grid, (ii) summing up of current leads from multielectrode generator, (iii) high electrical insulation required for the transformer and (iv) protection against interelectrode breakdown and current leakage in the channel. 


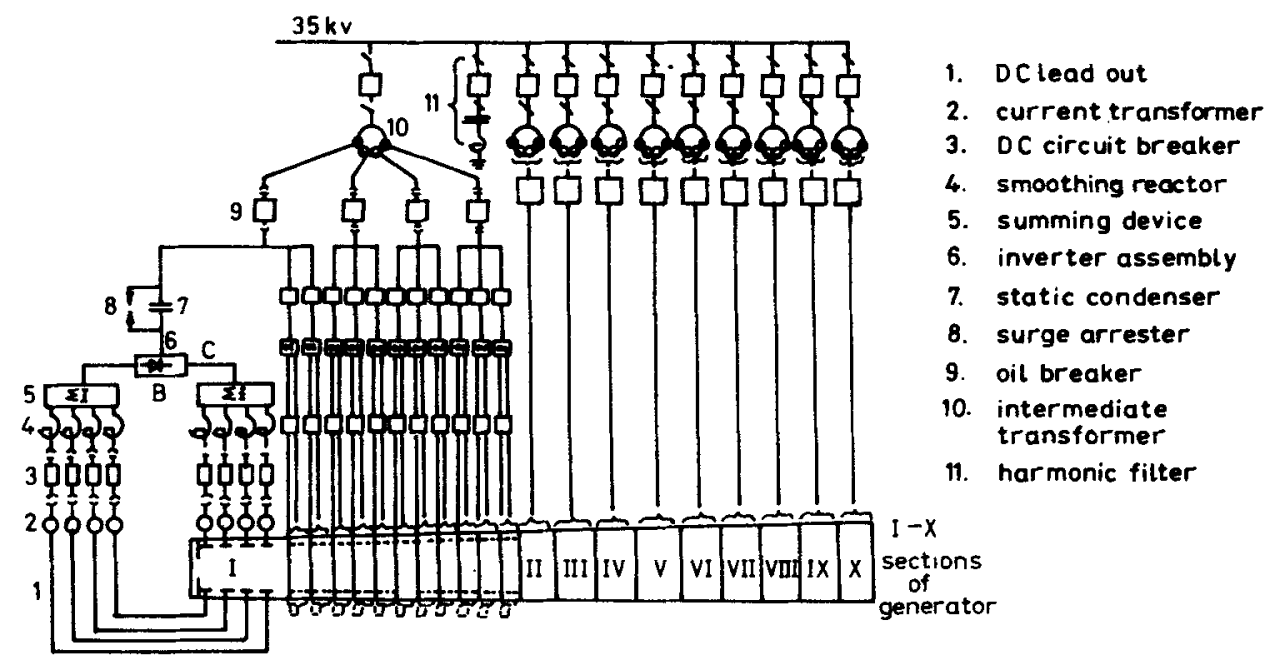

Figare 24. Block diagram of $500 \mathrm{MW}$ MHD power plant with segmented Faraday channel (Petrick \& Shumyatsky 1978).

\subsection{Steam generator}

The development of a steam generator along with the turbomachinery in a MHD-steam plant has not yet received considerable attention. Although the steam generator will retain most of the distinctive features of a conventional power plant, there are some special design features which make it unique. The hot gases leave the MHD channel and enter the steam generator at $2200-2400 \mathrm{~K}$ with an enthalpy content $20 \%$ more than conventional steam generators (Petrick \& Shumyatsky 1978). This excess in enthalpy arises from the increased temperature, presence of ionizing additive and the use of oxygen enrichment. The diffuser, which may be treated functionally as a part of the steam generator, recovers the velocity head as a static pressure by reducing the nominal velocity of about $1000 \mathrm{~m} / \mathrm{s}$ to about $100 \mathrm{~m} / \mathrm{s}$ or lower. Extensive investigations have been carried out on model steam generator at U-02 and U-25 facilities (Sheindlin 1973; IVTAN Report 1973; Mostinskii et al 1983).

The presence of seed compounds in the combustion products (viz $\mathrm{KOH}, \mathrm{K}_{2} \mathrm{CO}_{3}$ and $\mathrm{KHCO}_{3}$ for sulphur-free clean fuel systems) distinguishes the various zones of the steam generator. In the zones where the gas temperatures are greater than $1600 \mathrm{~K}$, the seed condenses on cold surfaces as a mixture of $\mathrm{KOH}$ and $\mathrm{K}_{2} \mathrm{CO}_{3}$ in a molten state. The surfaces of the tubes are characterized by a porous surface close to the metal surface followed by a solid surface and a molten flowing surface on top (Sheindlin 1973). With sulphurous compounds $\mathrm{K}_{2} \mathrm{SO}_{4}$ is formed in addition. In direct coal-fired system a large number of chemically reactive species are formed with complex equilibria and operational characteristics of heat transfer surfaces. Very little work has been done on slag-related problems.

4.7a $\mathrm{NO}_{x}$ emissions Since MHD combustors are operated under fuel-rich conditions $(\alpha=0.85-0.95)$ to reduce $\mathrm{NO}_{x}$ emissions, the steam generator design incorporates two provisions: (i) large residence time of the order of 3 seconds at $1600 \mathrm{~K}$ to decompose $\mathrm{NO}_{x}$ emissions; (ii) introduction of additional air to promote secondary combustion. 
The general philosophy of MHD downstream gas management including the special features of the $\mathrm{NO}_{x}$ reduction has been dealt by Johnson et al (1978). The reduction of high concentration of NO by ammonia injection was studied by Ohtake et al (1983) at Japanese ETL Mark VII facility. The optimal NO removal was obtained under temperature conditions $1273-1323 \mathrm{~K}$ with $\mathrm{NH}_{3}$ / NO ratio slightly higher than 1 .

Another problem associated with seed is the temperature zone $1100-1400 \mathrm{~K}$ when the seed melts. If the gas is allowed to pass through tube bundles in this temperature region the molten seed forms viscous coatings obstructing gas flow. Normally this temperature zone should be completely avoided in the steam generator. This is accomplished by recirculation in the U-25 facility. Now the seed forms a powdery deposit on the coolant tube which can be mechanically removed (Sheindlin 1973; IVTAN Report 1973).

The steam generator operates with the gases at near-atmospheric pressures. With the combustor operating about 5-10 ata, the pressure drop occurs at the channel due to ponderomotive forces. If the magnet field gets switched off or the load gets shed accidentally, there will be sudden pressure surges in the steam generator which should be adequately taken care of.

In summary, the steam generator with associated turbomachinery has not attracted as much consideration as the other units dealt with in this chapter. This trend should be discouraged as the commercial viability will be mostly decided by this unit and reliability of operation.

\subsection{Materials development for MHD power generation}

The development of high temperature materials for MHD application is one of the most challenging areas. The material in contact with high temperature gas/plasma in MHD generator is simultaneously subjected to stresses of mechanical, thermal, chemical and electromagnetic nature. In the case of combustor, the electromagnetic interaction with plasma is minimum, but the gas temperature and the seed/slag contact is high. The operating temperatures and seed residence time in the combustor are much larger compared to the MHD generator. In the case of air preheaters on the other hand the temperatures are relatively low but the thermal cycle of the heating media results in spalling and mechanical fracture of the material. These are the three main components in the MHD plant where the high temperature refractory materials have to perform under difficult conditions. The materials have been developed and tested separately for each of the three applications. For the present discussion the progress in this field will be reviewed under the three headings, namely, materials for air preheater, combustor and MHD generator.

4.8a Materials for airpreheater As mentioned earlier recuperators have not been found attractive for MHD plants because of the problems of fabrication, mechanical strength and fluid leakage. Thus most of the effort in this direction has been to develop the regenerative heat exchangers. The heating media consists of pebble beds or checker brick assembly with open holes. Majority of the investigations have been made with heating media of $\mathrm{Al}_{2} \mathrm{O}_{3}$ or $\mathrm{MgO}$. However, combinations of $\mathrm{Mg}-\mathrm{Cr}$ or $\mathrm{Mg}$-Al oxides appear to be superior for mechanical strength and thermal shock resistance. Also these combinations show less seed/slag attack and deformation under load.

For coal-fired MHD plant and air preheat of $2000^{\circ} \mathrm{K}$ and above suitable materials do not exist as yet. At the same time no direct efforts to develop material for this 
application have been reported in recent literature. An alternative approach such as higher oxygen enrichment in place of high preheat is being seriously considered for fast realisation of commercial MHD plant (Lippert \& McCutchan 1980). This decision is made primarily by the fact that the present-day materials cannot withstand the required conditions and the development of suitable newer materials appears to be both timeconsuming as well as expensive.

4.8b Combustor material The material for combustor lining is required to reduce the heat loss through the walls. The plasma temperature in this region is high (approximately $3000 \mathrm{~K}$ ) and rich in species from seed material. Typical residence time of seed in the combustor is of the order of milliseconds as compared to microseconds in the MHD generator. Also in the case of coal-fired systems slag is present in abundance. Thus seed/slag attack on the lining material is quite pronounced.

The information on material behaviour in the combustor is practically absent from the literature. At the same time it is known from experience that no satisfactory material has been found which can withstand the environmental conditions for long time. In the U-02 and U-25 facilities in Moscow, combustor lining consists of zirconia concrete stabilized with calcium oxide. It is reported that with clean fuel (natural gas), this material is found satisfactory for several hundreds of hours (approximately $500 \mathrm{hr}$ ) of operation at $2300-2400^{\circ} \mathrm{K}$. However, material with longer durability will be preferred. In the selection of material it is also important to ensure its compatibility with other materials in the system and in particular with the materials in the MHD channel.

The Avco experience with castable magnesia-lined combustor indicates that this material is satisfactory for operation under slagging as well as non-slagging conditions (Petty et al 1975). The MgO lining lasted for several hundred hours. The heat losses through the walls were found to be reduced in the slagging operation, presumably due to the additional coating of slag layer. The plasma temperatures of $3000 \mathrm{~K}$ were obtained and the average heat loss was of the order of $7-8 \%$ of the thermal input.

In conclusion, it may be added that while the casing material for combustor is easy to select the refractory lining material and their optimum usage require further consideration.

4.8c Material for MHD generator The design and development of stable and long duration channels has been the main concern of scientists and engineers in the field of MHD power technology. To that extent, suitable high temperature materials play an important role in this effort. High strength construction materials operating under normal conditions (required for channel housing) do not pose serious difficulties. But suitable materials to work in contact with plasma have not yet been located. Towards this end major efforts have been devoted in several countries like the USA, the USSR, France, England, Poland, Japan and China. Over a period of years significant progress has been noted but much more remains to be done in this field.

The primary constraint of material durability has forced the designers to compromise with less optimum designs of the channel or to think of alternatives like replacing electrodes periodically. Both the American and Soviet recent studies on commercial MHD plant considered the necessity of frequent duct change-over. With the present-day technology it is believed that the life of MHD generator of about 250-500 hours is possible (Harvey et al 1979; Kirillin \& Sheindlin 1980), whereas the MHD system analysis suggests desirable channel life of around 2000 hours or more. This reflects seriously on the design of plant equipment layout and other engineering details. 
The recent interest in coal-fired MHD plants has introduced additional problems of electrochemical interactions of slag with the channel materials. Some of these problems have already been identified under $\$ 4.5$ (MHD generators). Several approaches are being pursued today to overcome these problems; such as: (i) the development of new materials; (ii) the development of new technologies and processes, and (iii) the development of new engineering concepts using standard materials. With the experience gained so far it is now possible to define tentative guidelines for the selection and qualification of material for channel components.The refractory materials in general should have the following properties:

(i) Electrical resistivity: For electrode material the resistivity should be less than $1 \mathrm{ohm}-\mathrm{cm}$ and should withstand current densities of 1-2 Amp/ $\mathrm{cm}^{2}$ whereas for interelectrode insulations the resistivity should be greater than $100 \mathrm{ohm}-\mathrm{cm}$ and the dielectric breakdown must be more than $4 \mathrm{kV} / \mathrm{m}$ at elevated temperatures.

(ii) Corrosion resistance: Materials must resist seed and coal slag attack.

(iii) Erosion resistance: Materials must resist erosion due to high velocity $(1000-2500 \mathrm{~m} / \mathrm{s})$ of gases and particulates.

(iv) Thermionic emission of electrons: Cathode and anode should be good emitter and acceptor of electrons.

(v) Thermal conductivity: Must be adequate to transmit high heat fluxes from plasma at temperatures of $3000^{\circ} \mathrm{K}$. Specific heat fluxes are considered as design input data.

(vi) Oxidation/reduction resistance and chemical stability: Materials must remain stable under oxygen pressure of $10^{-3}-10^{-2}$ atmosphere. Generally low vapour pressure and high melting points are required.

(vii) Compatibility: Materials must be chemically compatible with all adjacent materials.

(viii) Thermal shock: Materials must resist thermal shock conditions caused by start-up and shut-down conditions as well as due to large thermal gradients under operating conditions.

It is noted from the table above that some of these requirements impose contradictory conditions on the material properties. For example, it is known that material with controlled porosity shows higher thermal resistance which at the same time is not suitable from the chemical corrosion point of view. Such requirements make it difficult to specify material properties in an absolute sense.

Today high purity $\mathrm{Al}_{2} \mathrm{O}_{3}$ and $\mathrm{MgO}$ appear to be popular as insulator materials. These materials exhibit good chemical and structural stability and high electrical resistivities of the order of $10^{3}-10^{5} \mathrm{ohm}-\mathrm{cm}$ at temperatures around $1975 \mathrm{~K}$. Between the two, $\mathrm{MgO}$ is preferred to $\mathrm{Al}_{2} \mathrm{O}_{3}$ because of its higher resistance to seed attack. Sata \& Kasukawa (1980) have tested more than 65 kinds of refractory material for alkali corrosion using $\mathrm{K}_{2} \mathrm{SO}_{4}$ melts and $\mathrm{K}_{2} \mathrm{SO}_{4}-\mathrm{K}_{2} \mathrm{CO}_{3}$ melts. The results indicate $\mathrm{MgO}$ and $\mathrm{ZrO}_{2}-\mathrm{CaO}_{2}$ have strong resistance whereas $\mathrm{Al}_{2} \mathrm{O}_{3}$ showed good results only in $\mathrm{K}_{2} \mathrm{SO}_{4}$ melts. Extensive work has been done on the development of magnesia ceramic insulators for the channel, with encouraging results (Telegin et al 1976). Combinations of $\mathrm{MgO}$ and $\mathrm{Al}_{2} \mathrm{O}_{3}$ are also being evaluated for this application.

For electrodes, apart from metal and their alloys (Hruby et al 1980) oxides of zirconia and lanthanum have been investigated extensively. Zirconia stabilised with $\mathrm{CaO}$ and $\mathrm{Y}_{2} \mathrm{O}_{3}$ have yielded encouraging results upto $1700 \mathrm{~K}$. However, the low thermal and electrical conductivity and ionic conduction of zirconia are some of the objectionable 
features of this material. Hosler \& Frederikse (1975) have attempted to increase the electronic conduction in zirconia by adding $\mathrm{CeO}_{2}$. The results indicate that electronic conduction increases with the $\mathrm{Ce}^{+3}$ content. However, more than $50 \%$ electronic conduction is only possible (around $1000 \mathrm{~K}$ ) when $\mathrm{CeO}_{2}$ becomes the major constituent. Further, the study indicates that a composition of $80 \% \mathrm{CeO}_{2}-18 \%$ $\mathrm{ZrO}_{2}-2 \% \mathrm{Ta}_{2} \mathrm{O}_{5}$ is a better candidate for MHD electrode material as it combines all the good features in one compound namely, high conductivity, nearly $100 \%$ electronic conduction, single phase structure and chemical stability upto $1900 \mathrm{~K}$. Zirconium oxide doped with $\mathrm{CeO}_{2}$ electrodes have also been prepared by Rossing et al (1975). The authors have prepared samples with differing compositions and microstructure to investigate the effect of electrical properties and thermomechanical behaviour on electrode performance. Akopov et al (1975) have investigated electrodes having composition $\mathrm{ZrO}_{2}(85 \mathrm{~mol} \%)+\mathrm{CeO}_{2}(12 \mathrm{~mol} \%)+\mathrm{Y}_{2} \mathrm{O}_{3}(3 \mathrm{~mol} \%)$ with $50 \%$ electronic conduction. The electrical resistivity of this material at $1900 \mathrm{~K}$ is less than $1 \mathrm{ohm}$ $\mathrm{cm}$. To provide electronic conduction below $1900 \mathrm{~K}$, components based on $\mathrm{CeO}_{2}$ in solid solution with rare earth oxides were used. Current take-off below $1300 \mathrm{~K}$ was realised with heat resistance alloys. Electrode and current conducting compounds were incorporated in the same ceramic structure. Authors report encouraging results from this system.

The electrical properties of the ternary solid solutions of the type $\left(\mathrm{ZrO}_{2_{1-x}}\right.$ $\left.\mathrm{CeO}_{2 x}\right)_{0.9}-\mathrm{Y}_{2} \mathrm{O}_{30.2}(0<x<1)$ have also been studied by Cales \& Baumard (1980) over a large range of temperatures and oxygen partial pressures. The electrical conductivity is both ionic and electronic and at a given temperature and oxygen partial pressure is strongly dependent on ceria concentration. The conductivity of pure yttriastabilized zirconia is entirely ionic, the electronic part appearing with ceria content possibly as a result of redox equilibrium between tetravalent $\mathrm{Ce}^{4+}$ and trivalent $\mathrm{Ce}^{2+}$ cerium ions.

Other materials which have received considerable attention are variations of $\mathrm{LaCrO}_{3}$. The electrical conductivity of $\mathrm{LaCrO}_{3}$ is high but the loss of chromium at high temperatures results in excess of $\mathrm{La}_{2} \mathrm{O}_{3}$ which is hygroscopic in nature. Substitution of $\mathrm{Sr}, \mathrm{Mg}$ and $\mathrm{Ca}$ produces resistivities of the order of $0.1 \mathrm{ohm}-\mathrm{cm}$ and also suppresses the evaporation of chromium. The loss of chromium and attack by water and seed lead to rapid degradation of this material (Sata \& Kasukawa 1980). Nevertheless because of high electronic conduction, this material has long sustained interest as generator electrode material. Over a period of years many attempts have been made to improve the properties of this material.

Suppression of chromium in $\mathrm{LaCrO}_{3}$ by substitution with magnesia has been attempted by George et al (1976). The authors found that the material, designated as LC $20 \mathrm{M}$ exhibits good sintering characteristics in single firing at $1650 \mathrm{~K}$ with a porosity of less than $10 \%$ and grain size of 3-5 $\mu \mathrm{m}$. The electrical resistivity was around $0.2 \mathrm{ohm}-\mathrm{cm}$ with a very low temperature coefficient. The sample withstood current density of the order of $20 \mathrm{Amp} / \mathrm{cm}^{2}$ for long duration. The thermionic work function $W_{p}=2.75 \mathrm{eV}$ and the Richardson constant, $A_{R}=0.11 \mathrm{~A} / \mathrm{cmK}^{2}$ were found to be suitable for MHD electrode applications (Pai et al 1980). Further development along this line includes the investigations of combinations of $\mathrm{LaCrO}_{3}-\mathrm{SrZrO}_{3}$ and $\mathrm{LaCoO}_{3}-$ LC $20 \mathrm{M}$ (George et al 1980). Preparation and electrophysical properties of $\mathrm{La}_{1-x} \mathrm{Ca}_{x} \mathrm{CrO}_{3}$ have been reported by Jiang Dang-liang et al (1980). The compatibility of calcia-stabilized zirconia (csz) and $\mathrm{La}_{1-x} \mathrm{Ca}_{x} \mathrm{CrO}_{3}$ was also included in this study. 
The authors found electrical conductivity of $\mathrm{La}_{1-x} \mathrm{Ca}_{x} \mathrm{CrO}_{3}$ to increase slightly with the doping of $\mathrm{Ca}^{2+}$ and almost independent of temperatures. At high temperatures its conductivity was about 1 order of magnitude higher, than that of csz. The evaporation rate of $\mathrm{LaCrO}_{3}$ when doped with $\mathrm{Ca}$ or $\mathrm{Sr}$ did not show any change nor was there any change in the electrical conductivity of $\mathrm{La}_{1-x} \mathrm{Ca}_{x} \mathrm{CrO}_{3}$ after vaporization. The thermal and electrical matching between $\mathrm{La}_{1-x} \mathrm{Ca}_{x} \mathrm{CrO}_{3}$ and $\mathrm{Csz}$ was found to be good specially at temperature below $1800 \mathrm{~K}$. The material has been successfully tested in the MHD facility for more than 200 hours.

Using oil combustion plasma, under simulated test conditions the following combinations of materials (metal ceramic composites) have been found suitable by Nomura et al (1980).

Anode material: $(36 \mathrm{Cr}-20 \mathrm{Ni}-2 \mathrm{Mo}-\mathrm{Fe})+10 \mathrm{Al}_{2} \mathrm{O}_{3}, 70 \mathrm{ZrO}_{2}+30 \mathrm{LaCrO}_{3}$

Cathode material: $(16 \mathrm{Cr}-7 \mathrm{Fe}-\mathrm{Ni})+10 \mathrm{LaCrO}_{3}, 75 \mathrm{ZrO}_{2}+25 \mathrm{CeO}_{2}$

Insulating material: $\mathrm{MgO} ; 30\left(\mathrm{Al}_{2} \mathrm{O}_{3}\right)+30(\mathrm{AIN})+40\left(\mathrm{Si}_{3} \mathrm{~N}_{4}\right)$.

On the basis of theoretical analysis the authors suggest that to prevent thermal damage, the temperature difference between the elements must be reduced. A figure of merit, $\Gamma$ has been evolved so that the resistance to normal thermal stress can be computed,

$$
\Gamma=(1-v) S / E \alpha,
$$

where $v$ is the Poisson ratio, $S$ is the tensile strength, $E$ is the Young's modulus, and $\alpha$ is the linear expansion coefficient. It is inferred that higher the value of $\Gamma$, less susceptible will be the material to thermal stress damages. This criteria has been validated by considering the examples of $\mathrm{Al}_{2} \mathrm{O}_{3}$ and $\mathrm{MgO}$. Consistent with observations and as predicted it is seen that $\mathrm{Al}_{2} \mathrm{O}_{3}$ can withstand thermal stress better than $\mathrm{MgO}$.

The properties of $\mathrm{YCrO}_{3}$ modified by $\mathrm{CaO}$ have been examined by Andrezej \& Kulak (1980) for MHD generator electrode. This material shows good thermal and electrical conductiviies and appears to be a good material for channel electrode. Several materials have been investigated for super-hot wall electrodes (Pober et al 1980) including iron-aluminium spinel, zirconia-yttria, zirconia-ceria and strontium zirconate-lanthanum strontium ferrite solid solutions. It has been found that a wide single phase solid solution region exists in the strontium zirconate lanthanum ferrite strontium ferrite ternary around $1800 \mathrm{~K}$. Several of these compounds have melting point about $2300 \mathrm{~K}$ and resistivity in the range of $10 \mathrm{ohm}-\mathrm{cm}$ and so are suitable for MHD electrode applications.

The properties of slag and slag coated electrodes have been the subject of investigations in recent years. Effects of slag on MHD generator performance have been studied by Bogdanska et al (1975). The investigations included the study of the electrical and chemical properties of coal slag and their influence on electrode behaviour. Very good results have been reported for stainless steel electrodes (operating approximately at $900 \mathrm{~K}$ ) with moving slag layer on them. Cathode drops of $35 \mathrm{~V}$ were observed with $2-3 \mathrm{amp} / \mathrm{cm}^{2}$. However difficulties were experienced in securing suitable insulations between the electrodes and through the side walls in the Faraday generator. Figure 25 shows schematically the arc-slag interaction on stainless steel electrode as seen visually. Crawford et al (1975) at the University of Tennessee have analysed the interaction of potassium seed with slag particles in the combustion plasma and with the slag layer on cold electrode walls. Comparison of equilibrium 


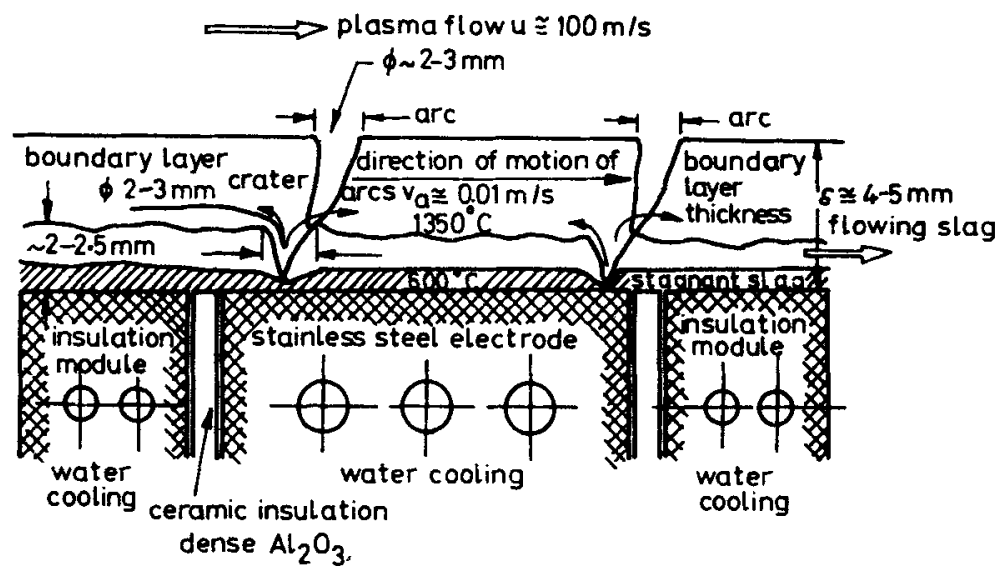

Figure 25. Schematic of arc-slag interaction on cold stainless steel electrode ( $900 \mathrm{~K}$ at steel surface) (Bogdenska et al 1975).

calculations of potassium reacted with coal slag (approximately 15\% ash) with the available data is given in figure 26 . The authors have developed a calculation procedure including slag and gas dynamic properties to predict the thickness and energy loss characteristics through the slag layer. Thus for given properties of a slag the calculation procedure could be useful for the design of MHD channel.

The spinel alumina electrode (see figure 27) has been studied by Mason et al (1975) for open cycle coal-fired MHD systems. The authors mention the following advantages of this design: (i) completely electronic conductivity and low temperature dependance; (ii) operation temperatures will allow optimisation of slag properties; (iii) absence of resistive reaction layer at the hot or cold electrode faces; (iv) dissolution of spinel and alumina can be minimised by control of slag chemistry; (v) the fusion of iron into alumina can be modified by slag composition, temperature and partial pressure of oxygen in the combustion plasma; (vi) grading of spinel layer as shown in figure 28 will minimise the driving force for inter diffusion with alumina at the hot end of the modules adjacent to the slag.

The electrochemistry of slagging electrodes has been analysed by a number of workers (Cadoff \& Rossing 1980; Cannon et al 1978). The study deals with the role of slag chemistry, temperature, electrode material and conduction mechanism of slag and

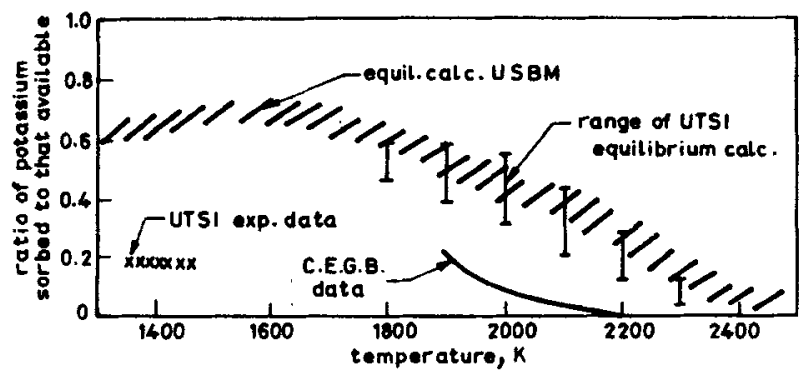

Figure 26. Comparison of equilibrium calculation of potassium reacted with coal slag (approx. 15\% ash) with available experiemental data. 


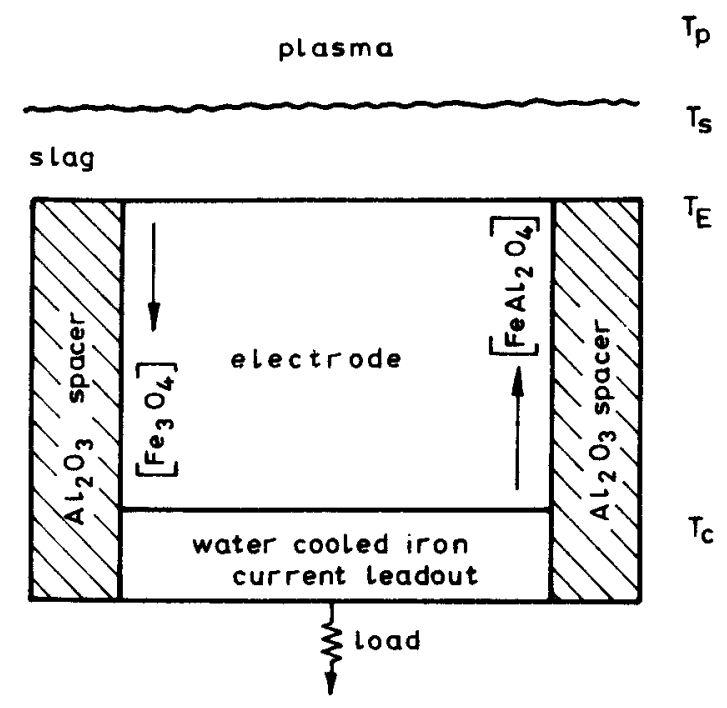

Figure 27. Schematic of spinel electrode module consisting of graded $\mathrm{Fe} \mathrm{Al}_{2} \mathrm{O}_{4}-\mathrm{Fe}_{3} \mathrm{O}_{4}$ layer on an iron (or $\mathrm{Fe}-\mathrm{Al}$ alloy) current extractor and with a chemically compatible $\mathrm{Al}_{2} \mathrm{O}_{3}$ insulator (Mason et al 1975).

electrodes on corrosion. It is suggested that the electrochemical reactions can be minimised by modifying slag properties (that is increasing electrical and electronic conductivity) and by judiciously selecting materials whose electrical conductivity and conduction mechanism match with that of slag.

This brief review indicates the present status of the materials which have been investigated for possible applications in MHD technology. Though considerable understanding of the subject is evidenced during the last few years, it is also indicative of the need of lot more intensified efforts in this area. The dominant physicochemical processes in the MHD generator and other components must be addressed along with the material constraints. The basic needs are the appropriate modelling studies that will be useful in predicting the performance-limiting properties of the materials of which the crucial components are fabricated.

\section{Development of plasma diagnostics and other subsystems for MHD applications}

The status of technology discussed thus far relates directly to the MHD power generation process. The state of art as regards the non-standard components essential for MHD power generation has been covered in \$4. In order to successfully develop and test the performance of these components, special tools, techniques and procedures are required which can yield unambiguous information. These, broadly termed as diagnostic techniques, are dealt with in $\$ 5.1$. Apart from the main components identified in $\$ 4$ there are several other subsystems which are well known in industry. They may need suitable modifications for fitting in an MHD plant and these are given in $\S 5.2$. 


\subsection{Plasma diagnostics}

The identification and characterisation of the physical phenomena taking place at each stage in the MHD system is difficult but necessary to understand the process fully. Different units in the MHD system come in contact with high temperature corrosive gases in one form or the other. The interaction with the gas differs in terms of its temperature, composition, electrical and thermal conductivity and flow pattern. It is therefore essential to know these properties of the high temperatures gas before attempting to understand its interaction with the unit. In short, electrical, thermal and flow properties of the working media (plasma) must be known to a high degree of accuracy in the entire MHD system, and in combustor and MHD generator in particular. The measurements of gas (plasma) temperature, plasma density, electrical conductivity, seed concentration and the flow velocities are necessary in the generator as well as the combustor (Self \& Kruger 1977; Self 1980). In addition, to analyse the electrical characteristics of the generator and the interaction of plasma with electrode and insulating walls of the channel, it is necessary to know the charge, heat and mass transfer to the respective elements of the channel. While effects like chemical attack of slag/ash on the material can be studied after the hot run, the behaviour of plasma in bulk and its interaction at the walls of the generator (and combustor) can only be investigated during operation. For such information in situ measurements are required. The general diagnostic techniques for MHD application can be classified under 3 headings, namely, (i) standard measuring techniques (commercially available), (ii) techniques with known physical principles to be adapted for MHD application, and (iii) non-standard measuring techniques involving development efforts. A classification of this type is given in table 8.

5.1a Standard techniques The standard measurements using known techniques have to be properly engineered to suit the generator conditions. For example, transducers sensing pressure, heat fluxes, and temperature have to be shielded to avoid effects of magnetic field, excessive heat and strong temperature gradients. The heat transfer from combustor walls have been used as a diagnostic tool to optimize combustor design for

Tale 8. Diagnostic techniques for MHD generator

\begin{tabular}{|c|c|c|}
\hline $\begin{array}{c}\text { Standard measuring } \\
\text { techniques } \\
\text { (commercially available) }\end{array}$ & $\begin{array}{l}\text { Principles known, } \\
\text { technique to be adopted } \\
\text { for MHD application }\end{array}$ & $\begin{array}{c}\text { Non-standard techniques } \\
\text { involving } \mathbf{R} \text { and } \mathbf{D} \\
\text { efforts }\end{array}$ \\
\hline $\begin{array}{l}\text { a) Pressure measurement } \\
\text { b) Temperature using } \\
\text { thermocouples } \\
\text { c) Potential measurement } \\
\text { d) Current measurement } \\
\text { e) Heat flux measurement }\end{array}$ & $\begin{array}{l}\text { a) Plasma temperature } \\
\text { measurement } \\
\text { (spectroscopy) } \\
\text { b) Measurement of } \\
\text { electrical conduc- } \\
\text { tivity of plasma } \\
\text { c) Seed concentration } \\
\text { d) Temperature using } \\
\text { pyrometers } \\
\text { e) High speed camera } \\
\text { and photographic } \\
\text { techniques }\end{array}$ & $\begin{array}{l}\text { a) Electrostatic probe } \\
\text { for density, temperature } \\
\text { and flow velocity } \\
\text { of plasma } \\
\text { b) Pressure pulsations } \\
\text { c) Enthalpy probes } \\
\text { d) Doppler shift } \\
\text { velocimetry and } \\
\text { thermometry. } \\
\text { e) Laser/microwave } \\
\text { interferometers }\end{array}$ \\
\hline
\end{tabular}


MHD power plants by Roy (1980) and Roy \& Crawford (1980) who has compared heat flux distribution with quasi-one-dimensional model. Recently Satyamurthy et al (1979) have estimated the error in steady state temperature measurements due to conduction along with thermocouple leads. An expression has been derived by which necessary correction for conduction through the thermocouple can be estimated for a given data. Alternatively the thermocouple should be placed so that its normalised length $(l / D)$ along the isothermal path is of the order of 10 , where $l$ is the length of the sensor along the isothermal path and $D$ is its diameter. The error decreases exponentially as $l / D$. The use of thermocouple or any other direct contact method for steady state gas temperature measurement is not generally acceptable. Such techniques are only reliable for measurements of temperature of solid body where good thermal contact is possible. For gas temperature measurements optical/spectroscopic methods give better estimates.

5.1b Measuring techniques Table 9 gives a summary of techniques which are currently used and/or being developed for the measurement of plasma properties. The physical principles of these have been well understood. The development of experimental

Table 9. Techniques for measuring MHD plasma properties

\begin{tabular}{|c|c|c|}
\hline Plasma parameters & Technique & Remarks \\
\hline \multirow[t]{2}{*}{ 1. Temperature } & $\begin{array}{l}\text { (i) Line reversal } \\
\text { method } \\
\text { (ii) Line intensity } \\
\text { method }\end{array}$ & $\begin{array}{l}\text { (i) Simple, non-intrusive } \\
\text { and quite accurate } \\
\text { (ii) Non-intrusive, but needs } \\
\text { atomic transition } \\
\text { probabilities and } \\
\text { have accuracy limited to } \\
\text { their degree of } \\
\text { uncertainty }\end{array}$ \\
\hline & $\begin{array}{l}\text { (iii) By measurement of } \\
\text { Doppler width }\end{array}$ & $\begin{array}{l}\text { (iii) Quite accurate, } \\
\text { needs high resolving } \\
\text { power instruments }\end{array}$ \\
\hline $\begin{array}{l}\text { 2. Electron and ion } \\
\text { concentration }^{b}\end{array}$ & $\begin{array}{l}\text { (i) Electrostatic } \\
\text { probe }\end{array}$ & $\begin{array}{l}\text { (i) Good spatial } \\
\text { resulution, } \\
\text { accuracy } \sim 50 \%\end{array}$ \\
\hline & $\begin{array}{l}\text { (ii) Sub-millimeter } \\
\text { interferometry }\end{array}$ & $\begin{array}{l}\text { (ii) Complex measurement } \\
\text { technique for } \\
\text { infrared lasers }\end{array}$ \\
\hline \multicolumn{3}{|l|}{ 3. Electrical } \\
\hline conductivity ${ }^{c}$ & (i) R.F. probe & $\begin{array}{l}\text { (i) Intrusive, } \\
\text { accuracy } \sim 30 \%\end{array}$ \\
\hline 4. Velocity & $\begin{array}{l}\text { (i) Laser } \\
\text { anemometry }\end{array}$ & $\begin{array}{l}\text { (i) Non-intrusive, } \\
\text { accurate technique } \\
\text { with good spatial } \\
\text { and temporal } \\
\text { resolution }\end{array}$ \\
\hline
\end{tabular}

References:

¿Self (1980); Reif et al (1976); Gaydon (1970); Lapworth (1974); Daily (1978).

${ }^{\circ}$ Clements (1978); Swift \& Schwar (1970); Self et al (1977); Kuzmenko \& Self (1983).

'Gaponov et al (1974); Balashov et al 1977; Jayakumar et al (1977); Vendall (1976).

' Beer \& Chigier (1972); Drain (1980); Self (1976). 
techniques, sophisticated instrumentation and data handling systems, in general, decides the accuracy of the measurement. It has already been observed that good diagnostics of plasma is necessary in order to develop and validate physical models of the MHD generator, combustor etc. The computer models which have been referred to earlier are based on the experimental data generated through these measurements. Consequently, the plasma diagnostics have to be very reliable if this information is to be used for scaling up the designs of the MHD generator.

Ashin et al (1975) reported the development of techniques for finding the concentration of charged particles in the plasma of MHD generator. The authors have applied the method of electrical probes and submillimeter laser interferometry to determine the beam average electron density. These methods were applied to a plasma seeded with potassium, rubidium and cesium salts. The temperature and ion concentration in the plasma determined respectively by line reversal technique and absolute line intensity measurements. The data thus obtained was used to calculate electron concentration which was compared with ion concentration determined by other techniques. The group of scientists at the Institute of High Temperature; Moscow has evolved a complex plasma diagnostic system consisting of several techniques to measure and control the flow of plasma in MHD plant (Balashov et al 1980). The diagnostic system includes spectral, laser and probe methods of plasma investigations. Spectral methods are used to measure plasma temperature and seed atom concentration and radiant heat flux from plasma to the wall. Laser is used to measure ion density and electron collision frequency. Probes are used to measure the electrical conductivity of the plasma and electron concentration in the generator. The spectral and laser methods monitor the plasma continuously whereas the probes are used only for short time when inserted into the plasma. The plasma parameters are measured in the combustor, the nozzle, the inlet of the generator, and in the diffuser.

The advent of laser spectroscopy in combustion research has led to a number of novel techniques yielding remote, in situ, spatially and temporarily resolved measurements of important parameters. Eckbreth (1980) has reviewed the recent advances in laser diagnostics for temperatures and species concentrations viz. spontaneous Raman scattering, Rayleigh scattering, coherent anti-stokes Raman spectroscopy (CARS), stimulated Raman gain/loss spectroscopy and laser excited fluorescence.

The velocity, temperature, and electron number density/profile in boundary layer of combustor driven MHD generator were measured by Daily et al (1975). The gas temperature and electron number density were both measured spectroscopically, whereas laser doppler velocimeter, developed at Stanford University (Self 1980) was used to determine the velocity profile. The experimental results were compared with the two-dimensional turbulent boundary layer calculations.

In view of the recent interest in coal-fired system additional measurements of the characteristics of ash carry-over are required to adequately account for its behaviour. All parameters such as ash, composition, particle size distribution, slag/seed interaction must be measured with good spatial and temporal resolution in the generator as well as in the boundary layer. The spectroscopic methods of temperature measurement appear satisfactory for clean combustion plasma. However, the validity of these techniques must be established for ash-laden plasmas. The same is the case with the measurement of electrical conductivity and charge concentration measurements.

Measurements of the size and concentration of ash droplets in coal-fired MHD plasma have been attempted by Ariessohn et al (1980). A two wavelength laser transmissometer 
has been used to make the in situ measurements of ash droplet size and concentration in a coal combustion plasma. Combustor parameters were varied to achieve various ash loading, flame temperature and residence time. Measurements were performed on coals from Illinois and Montana coal fields. Ash droplet mean diameters of $1.4-2.8 \mu \mathrm{m}$ were observed with Illinois coal and mean diameter of 1.3-2.2 $\mu \mathrm{m}$ were observed from Montana Rosebud Coal. Ash droplet size appeared to be a decreasing function of temperature and relatively independent of stoichiometry, residence time and ash loading.

The present-day instrumentation does not permit the measurements in the MHD generator in the presence of magnetic field. In particular plasma conductivity and charge distribution are the quantities which are strongly influenced by the magnetic field. As yet there are no reliable techniques which can be used for this purpose. Also important are the measurements of thermal and electrical boundary layer effects in the generator. Temperature and charge density profiles have not been accurately measured.

More refined and convenient techniques with improved reliability are needed for plasma diagnostics. These techniques should aim at improving the spatial and temporal resolution and should be applicable in the presence of magnetic field and ash particles in the system. Several such techniques are under development at Mississippi State University (Murphree et al 1983).

\subsection{Subsystems development}

Apart from the ones that have already been identified, there are several other subsystems in an MHD installation, which need development. Although the systems mentioned here are well known to the industry, they have to be suitably modified and evaluated for MHD applications. Following are some of the items belonging to this category: (i) coal gasification, (ii) ionizing seed injection system, (iii) seed recovery/regeneration unit, (iv) diffuser, (v) testing and evaluation of metals and alloys for high temperature components.

5.2a Coal gasification For MHD plants alternative to direct coal combustion is the route through coal gasification. The main advantage of coal gasification is its potential for removing ash from the combustion products. Though there are energy and cost penalty for gasification process, the scheme is conceptually attractive specially when using high ash coals. Problems associated with coal gasification for MHD application are unique when compared to the conventional gasification processes. For MHD application it is of interest to have gases of high heating value and free from ash. Calculations as well as experience however show that for high heat value the outlet gas temperature from gasifier should also be high generally in excess of the slagging temperature of the ash. This makes the problem of cleaning the gas, rich in suspended ash, difficult without lowering the temperature. Attempts to reduce the temperature of exit gas below the fusion temperature of the ash will necessitate additional heat input in the system to achieve the desired plasma temperature in the combustor. The existing gasification processes (Vorres 1980; Larson 1981) are therefore disqualified for MHD plants. Several alternatives have been proposed and are being studied actively. So far however no successful results have been reported. This leaves the problem of suitable gasification process for MHD applications open for further development work. However, a number of MHD cycle studies involving coal gasification have been reported by Pashkov et al 
(1976). Schemes involving gasifier at channel exit are also being investigated at the Swierk facility in Poland (Brozozowsky et al 1983).

5.2b Ionizing seed injection system The importance of ionizing seed to achieve high plasma conductivity is well known. The ionisation of seed and its recovery have a direct consequence on the economics of power from MHD process. From the economic considerations potassium salt (ionisation potential $4.34 \mathrm{eV}$ ) has been taken as the accepted seed material although cesium salt (ionisation potential $3.89 \mathrm{eV}$ ) would be preferred for seed. Recently possibilities of mixing potassium cesium salts for seeding have been considered. It is shown that a mixture of $15 \% \mathrm{CsCO}_{3}+85 \% \mathrm{~K}_{2} \mathrm{CO}_{3}$ and with $99 \%$ seed regeneration can result in substantial economic gain for the $1000 \mathrm{Mw}$ plant (Petrick \& Shumyatsky 1978). At the same time the recovery of cesium and potassium mixture does not appear to be any more difficult than the recovery of potassium alone.

The problems that have to be addressed under this heading are (a) uniform seed dispersion and controlled droplet size for high degree of ionisation, (b) suitable position of seed injection into the combustor to minimise seed/slag interaction and loss of seed along with slag rejection. This is possible if the seed particles are successfully prevented from reaching combustor walls and getting entrapped in the slag coating, (c) for higher MHD plant efficiency supersaturated solutions/dry seed injection is more desirable. Work towards this end has to be intensified.

5.2c Seed recovery and regeneration system Seed from the MHD discharge will have to be recovered and recycled for economic reasons. Seed recovery is also important from the standpoint of sulphur emission control in the environment. In the case of gas-fired systems, seed condenses as molten $\mathrm{K}_{2} \mathrm{CO}_{3}, \mathrm{KOH}$, on the heat transfer surface of the radiant and semi-radiant portion of the steam generator. Both U-02 and U-25 employ cold funnel to extract molten $\mathrm{KOH}$ under the steam generator. A significant portion of seed is also deposited on the surface of steam generator in the form of $\mathrm{K}_{2} \mathrm{CO}_{3}$ (or as $\mathrm{K}_{2} \mathrm{SO}_{4}$ in the presence of sulphur) or as mixture of $\mathrm{K}_{2} \mathrm{CO}_{3}$ and $\mathrm{K}_{2} \mathrm{SO}_{4}$. This deposit can be flushed down or mechanically removed from the pipes and processed for reuse. Bag filter system, venturi scrubber with cyclone collector and electrostatic precipitation have been studied for seed recovery system with promising results.

In the sulphur-free systems using wet seed recovery methods, the solution collected is rich in $\mathrm{KHCO}_{3}$ and $\mathrm{K}_{2} \mathrm{CO}_{3}$ plus small quantities of other elements. As $\mathrm{KHCO}_{3}$ cannot be directly fed to the combustor, $\mathrm{KHCO}_{3}$ is converted to $\mathrm{K}_{2} \mathrm{CO}_{3}$. It is believed that seed regeneration in sulphur-free system should not cause any difficulty.

In the case of coal-fired systems seed has to be recovered from slag. For this purpose two approaches are being followed namely, (a) separation of seed from ash prior to regeneration, and (b) first regeneration of seed and ash mixture and then separation of ash. Which of the two will be finally adopted is still not clear.

The recovery of sulphur and seed both have commercial values. In this case the salt $\mathrm{K}_{2} \mathrm{SO}_{4}$ is converted to $\mathrm{K}_{2} \mathrm{CO}_{3}$ and $\mathrm{H}_{2} \mathrm{~S}$. $\mathrm{K}_{2} \mathrm{CO}_{3}$ goes back to combustor as seed whereas $\mathrm{H}_{2} \mathrm{~S}$ is further processed to recover sulphur. Following reactions are being studied for this purpose:

A) at $T=1073 \mathrm{~K}$

$$
\mathrm{K}_{2} \mathrm{SO}_{4}+x \mathrm{CO}+(4-x) \mathrm{H}_{2} \rightarrow \mathrm{K}_{2} \mathrm{~S}+x \mathrm{CO}_{2}+(4-x) \mathrm{H}_{2} \mathrm{O}
$$


at $T=773 \mathrm{~K}$

$$
\mathrm{K}_{2} \mathrm{~S}+\mathrm{CO}_{2}+\mathrm{H}_{2} \mathrm{O} \rightarrow \mathrm{K}_{2} \mathrm{CO}_{3}+\mathrm{H}_{2} \mathrm{~S}, \text { and }
$$

B) at $T=1373 \mathrm{~K}$

$$
\mathrm{K}_{2} \mathrm{SO}_{4}+2 \mathrm{C} \rightarrow \mathrm{K}_{2} \mathrm{~S}+2 \mathrm{CO}_{2}
$$

at $T=298 \mathrm{~K}$

$$
\mathrm{K}_{2} \mathrm{~S}+\mathrm{CO}_{2}+\mathrm{H}_{2} \mathrm{O} \rightarrow \mathrm{K}_{2} \mathrm{CO}_{3}+\mathrm{H}_{2} \mathrm{~S}
$$

In a recent study (Joubert et al 1976) it is shown that under certain conditions reactions in (A) can result in almost complete seed regeneration and sulphur removal from the mixture of $\mathrm{K}_{2} \mathrm{SO}_{4}$ and ash. TRW has laboratory tested and patented an MHD seed regeneration process which operates at temperatures from ambient to $70^{\circ} \mathrm{C}$. This is based on the fact that a single chemical (calcium formate) highly soluble in water is available cheaply and can regenerate MHD seed in a single step without heat (Meyers \& Hart 1982).

Selection of most efficient, economic and reliable method of seed/ash collection system is still an open question. All the schemes mentioned above need further development. Seed recovery and regeneration with coal-fired systems appear more complex. It is established that more than $99 \%$ of sulphur in the fuel reacts with seed forming $\mathrm{K}_{2} \mathrm{SO}_{4}$. Consequently $\mathrm{SO}_{x}$ emission from MHD plant is not a serious problem. However, desulphurisation of seed has to be further studied. This may affect the cycle efficiency and overall economy of the MHD power generation.

5.2d Diffuser The function of the diffuser is to reduce the high speed of the plasma and recover the temperature and pressure. Because of the unknown boundary conditions at the channel outlet/diffuser inlet, it is difficult to apply standard aerodynamic considerations to design the MHD diffuser. This arises due to the surface structure and electromagnetic interaction of plasma which in turn leads to thick boundary layers with distorted profiles. Thick boundary layers can lead to flow choking conditions thereby disturbing the fluid dynamics in the system. So far only diffusers (both for subsonic and supersonic flows) with straight wall construction have been studied. More analytical as well as experimental work is necessary to optimise diffuser design in terms of area ratio, Mach Number, aspect ratio etc to achieve efficient pressure recovery.

5.2e Testing and evaluation of metals and alloys for high temperature components The need for development of high temperature ceramic material has been outlined earlier (\$4.8). For the construction of metallic component, there is a wide variety of high temperature and corrosion resistant alloys to choose from. However for the successful demonstration of economic and technical feasibility of MHD technology there is a need for development of metallic components - specially for long duration applications. For example, materials with improved stress rupture and thermal fatigue properties could be effectively used for the boiler, combustor, air preheater etc. for which proven technology for long term performance is still not available. Other items which could use improved metallic components include containment vessel, valves, pumps and water cooling systems.

Metal boiler tubes exposed to seeded combustion products are highly susceptible to corrosion. The details of corrosion activity of slag layer on the tube wall are not fully investigated. Heat exchangers used in conjunction with regeneration also face similar problems. In this case the heat exchanger tubes operate at higher temperature so that 
the corrosion rates and thermal stresses are expected to be high. The data on corrosion rates of complex sulphates with different constituents of the boiler tube alloys is not adequate to analyse this problem fully. The available data indicates that most of the ferritic and austenitic stainless steel have unacceptably high corrosion rates. Only nichrome (60\% chromium $40 \%$ nickel) which is difficult to fabricate shows acceptable level of metal loss. Nalesan (1982) has also investigated the corrosion behaviour of carbon steel, chromium molybdenum ferritic steels, type 310 stainless steels, Incoloy 800 etc after exposure over $500 \mathrm{hr}$ to complex gas mixtures that simulate MHD working medium. Results indicate the suitability of low chromium alloys upto $700 \mathrm{~K}$ and stainless steel and Incoloy to $750 \mathrm{~K}$. To select suitable construction material following are the other properties which must be considered: (a) corrosion resistance to seed/slag and sulphur, (b) creep, (c) fatigue, (d) temperature embrittlement, (e) fabricability, and (f) physical properties such as melting point, thermal expansion, thermal conductivity, elastic constants and phase transformation.

The development and evaluation of material programme thus should include testing and evaluation of alloys, long term corrosion studies and long term stress rupture, thermal fatigue and thermochemical tests.

\section{Technoeconomic and environmental aspects of MHO power generation}

A technology to be commercially acceptable has to be competitive with the existing technologies. In this case MHD power generation process must be compared with thermal and nuclear power. More than 20 years ago when the MHD technology was in its infancy, Kantrowitz \& Sporn (1959) projected a high conversion efficiency and low cost of MHD power. They had predicted that the cost of a $500 \mathrm{MW}$ MHD-steam plant would be about 2-3 times less than that of a nuclear plant and would be comparable to a thermal plant of similar rating. The conversion efficiency of the MHD steam plant was estimated to be between 50 and $60 \%$ as opposed to 30 and $40 \%$ in other cases. With the development of technology and added experience in design, building, and operation of complex MHD equipment, these predictions are still valid in general. For instance, the conversion efficiencies of $45-50 \%$ have been estimated in more recent studies for the first generation and $50-60 \%$ in subsequent MHD-steam plants. Such conclusions have been independently drawn both in the USA (Seikel et al 1976) and in the USSR (Popyrin \& Pschenichnov 1976). Also it is believed that the capital cost of a 500 mW MHD-steam plant would be comparable to the advanced thermal plant and considerably cheaper than the nuclear plants incorporating full controls for safety and environmental acceptance.

To make realistic predictions of the cost of a complex technology is not easy specially when no direct experience is available on working models of commercial scale. The biggest working MHD model plant (U-25) is about 10 times smaller than the proposed commercial MHD plant. Under the circumstances the technoeconomic studies can only serve as a guideline for future development and make relative assessment of the technology.

\subsection{USA cost estimates}

The most comprehensive study on the subject as of today is the Energy Conversion Alternative Study (ECAS) conducted in the USA (NASA 1976). The study compares 30 
different configurations of MHD steam plant. The plant parameters which are treated as variables include (i) type of coal, (ii) combustor design and percentage of slag rejection, (iii) operating pressure for combustor, (iv) oxygen enrichment, (v) type of air preheater and amount of preheat, (vi) type of MHD generator, (vii) magnetic field, (viii) percentage of seed injection, (ix) electrical loading parameter, and (x) plant capacity factor.

It is concluded from this analysis that the cost of power produced from MHD steam plant is relatively insensitive to the parameters mentioned above except for the plant capacity and capital equipment cost. This is presumably because $50 \%$ of the estimated cost accounts for contingency, escalation and interest rates. On the other hand, the cost of electricity is a strong function of fuel and material cost. The escalation in the material cost is quite unfavourable in the case of open cycle MHD-steam plant compared to open cycle gas turbine-steam plant. The report also indicates that open cycle MHD is much more sensitive to the plant capacity factor than any other concepts considered in this study. The relative position of MHD power cycle compared to other advanced cycles is given in figure 28 .

\subsection{USSR cost estimates}

Parallel studies of similar nature, with emphasis on optimising components as well as total plant performance, have been conducted at the Institute of High Temperature, Moscow (Kirillin et al 1975a). Thermal efficiency of open cycle MHD power plants, using a generalised diagram of MHD generator characteristic, was analysed by Ivanov et al (1975b). The feasibility of high oxygen enrichment has been suggested to increase the MHD plant efficiency and to decrease the weight and size of the magnet. However, this leads to increase in initial parameters of working media. The influence of increased oxygen enrichment on nitrogen fixation also seems promising. The question of oxygen storage against oxygen plant capacity for peak load application has also been studied. In this case the MHD generator parameters (coefficient of enthalpy extraction, pressure and the enthalpy in the combustor) were selected by optimisation technique, while

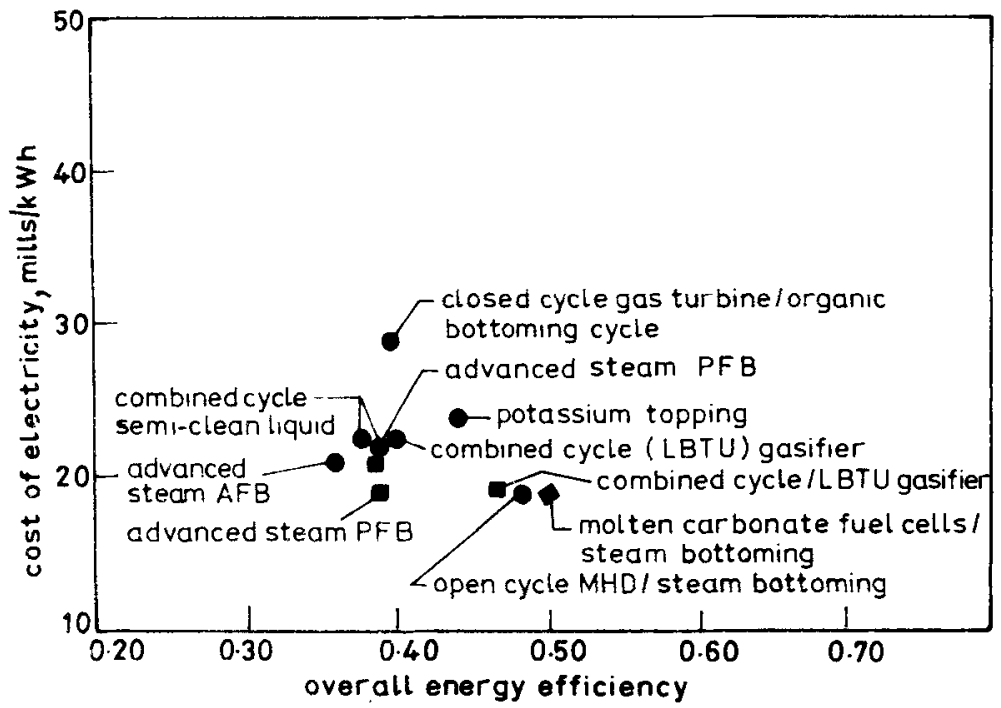

Figure 28. Comparison of OCMHD/steam cycle with other advanced cycles (NASA 1976). 
variation in intermediate load MHD power was considered by varying oxygen enrichment of the oxidizer. Figure 29 gives the logic diagram for the optimisation technique used in this study.

For gaseous fuels, studies in the Soviet Union project capital cost of MHD power between 160 roubles $/ \mathrm{kW}$ (maximum) and 102 roubles $/ \mathrm{kW}$ (minimum). Thus an average capital cost of MHD power of $130 \pm 30$ roubles/ $k W$ for first generation has been estimated (Popyrin \& Pschenichov 1976). Under similar conditions the cost of conventional thermal power is about 110 roubles $/ \mathrm{kW}$. Considering the complexities in the new technology and that these are prototype units, which always tend to be more expensive, the slightly higher cost of MHD compared to thermal is quite understandable. It is encouraging that several independent studies on the subject are in agreement within the limits of variations in the input conditions. The study shows that the most expensive components are oxygen plant, steam generator, low temperature air preheater, inverter unit and the superconducting magnet system. These conclusions are in general agreement with the studies made in the USA. The highest fraction (about $33 \%$ ) of the cost accounts for MHD train, that is generator, superconducting magnet, oxygen

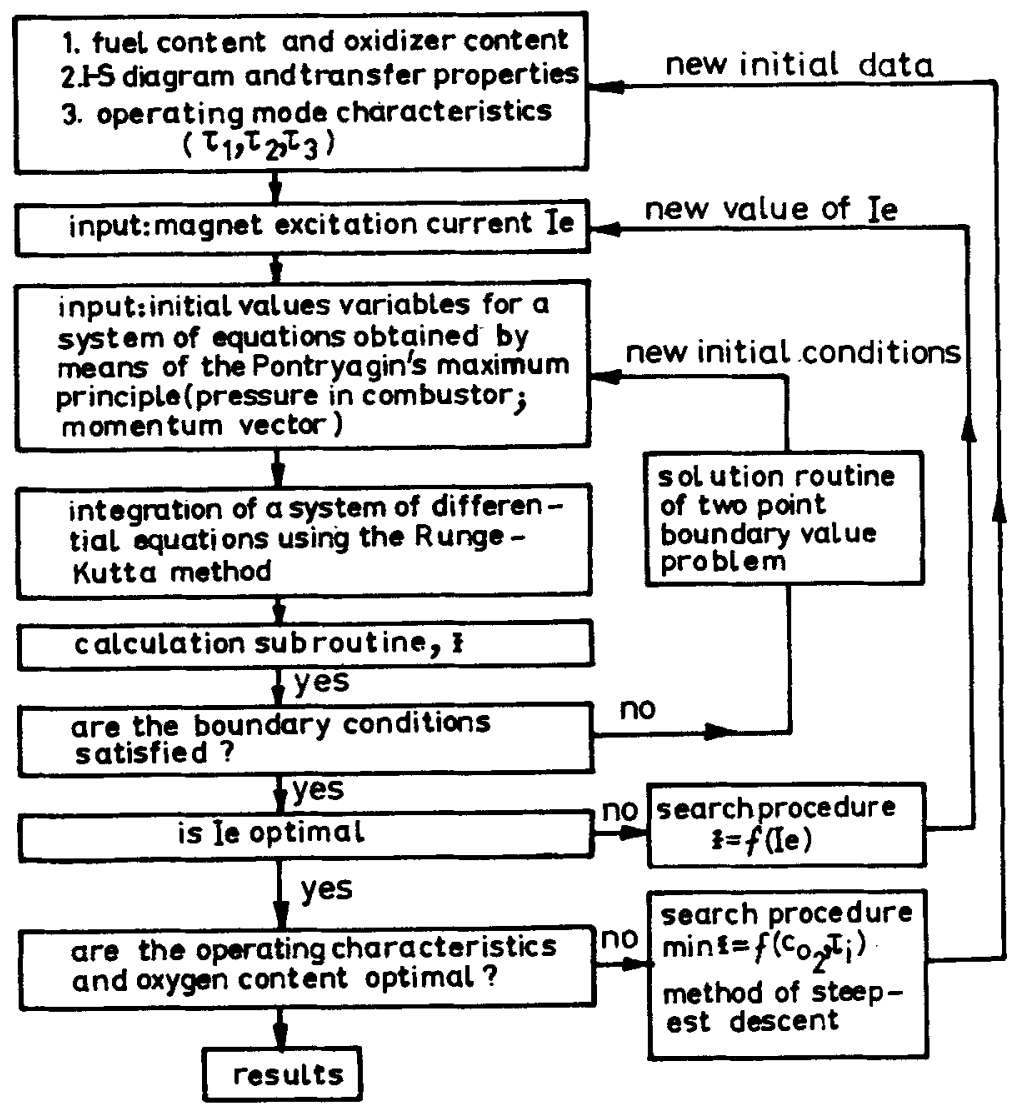

Figure 29. Logic diagram for nonlinear optimisation procedure for intermediate load MHD plant with different oxygen enrichment, $\tau_{1}, \tau_{2}, \tau_{3}$ : Durations of power plant operation, oxygen accumulation and oxygen plant shut down (Ivanov et al 1975). 
plant and ceramic air preheater. Of this, approximately $17 \%$ of the plant cost is in the magnet system alone. The difference in cost estimates in USSR and USA in absolute terms are difficult to explain. This probably arises from the different economic standards and costing procedure.

Figure 30 summarises the cost of electricity from open cycle MHD steam power plant with different parameters (Jayakumar et al 1978). If the fuel cost is less than 15 roubles/unit, the thermal plant is more economical (region $A$, curve 6 ) whereas if the fuel cost is higher than 15 roubles/unit, MHD is more economical (region B, curve 4). Table 10 lists the short term and long term objectives required to make open cycle MHD viable. Some of these parameters have been used as guidelines for the development of MHD technology and are reflected in the earlier discussions.

\subsection{Recent studies on MHD economics}

Two recent studies extending the scope of ECAs are (a) parametric studies of potential early commercial MHD power plants (PSPEC) (Staiger et al 1980) and (b) open cycle MHD systems analysis (Lippert 1980). Under PSPEC assessment programme, Avco and GE made independent evaluation of 3 base case plants and parametric variations about the base cases. It was found that plants using separate firing of advanced HTAH with fuel from advanced coal gasifiers and plants using an intermediate temperature metallic recuperative heat exchanger to heat oxygen enriched combustion air, are comparable in terms of performance and cost of electricity. However, the two estimates from Avco and GE differ in the estimate of capital cost for MHD cycles and the magnet systems. The recommendation of PSPEC study is to follow the route of intermediate preheat and high oxygen enrichment of combustor air. The oxygen enrichment plant offers advantages over the separately fired plant in simplicity and avoidance of a number of systems which require technological development. With high oxygen enrichment, gasifier system, gas clean-up system and regenerative air preheater systems can be eliminated. The study further recommends detailed plant layout studies to permit better estimates of performance and cost.

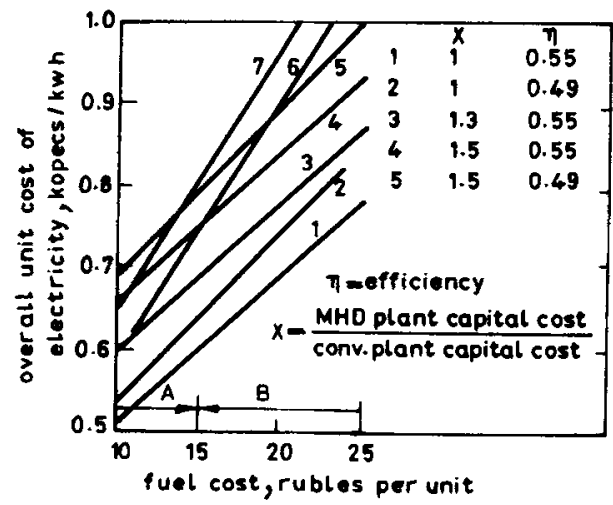

Figure 30. Dependence of calculated expenditures on fuel cost. (Operating hours 7000/yr). 1-5 MHD plants, 6 gas-fired thermal plant, 7 coal-fired thermal plant. 8: Range of operation more economical for MHD plant (curve 4) than conventional plant (curve 6). (Petrick \& Shumyatsky 1978). 
Table 10. Short term and long term parameter values to make open cycle MHD viable

\begin{tabular}{|c|c|c|}
\hline Parameters & Short-term & Long-term \\
\hline Combustor pressure $\left(10^{5} \mathrm{Pz}\right)$ & $6-9$ & $>9$ \\
\hline Air preheat temperature (K) & $\begin{array}{l}1500 \\
\text { (1950-2000 for natural gas) }\end{array}$ & $2000-2250$ \\
\hline Seed (wt $\%)$ & $i$ & 1 or (K-Cs mixture) \\
\hline Hall voltage $(\mathrm{kV} / \mathrm{m})$ & 3 & 6 \\
\hline Hall parameter & 4 & 6 \\
\hline Magnetic field strength (T) & 5 & 7 \\
\hline Load parameter & $0-8-0.85$ & $0.8-0.85$ \\
\hline Plant availability factor & 0.8 & 0.8 \\
\hline \multicolumn{3}{|l|}{ Diffuser recovery } \\
\hline coefficient & 0.8 & 0.8 \\
\hline Channel velocity & $\begin{array}{l}\text { high subsonic or } \\
\text { supersonic }\end{array}$ & $\begin{array}{l}\text { high subsonic or } \\
\text { supersonic }\end{array}$ \\
\hline \multicolumn{3}{|l|}{ Options } \\
\hline Air preheater & Indirect & Direct-fired \\
\hline Generator configuration & Faraday or diagonal & Faraday \\
\hline Bottoming plant & Standard steam cycle & $\begin{array}{l}\text { Advance steam cycle } \\
\text { (gas turbine if technology } \\
\text { can be advanced to } 1145 \mathrm{~K} \text { ) }\end{array}$ \\
\hline Combustor & Direct flow for natural gas & \\
\hline Fuel & $\begin{array}{l}\text { Wet high-sulphur coal- } \\
\text { Clean fuel for separately- } \\
\text { Fired preheater (gas) }\end{array}$ & $\begin{array}{l}\text { dry low-sulphur coal- } \\
\text { clean fuel (gas) }\end{array}$ \\
\hline Plant performance & $0-44-0.50$ & $0.55-0.65$ \\
\hline
\end{tabular}

Ref. Petrick \& Shumyatsky (1978)

In the other study involving open cycle MHD systems (Lippert 1980) the emphasis has been placed on selecting MHD plant components with low technical risks and high overall plant reliability. In so doing the authors have preferred to sacrifice high conversion efficiencies in favour of plant reliability and early commercialisation of MHD power. The summary and comparison of 4 open cycle MHD plants considered in this study are given in table 11.

To ensure high plant availability, in the plant design No. 10, two parallel MHD trains (including combustor, magnet, generator, diffuser and radiant heat exchanger) each capable of maximum MHD power rating of $319 \mathrm{MW}$ have been provided. Under normal operating conditions each channel will run at $86.7 \%$ of its rated value. Figure 31 gives the cycle diagram of the plant design No. 10. When one channel is out of operation or being replaced, the other channel operates at design rating and the down stream components operate in off-design mode at reduced flow. The overall energy efficiency for this design is estimated to be $42.1 \%$ at full load conditions and $40.2 \%$ at half load. Thus using dual channel approach, it has been possible to achieve the required plant availability which is comparable to a conventional coal steam plant but with improved energy efficiencies. The summary of capital cost break-up for this configuration is given in table 12. In the third phase study of the potential early commercial MHD power plants (Hals et al 1982) have estimated the specific cöst estimate of a $500 \mathrm{MW}$ MHD plant as 838 dollars per $\mathbf{k W}$ resulting in a reduction of electricity cost of $3.7 \mathrm{mills} / \mathrm{kWh}$ as compared 
Table 11. Summary and comparison of EPRI/W-OCMHD plant characteristics

\begin{tabular}{|c|c|c|c|c|}
\hline Parameters & $\begin{array}{c}\text { EPRI } / W \\
\text { Plant design } 1\end{array}$ & $\begin{array}{c}\text { EPRI } / W \\
\text { Plant design } 6\end{array}$ & $\begin{array}{c}\text { EPRI } / W \\
\text { Plant design } 8\end{array}$ & $\begin{array}{c}\text { EPRI } / W \\
\text { Plant design } 10\end{array}$ \\
\hline \multicolumn{5}{|l|}{ Design } \\
\hline $\begin{array}{l}\text { Type plant (method of air } \\
\text { prebeat) }\end{array}$ & Direct-fired & $\begin{array}{l}\text { Separately } \\
\text { fired }\end{array}$ & $\begin{array}{l}\text { Oxygen- } \\
\text { enriched }\end{array}$ & Direct-fired \\
\hline Coal type & Illinois No. 6 & Illinois No. 6 & Montana & Illinois No. 6 \\
\hline $\begin{array}{l}\text { Method of sulphur } \\
\text { control }\end{array}$ & $\begin{array}{l}\text { Conventional } \\
\text { scrubber }\end{array}$ & $\begin{array}{l}\text { Conventional } \\
\text { scrubber }\end{array}$ & $\begin{array}{l}\text { Seed } \\
\text { regeneration }\end{array}$ & $\begin{array}{l}\text { Seed } \\
\text { regeneration }\end{array}$ \\
\hline Air prebeat $\left({ }^{\circ} \mathbf{K}\right)$ & 1644 & 1922 & 1100 & 1611 \\
\hline Combustion pressure (atm) & 7.84 & $9 \cdot 80$ & 7.84 & 5.97 \\
\hline Combustion temperature $\left({ }^{\circ} \mathbf{K}\right)$ & 2787 & 2898 & 2783 & 2764 \\
\hline Stock temperature $\left({ }^{\circ} \mathbf{K}\right)$ & 450 & 450 & 378 & 377 \\
\hline \multicolumn{5}{|l|}{ Performance } \\
\hline Net power plant output (MWe) & 858 & 993 & 1000 & 1018 \\
\hline Gross MHD power (MWe) & 621 & 619 & 585 & 640 \\
\hline Gross T-G power (MWe) & 479 & 612 & 603 & 526 \\
\hline Overall energy eficiency $(\%)$ & 43.7 & $42 \cdot 1$ & $37 \cdot 7$ & $42 \cdot 1$ \\
\hline Heat rate ( $\mathrm{kcal} / \mathbf{k W h})$ & 1972 & 2047 & 2281 & 2042 \\
\hline Est. plant EFOR (\%) & $32 \cdot 1$ & $30-3$ & $21 \cdot 3$ & 23.4 \\
\hline \multicolumn{5}{|l|}{$\begin{array}{l}\text { Costs (expressed in } \\
\text { mid-1978 \$) }\end{array}$} \\
\hline Capital Costs $\left(\$ \times 10^{6}\right)$ & 899 & 1138 & 988 & 1055 \\
\hline $\begin{array}{l}\text { Specific capital costs, } \\
(\$ / \mathbf{k W e})\end{array}$ & 1047 & 1146 & 988 & 1036 \\
\hline \multicolumn{5}{|l|}{ Cost of electricity } \\
\hline Capital & 307 & 33.6 & 29.0 & $30-4$ \\
\hline Fuel & $9 \cdot 1(17.6)$ & $9 \cdot 5(18.3)$ & $4 \cdot 5(8 \cdot 7)$ & $9.5(18.3)$ \\
\hline $\begin{array}{l}\text { Operation and } \\
\text { maintenance }\end{array}$ & $4.9(9.2)$ & $4.0(7.5)$ & $2.6(4.9)$ & $3.9(7.4)$ \\
\hline Total & $44 \cdot 7(57.5)$ & $47 \cdot 1(59 \cdot 0)$ & $36 \cdot 1(42.6)$ & $43.8(56 \cdot 1)$ \\
\hline
\end{tabular}

Assumes a 0.70 capacity factor. Costs in parantheses are levelized values in terms of 1995 US dollars. EFOR - efiective forced outage rate.

Ref. Lippert et al (1980)

to conventional steam technology. The capital costs projected in this study are lower than earlier projected figures (table 12).

\subsection{Environmental aspects}

With the current interest in environmental pollution, each energy source is being looked from the view point of its effect on surroundings. With the provision of seed recovery, and high thermal efficiency, MHD plants are expected to offer minimum contamination of environment -emissions and thermal pollution. Although several countries have their own standards of emissions and control, both USA and Japan have extremely strict standards. In USA the Environmental Protection Agency (EPA) has been responsible for the maintenance of clean environment. During 1971, EPA adopted a new source performance standard (NSPS) for the control of the air pollution from large fossil 


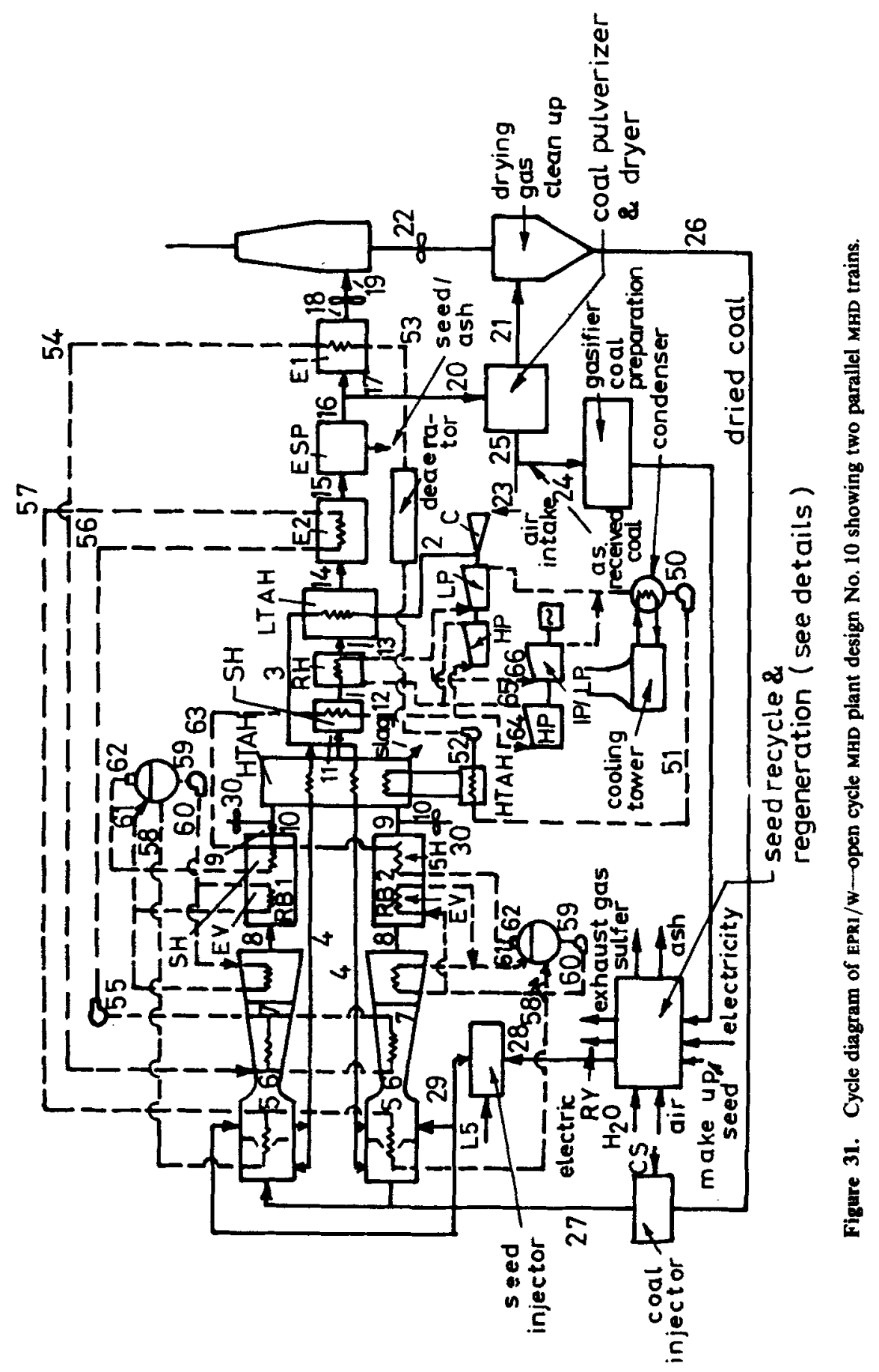


Table 12. Summary of plant capital costs EPRI/W plant design 10 , $1018 \mathrm{MWe}$

\begin{tabular}{lc}
\hline \multicolumn{1}{c}{ Cost components $(\$)$} & Cost (mid-1978) \\
\hline Direct material & $449.6 \times 10^{6}$ \\
Direct labour & $170.1 \times 10^{6}$ \\
Indirects & $315.3 \times 10^{6}$ \\
Total capital costs & $935.0 \times 10^{6}$ \\
Total constructed costs & $1055 \times 10^{6}$ \\
Cost per $/ \mathrm{kW}(\$ / \mathrm{kWe})$ & 1036 \\
\hline
\end{tabular}

Ref. Lippert et al (1980)

fuel-fired steam generating units which is being periodically updated (table 13) (Dimitry et al 1980; Stevenson 1980; Shaw 1980). Also shown in the table are 1974 emission levels, anticipated MHD emission and the proposed 1985 NSPS. It is obvious that MHD plants meet the 1971 NSPS levels. The stricter standards will also be met by MHD plant if designed accordingly.

Cain et al (1980) have discussed the environmental R and D needs of new systems including combined cycles, fluid bed combustion, fuel cells and MHD on a generalised economic and engineering basis. They summarize the major areas as seed reprocessing with sulphur recovery, effect of coal ash composition, possible fumes and $\mathrm{NO}_{x}$ reduction capability to meet future emission standards.

Hopenfeld (1979) has employed exact numerical solutions of $\mathrm{NO}_{x}$ concentrations in coal-fired MHD boilers to correlate the boiler parameters like diameter, stoichiometry and degree of slag carry-over. The results indicate that radiant boilers in commercial MHD plants would normally operate at stoichiometric ratios in the range 0.9-0.95 whereas a still lower ratio around 0.85 will be required to meet stricter EPA standards on $\mathrm{NO}_{x}$ emission.

Because of high temperature and oxygen contents in the MHD combustion products and consequently a higher concentration of nitric oxide in the flue gases of MHD plant compared to the conventional steam turbine power station, the recovery of nitric oxide as byproduct can therefore affect the economy of a MHD plant. The possibilities of manufacturing nitric and sulphuric acids from the flue gases have also been investigated by Wallet \& Gruber (1970).

Table 13. New source performance standard (NSPS) of fossil fuel-fired steam generating units (EPA, USA) (in $\mathbf{g} / \mathbf{K W h}$ )

\begin{tabular}{lccccc}
\hline & $\begin{array}{c}\text { US. Av. } \\
(1974)\end{array}$ & $\begin{array}{c}\text { NSPS } \\
(1971)\end{array}$ & $\begin{array}{c}\text { NSPS } \\
(1979)\end{array}$ & $\begin{array}{c}\text { NSPS } \\
(1985) \\
\text { (proposed) }\end{array}$ & $\begin{array}{c}\text { MHD } \\
\text { (ECAS) }\end{array}$ \\
\hline $\mathrm{SO}_{x}$ as $\mathrm{SO}_{2}$ & 5.10 & 1.86 & 1.86 & 0.92 & 0.77 \\
$\mathrm{NO}_{x}$ as $\mathrm{NO}_{2}$ & 1.71 & 1.08 & 0.98 & 0.23 & 1.10 \\
Particulate matter & 1.60 & 0.15 & 0.05 & 0.03 & 0.15 \\
\hline
\end{tabular}

Ref. Dimitry et al (1980); Stevenson (1980); Shaw (1980) 


\subsection{Retrofit and cogeneration}

The current national MHD programmes emphasise on large scale base load applications. However, the commercial deployment of this technology can be accelerated by retrofitting the MHD concept to an existing generating station. Fung et al (1980) have considered the installation of MHD topping cycle as a viable method for increasing the thermal efficiency and capacity of existing plants since it will reduce capital investments required for the commercial demonstration of MHD technologies.

The total energy concepts have also been applied to MHD cogeneration. Foust \& Jones (1980) have examined the MHD cogeneration for electrochemical industry in particular for production of aluminium which requires large quantities of electricity, steam, and high temperature air. The study deals with the thermodynamics of MHD cogeneration for aluminium and Chlor-alkali production. Using the detailed energy balance for MHD cogeneration for aluminium production and $27.4 \%$ enthalpy extraction at the MHD generator, it is predicted that $82 \%$ of the input fuel energy can be utilised for this process. The authors conclude that the concept developed here is also applicable to other metallurgical industries. Further, since electrochemical plant requires electrical input between 50 and $100 \mathrm{MW}$, this approach could facilitate early commercialisation of MHD cogeneration systems compared to utility base load plant of 500-1000 M.W electrical output.

In short, with the available information and experience, it is now possible to have tailor-made open cycle MHD power plant with the desired performance for base load, intermediate load or peak load applications. The plant efficiency, availability and cost of electricity will depend on the choice of parameters and selection of equipment. Most encouraging is the fact that several independent studies in the USA and the USSR confirm the technological feasibility as well as the economic benefits of open cycle MHD power over conventional steam power.

It would be appropriate to end this chapter with the utility performance requirements (Walter \& Ike 1982) of MHD system summarized succinctly as follows: size, reliability, durability, maintainability, efficiency, information systems, constructability, safety, flexibility, operability, environmental aoceptance, cost and economic factors, availability and siteability.

\section{Concluding remarks}

The progress in the field of MHD power generation during the last 10 years has been summarised in this report. On the basis of this review it is now possible to draw the following conclusions:

(i) The scientific principles of MHD power generation have been fully established and are well beyond the stage of laboratory experiments.

(ii) Adequate scientific and engineering data is available to undertake the commercial plant designs of open cycle MHD steam plants using clean fuel such as natural gas.

(iii) Compared to clean fuel, coal based MHD power is relatively more complicated.

(iv) Key $\mathbf{R}$ and $\mathbf{D}$ problems for gas/coal-based MHD power have been identified. Solutions to these problems are well within the scope of the present day technology. (v) Several independent studies confirm the technical and economical benefits of MHD power. 
(vi) The plant configuration and the alternate selection of component offer sufficient flexibility in the selection of plant design for early commercialisation.

(vii) Given adequate $\mathrm{R}$ and $\mathrm{D}$ support, MHD power can become commercial within this decade and well established before the end of this century.

(viii) Apart from power generation the potential of MHD technology in other industries is also recognised. In the areas of defence, aerospace, nuclear and geophysics, the development of MHD technology has a well defined place.

Broadly, the $\mathbf{R}$ and $\mathrm{D}$ problems which must be pursued actively for early realisation of MHD power generation are the following: (i) Coal gasification and properties of slag including seed/slag chemistry. (ii) Development of high temperature, high efficiency combustor, air preheater, channel, diffuser, radiant boiler, regenerators and other subsystems. In all these developments, long term operation must be emphasised. (iii) Development of superconducting magnet, and inverter systems along with the associated equipment and technology. (iv) Better understanding of the plasma dynamics and electrochemistry in the combustor and channel. More accurate information as regards to heat and mass transfer in all components of the cycle. (v) Development of plasma diagnostics with improved spatial and temporal resolution suitable for use in the presence of magnetic field and slagging conditions. (vi) Development and testing of high temperature insulating and conducting material. (vii) Development and testing of metal alloys with improved thermal and corrosion resistive properties.

Finally though considerable progress has been noted in the field of MHD power generation during the last 10 years, it is very essential to augment the $R$ and $D$ efforts to realise the full potential of this technology within the next two decades.

The authors wish to thank Dr R Ramanna and Mr C Ambasankaran for their encouragement throughout this work. The authors have greatly benefited from the discussions with the scientists of the Institute of High Temperatures, Moscow under the joint Indo-ussR collaboration. The authors would also like to acknowledge the assistance received from their colleagues at the Bhabha Atomic Research Centre and Bharat Heavy Electricals Limited.

The MHD project in India is fully sponsored by the Department of Science and Technology under whose auspices this report has been prepared.

\section{List of symbols}

$\begin{array}{ll}A & \text { area }\left(\mathrm{m}^{2}\right) \\ B & \text { magnetic induction }(\mathrm{T}) \\ C_{p} & \text { specific heat }(\mathrm{J} / \mathrm{kg} \mathrm{K}) \\ E & \text { electric field }(\mathrm{V} / \mathrm{m}) \\ e & \text { internal energy }(\mathrm{J} / \mathrm{kg}) \\ G & \text { mass flow rate }(\mathrm{kg} / \mathrm{s}) \\ j & \text { current density }\left(\mathrm{A} / \mathrm{m}^{2}\right) \\ K & \text { load factor } \\ k & \text { thermal conductivity }(\mathrm{W} / \mathrm{mK}) \\ P & \text { pressure (Pa) } \\ R & \text { universal gas constant }(\mathrm{J} / \mathrm{mol} \mathrm{K})\end{array}$




$\begin{array}{ll}T & \text { temperature }(\mathrm{K}) \\ t & \text { time }(\mathrm{s}) \\ U & \text { velocity in } x \text { direction }(\mathrm{m} / \mathrm{s}) \\ V_{i} & \text { ionization potential }(\mathrm{V}) \\ v & \text { velocity }(\mathrm{m} / \mathrm{s}) \\ x, y, z & \text { coordinates } \\ \beta_{e} & \text { Hall parameter } \\ \varepsilon & \text { relative efficiency of topping cycle } \\ \eta & \text { efficiency } \\ \mu_{0} & \text { permeability }(\mathrm{H} / \mathrm{m}) \\ \rho & \text { density }\left(\mathrm{kg} / \mathrm{m}^{3}\right) \\ \sigma & \text { electrical conductivity }(\mathrm{S}, \mathrm{mho} / \mathrm{m}) \\ \tau & \text { collision time }(\mathrm{s}) \\ \omega_{e} & \text { cyclotron frequency }\left(\mathrm{s}^{-1}\right)\end{array}$

\section{Acronyms}

AVCO, AERL

Avco Everett Research Laboratory, Inc., usA

BARC

BHEL

CARS

Bhabha Atomic Research Centre, Bombay

CDIF

Bharat Heavy Electricals Limited

coherent anti-Stokes Raman spectroscopy

CTF

component development and integration facility, usa

DST

ECAS

EPA

EPRI

GE

HTAH

IVTAN

LDV

MFD

MGD

MHD

controlled thermonuclear fusion

Department of Science and Technology, Government of India

energy conversion alternatives study

Environmental Protection Agency, USA

Electric Power Research Institute, usA

General Electric

high temperature air heater

Institute of High Temperature, UsSR, Academy of Sciences

laser Doppler velocimetry

magnetofluid dynamics

Magneto gas dynamics

magnetohydrodynamics

MPD

Magneto plasma dynamics

NSPS

PSPEC

$\mathbf{R}$ and $\mathbf{D}$

UTSI

new source performance standard

parametric studies of potential early commercial MHD power plants

Research and development

University of Tennessee Space Institute, USA

\section{References}

Agafonova M I, Volovik A V, Kashtanova S P, Nuss V P, Pishikov S I, Razygraev V I, Sokolski A G, Shklyar F R, Shpilrain E E 1980 MHD electrical power generation, Proc. Seventh Int. Conf., MIT, Cambridge, Mass., USA, Vol I, p 397

Akopov F A, Gordon V G, Osika V V, Rekov A I, Serebrennikova V E, Spiridonov E G, Cheryshov G R 1975 MHD electrical power generation, Proc. Sixth Int. Conf., Washington D C, Vol II, p 129

Ali Kettani, Hoyaux M 1973 Plasma engineering (London: Butterworth) 
Ambasankaran C, Rohatgi V K, Ramaprasad V R 1975 MHD electrical power generation, Proc. Sixth Int. Conf., Washington D C Vol I, p 11

Amichand, Sawhney B K 1981 Energy Conv. and Mgmg., 21: 77

Ananthapadmanabhan P V et al 1982 Proc. Indian Acad. Sci. (Engg. Sci) S: 169

Andrez Dr Ing, Alicja Kozlik-Kalak 1980 MHD electrical power generation Proc. Seventh Int. Conf. MIT, Cambridge, Mass., USA, Vol I, p 300

Ariessohn P C, Eustis R H, Self S A 1980 MHD electrical power generation, Proc. Seventh Int. Conf., MIT, Cambridge, Mass., USA, Vol II, p 807

Ashin M I, Vasileva I A, Kosov V F, Nefedov A P, Undev D N 1975 MHD electrical power generation, Proc. Sixth Int. Conf., Washington DC, Vol II, p 185

Baldi R W 1980 MHD electrical power generation, Proc. Seventh Int. Conf., MIT, Cambridge, Mass., USA, Vol II, p 433

Balashov N A, Batenin V M, Vasileva I A, Kosov V F, Nefedov A P, Pinkhasik D S, Rastegayeva Yu Z, Stankevich B 1, Tolchinskiy L S, Urinson A S, Yundev DN 1980 MHD electrical power generation, Proc. Seventh Int. Conf., MIT, Cambridge, Mass., Vol II, p 797

Balashov N A, Vasileva I A et al 1977 J. High Temp. 15: 1101

Barnett L R 1975 M S Thesis, University of Tennessex

Barshak A Ye, Bityurin V A, Granovskiy E A 1976 MHD electrical power generation, Third Joint US/USSR colloquium, Moscow

Beer J M, Chigier N A 1972 Combustion aerodymamics (London: Applied Science Publication)

Biberman L M, Zheleznyak M B, Mnatsakanyan A Kh, Rotinov A G, Tager S A 1980 High Temp. 18: 326

Bityurin V A, Buznikov A Ye, Dolinskiy Yu L, Kovabasyuk V I, Lyubimov G A, Maksimenko V I, Medin S A, Pishikov S I, Satanovskiy V R, Turovets V U, Shumyatsky B Ya 1980 MHD electrical power generation, Proc. Seventh Int. Conf. MIT, Cambridge, Mass., USA, Vol I, p 69

Bityurin V A, Ivanov P P, Koryagina G M, Lyubimov G A, Medin S A, Morozov G N, Prokop A S 1983 High Temp. 20: 306

Bityurin V A, Lyubimov G A 1969 High Temp. 7: 903

Bityurin V A, Lyubimov G A 1979 High Temp. 17: 879

Bityurin V A, Zhelnin V A, Olisevich A K, Osipov M E 1983 MHD electrical power generation, Proc. Eighth Int. Conf., Moscow

Bityurin V A, Zhelnin V A, Lyubimov G A, Medin S A 1978 High Temp. 16: 728

Blitshtein A A, Gusev Yu P, Pischikov S I, Pischikov V I 1979 High Temp. 17: 521

Branover H, Yakhot A, El-Boher A 1980 MHD electrical power generation, Proc. Seventh Int. Conf. MIT, Cambridge, Mass., USA, Vol. I, p 165

Breev V V, Panchanko V P, Chernukha V V 1977 High Temp. 15: 741

Brozozowsky W S 1980 Personal Communication

Brozozowsky W S, Dul J, Zielinski M, Fuksiewicz E, Witkowski R, Radzio B 1983 MHD power generation, Proc. Eighth Int. Conf., Moscow

Bunde R 1975 MHD power generation; Selected problems of combustion MHD generators (Berlin: Springer Verlag)

Bogdanska M, Brozozowski W S, Charuba J, Dabrowski K, Plata M, Zielinski M 1975 MHD electrical power generation, Proc. Sixth Int. Conf., Washington D C, Vol II, p 9

Cadoff L H, Rossing B R 1980 MHD electrical power generation, Proc. Seventh Int. Conf., MIT, Cambridge, Mass., USA, Vol I, p 254

Cain W C, Jahnig C E, Shaw H 1980 Chem. Engg. Progr. (October)

Cales B, Baumard J F 1980 Rev. Int. Hautes, Temper. Refract. Fr. 17: 137

Cannon W R, Yoshimura M, Mizusaki J, Sasamoto T, Pober R L, Hart J, Bowen H K, Louis J F 1978 XVII Symp, Engg. Aspects of MHD Stanford, CA

Chapman S, Cowling T G 1958 Mathematical theory of non-uniform gases II Ed. (Cambridge: University Press)

Clements R M, Smy P R 1978 AIAA J. Energy 2: 53

Crawford L W, Tempelmeyer K E, Martin J, Muchlhauser J 1975 MHD electrical power generation, Proc. Sixth Int. Conf., Washington D C Vol II, p 51

Cristea E D, Mihai D, Lemnean N 1983 MHD power generation Moscow

Das A K 1979 Ph.D. Thesis, University of Bombay

Das A K, Rohatgi V K 1983 MHD power generation, Proc. Eighth Int. Conf. Moscow 
Das A K, Venkatramani N, Rohatgi VK 1981 Coal-fired MHD power generation, Proc. Specialists Meeting, Sydney

Daily J W, Kruger C H 1978 AIAA J. Energy 2: 53

Daily J W, Kruger C H, Self S A, Eustis R H 1975 MHD electrical power generation, Proc. Sixth Int. Conf., MIT, Cambridge, Mass., Vol III, p 451

Devoto R S 1973 Phys. Fluids 16: 616

Dimitry P, Gambhir S P, Heil T J 1980 Combustion 51: 32

Doss E D, Ahluwalia R K 1983 J. Energy 7: 289

Doss E, Geyer H, El-Derini Z, Ahluwalia R K 1980 in Fluids engineering in advanced energy systems (ed.) C H Marston (New York: ASME Publication)

Drain L E 1980 The laser doppler iechnique (Chichestor: John Wiley)

Dvoishnikov V A 1980 High Temp. 18: 334

Eckbreth A C 1980 Paper presented at XVIII International Symposium on Combustion, Waterloo, Canada

Foust O J, Jones Jr. M S 1980 MHD electrical power generation, Proc. Seventh Int. Conf., MIT, Cambridge, Mass., USA, Vol II, p 850

Freeman M 1980 Doubling energy efficiency fusion p 251980 [April]

Fung T K, Griswold J W, Moyer J W 1980 IEEE Trans. Power Apparatus and Systems PAS-99: 1306

Gannon R E, Hals F A, Stickler D B 1975 MHD electrical power generation, Proc. Sixth Int. Conf. Washington D C, Vol II, p 289

Gaponov I N, Poberezhsky L P, Chernov Ya G 1974 Combustion and Flames 23: 29

Gaydon A G, Wolfhard H G 1970 Flames, their structure, radiation and temperature, (Chapman-Hall)

George A M, Pai J R, Rohatgi V K 1976 Engg. Aspects of MHD, XV Symp., Philadelphia PA, Vol II

George A M, Pillai C G S, Gopalakrishnan 1 K, Mathews M D, Nomin A C, Karkhanawala M D 1980 MHD electrical power generation, Proc. Seventh Int. Conf., MIT, Cambridge, Mass, USA, Vol I, p 306

Golovin A M, Peroschin V R 1976 J. High Temp. Moscow 14: 720

Gubasev A V, Ovchinnikov V L 1980 Magnetohydrodynamics 16: 86

Grundy R F (od.) 1978 Magnetohydrodynamics energy for electric power generation, Noyes Data Corporation, Park Ridge, New Jersey

Gupta G P, Rohatgi V K 1981 Proc. Third National Workshop on Atomic and Molecular Physics, Roorkee University

Gupta G P, Rohatgi V K 1981 Energy conversion and management 21: 9

Hals F, Pian C, Westra L, Morgan W, Bozzutoc, Clark J 1982 20th Symposium on engineering aspects of $M H D$, Irvine, California

Harvey R A, Maxwell C D, Miller J L, Demetriades S T 1979 EPRI, AF1230, Final Report

Haywood J B, Womack G J 1969 Open cycle MHD power generation (Oxford: Pergamon Press)

Hosler W R, Frederikse H P R 1975 MHD electrical power generation, Proc. Sixth Int. Conf., Washington D C, Vol II, p 67

Hopenfeld J $1979 \mathrm{~J}$. Energy 3: 335

Hruby V J, Kessler R, Petty S W, Weiss P 1982 20th Symposium on Engineering aspects of MHD, Irvine, California

Hruby V J, Morenski J, Petty S W, Solbes A 1980 MHD electrical power generation, Proc. Seventh Int. Conf., MIT, Cambridge, Mass., USA, Vol I, p 262

Hruby V J, Sadovnik I, Kessler R, Trefethen L 1983 MHD electrical power generation, Proc. Eighth Int. Conf., Moscow

Int. Conf. MHD power generation 1962 Newcastle-on-Tyne; 1964 Paris; 1966 Salzburg, Austria; 1968 Warsaw, Poland; 1971 Munich, FRG; 1975 Washington; 1980 Cambridge, Massachusetts; 1983 Moscow

Isaac Reif, Fassel V A, Kniseley R N 1976 Spectrochim. Acta 318: 377

Ishikawa M 1980 MHD electrical power generation, Proc. Seventh Int. Conf., MIT, Cambridge, Mass, USA, Vol II, p 503

Ivanov P P, Kovbasyuk, V 1, Koryagina, G M, Rogachev A P, Shumyatsky B Ya 1975 Teploenergetika No. $11, \mathrm{p} 8$

Ivanov P P, Koryagina G M, Kovbasyuk V I, Shumyatsky B Ya 1975 MHD electrical power generation, Proc. Sixth Int. Conf., Washington DC, Vol 1, p 21

IVTAN Report 1973 Investigations on U-25

Jayakumar R, Chakravarthy D P, Rohatgi V K 1977 Rev. Sci. Instrum. 48: 1709

Jayakumar R, Goyal D K, Ghosh S, Rohatgi V K 1978 Energy Res. 2: 265 
Jenkins M K, Nakamura T, Vilas T R, Eustis R H 1980 MHD electrical power generation, Proc. Seventh Int. Conf., MIT, Cambridge, Mass., USA Vol II p 495

Jiang Dang-Liang, Mao Zhi-Qiang, Wen-how, Wang Da-Qian, Pan Zhen-Su 1980 MHD electrical power generation, Proc. Seventh Int. Conf., MIT, Cambridge, Mass, USA, Vol I, p 292

Johnson T R, Im K H, Chow L S H, Blackburn P E, Singh R 1978 MHD electrical power operation, Fourth US/USSR Colloquim Washington DC

Joint US-USSR Colloquia MHD Power Generation 1974 Moscow; 1975 Washington; 1976 Moscow; 1978 Washington

Joubert J, Mossabauer P F, Ruppel T C, Bienstock D 1976 Engineering Aspects of MHD, Proc. Fifteenth Symp. Philadelphia, PA, p 741

Kannappan D, Bose T K 1977 Phys. Fluids 20: 1668

Kantrowitz A, Rosa R J 1975 The Phys. Teacher, p 455

Kantrowitz A, Sporn P 1959 Power 103: 62

Kayukawa N, Aoki Y, Ozawa Y, Yoshida M, Umoto J 1983 J. Energy 7: 280

Kazachkov Yu A, Kaxlovich T V, Korotkov B A, Kharitonov A I, Shipulin I I 1968 Energiya 14: 312

Kessler R, McClaine A W, Solbes A $1980 \mathrm{~J}$. Energy 4: 120

Kirillov V V 1979 High Temp. 17: 128

Kirillin V A, Shiendlin A Ya 1980 MHD electrical power generation, Proc. Seventh Int. Conf., MIT, Cambridge, Mass., Vol II, p 613

Kirillin V A, Sheindlin A E, Shumyatsky B Ya, Morozov G N 1975 Magnetohydrodynamic Facilities, Nauka, p 3

Klepeis J E, Cole J, Hruby V J, Louis J F 1975 MHD electrical power generation, Proc. Sixth Int. Conf. Washington DC, Vol I, p 251

Kordus A, Mitkowski E, Grzybowski A, Stiller J 1975 MHD electrical power generation, Proc. Sixth Int. Conf., Washington DC, Vol II, p 251

Kruger C H, Girshik S L 1983 MHD electrical power generation, Proc. Eighth Int. Conf., Moscow

Kuzmenko P J, Self S A $1983 \mathrm{~J}$. Energy 7: 176

Lapworth K C 1974 J. Phys. E7: 413

Larson J W 1981 Modern Power System 1: 39

Lightner R G, Dooley M T 1980 MHD electrical power generation, Proc. Seventh Int. Conf., MIT, Cambridge, Mass., USA, p 40

Lippert T E, McCutchan D A 1980 EPRI, AP-1463, Final Report, July

Lippert T A, McCutchan D A, Weeks K D 1980 MHD electrical power generation, Proc. Seventh Int. Conf., MIT, Cambridge, Mass., USA Vol II, p 673

Mason T O, Petuskey W T, Lang W W, Halloran J W, Yen F, Pollak T M, Elliott J F, Bowen H K 1975 MHD electrical power generation, Proc. Sixth Int. Conf., Washington D C, Vol II, p 77

Messerle H K, Manglick A 1978 J. Phys. D11: 1073

Meyers R A, Hart W D 1982 Engineering aspects of MHD, 20th Symp., Irvine, California

Mittal M L, Masapati G H, Rohatgi V K 1979 Energy Res. 3: 189

Montgomery D B 1975 Engineering problems of fusion research, Sixth Symp., San-Diego p 122

Montgomery D B, Hatch A M, Purcell J R, Marston P, Stekly Z J J 1975 MHD electrical power generation, Proc. Sixth Int. Conf., Washington D C, Vol IV, p 115

Mostinskii I L, Terekhov V A, Rapkin Yu. E, Shatunov V E, Lapecheva M A 1983 MHD Power Generation, Proc. Eigth Int. Conf., Moscow

Murphree D L, Shephard W S, Cook R L, Bauman L E, Srikantiah D V 1983 MHD Power Generation, Proc. Eighth Int. Conf., Moscow

Naidu T K, Hussain S Q, Chandra A, Sawhney B K, Sarkar M K, Sodha M S 1977 Int. J. Pure Appl. Phys. 15: 756

NASA 1976 Energy Conversion Alternative study (ECAS) NASA Lewis Res. Ctr. NAS 3-19406, NAS3-19407

Nalesan K 1982 Engineering aspects of MHD, 20th Symp., Irvine, California

National Symposia on Plasma Physics and Magnetohydrodynamics, India 1975 Bombay; 1977 Bombay; 1979 Bombay

Nedospassov A V, Poberezhskii L P 1979 High Temp. 17: 925

Neimann R C, Johanson E W, Mataya K F, Smith P R, Coppa A P, Tate E, Krajcinovic D, Pashkov S A, Pinkhasik D S, Prinvalov N P, Tsyganov S I 1980 MHD electrical power generation, Proc. Seventh Int. Conf., MIT, Cambridge, Mass., USA, Vo II, p 459 
Nomura A, Okuo T and Aiyama Y 1980 MHD electrical power generation. Proc. Seventh Int. Conf., MTT, Cambridge, Mass., Vol I, p 316

Ohtake K, Yoshikawa N, Nakanishi H, Nagano S 1983 MHD electrical power generation, Proc. Eighth Int. Conf., Moscow

Oliver D A 1975 MHD electrical power generation, Proc. Sixth Int. Conf, Washington D C, Vol I, p 329

Ozawa Y, Kayukawa N 1975 MHD electrical power generation, Proc. Sixth Int. Conf., Washington D C, Vol I, p 399

Ozawa Y and Kayukawa N 1980 MHD electrical power generation, Proc. Seventh Int. Conf., MIT, Cambridge Mass, USA, Vol II, p 516

Pai, Shih-I 1959 Introduction to the theory of compressible flow (Princeton, New Jersey: D Van Nostrand)

Pai J R, George A M, Rohatgi V K 1980 Appl. Phys. 22: 283

Pan Y C, Doss E D 1980 J. Energy 4: 252

Papic M M 1976 Can. J. Chem. Engg. 54: 413

Pashkov S A, Shishkov E V, Pekin M A, Makapova L N 1976 Principle schemes and MHD power plants using gasified solid fuels, IVTAN Report

Pericart J 1966 Round table discussion on liquid metal systems, Int. Symp. MHD, Salzburg, Vol II, p 1142

Petschek H E 1965 MHD Generators, Plasma Physics IAEA Vienna p 253

Petrick M, Shumyatsky B Ya (eds) 1978 Open-cycle MHD electrical power generation, A Joint USA/USSR Publication, Argonne III

Petty S, Rosa R J, Enos G 1975 MHD electrical power generation, Proc. Sixth Int. Conf., Washington D C, Vol I, p 231

Pober R L, Cannon W R, Bowen H K, Louis J F 1980 MHD electrical power generation, Proc. Seventh Int. Conf., MIT, Cambridge, Mass. USA, p 278

Poberezhskii L P 1978 High Temp. 16: 527

Pollina R, Larsen R, Westpfahl D $1980 \mathrm{~J}$. Noncryst. Solids 40: 197

Popyrin L S, Pshenichnov N N 1976 Energy aspects of MHD, Fifteenth Symp., Philadelphia, PA, pL, p 2.1

Prusova N M 1979 High Temp. 17: 712

Raju G V R, Dashiya R P, Gupta B 1983 J. Energy 7: 3

Ray E R, Schainkar R 1980 MHD electrical power generation, Proc. Seventh Int. Conf., MIT, Cambridge, Mass., Vol. I, p 421

Rohatgi V K, Shishkov E V 1981 Joint Indo/USSR Experiment, Final Report

Rohatgi V K, Venkatramani N 1980 Bull. Indian Phys. Assocn. 11: 119

Rohatgi V K, Venkatramani N, Jayakumar R, Das A K, Ramaprasad V R, 1975 MHD electrical power generation, Proc. Sixth Int. Conf., Washington D C, Vol 1, p 45

Rosa R J 1962 Phys. Fluids 5: 1081

Rosa R J 1968 Magnetohydrodynamic energy conversion (New York: McGraw-Hill)

Rosa R 1983 MHD electrical power generation, Proc. Eighth Int. Conf., Moscow

Rosa R J, Powell J R 1975 MHD electrical power generation, Proc. Sixth Int. Conf., Washington D C, Vol IV, p 72

Rossing B R, Cadoff L H, Gupta T K 1975 MHD electrical power generation, Proc. Sixth Int. Conf., Washington D C, Vol II, p 105

Roy G D 1980 ASME publication 80-HT-125

Roy G D, Crawford L W 1980 ASME Paper, 80-WA HT-11

Saari D D 1983 MHD Power Generation, Proc. Eighth Int. Conf., Moscow

Saari D D, Smyth R R, Marksberry C L, White L R, Townes H, Youngblood G E 1980 MHD electrical power generation, Proc. Seventh Int. Conf., MIT Cambridge, Mass, USA Vol I p 371

Sata T, Kasukawa K 1980 Rev. Int. Hautes, Temp. Refract. Fr 17: 174

Satyamurthy P, Marwah R K, Venkatramani N, Rohatgi V K 1979 Int. J. Heat Mass Transfer 22: 1151

Satyamurthy P, Venkatramani N, Rohatgi V K 1981 High. Temp. 19: 788

Satyamurthy P, Venkatramani N, Rohatgi V K 1982 Energy conversion and management 22:

Satyamurthy P, Venkatramani N, Rohatgi V K 1982 Engineering aspects of MHD, Twentieth Symp., Irvine, California

Satyamurthy P, Venkatramani N, Rohatgi V K 1983 MHD Power generation, Proc. Eight Int. Conf., Moscow Sawhney B K, Chandra A, Hussain S Q, Sodha M S 1976 J. Appl. Phys. 47: 3877

Scott M H, Altstatt M C, Wu Y C L, Holt W C, Dicks J B, Galanger E L, Clemons R W 1980 MHD electrical power generation, Proc., Seventh Int. Conf., MIT, Cambridge, Mass, USA, Vol I, p 88 
Seikel G R, Sovie R J, Burns R K, Burna G J, Burkhart J A, Nainiger J J, Smith J M 1976 Engineering aspects of MHD, Fifteenth Symp., Philadelphia, PA, p III4

Self S A 1976 Third US-USSR Colloquium on MHD power generation, Moscow

Self S A 1980 AIAA J. 80: 926

Self S A 1980 AIAA Paper, 80-0926, Global Technology 2000, Baitimore, USA

Self S A, Clements R M, Reigel F O, James R K 1977 AIAA J. Energy 1: 206

Self S A, Kruger C H 1977 AIAA J Energy 1: 25

Shamma S E, Zwick S A, Sacks R A, Doss E D 1980 MHD electrical power generation, Proc. Seventh Int. Conf., MTT, Cambridge, Mass., USA, Vol II, p 510

Shanklin R V 1973 Engineering aspects of MHD, Thirteenth Symposium, Stanford University, Calif.

Sharma R, Das A K, Venkatramani N, Rohatgi V K 1980 MHD electrical power generation, Proc. Seventh Int. Conf., MIT, Cambridge, Mass., USA, Vol II, p 539

Sharma R, Venkatramani N, Rohatgi V K 1979 BARC Technical Report No. 1020

Shaw H 1980 AICHE Symposium series 196 (76) 1

Shelkov E M, Nedospasov A V, Pashkov S A, Baranikov A H, Vasiliev N N, Lukash B E, Shatalov G E, Kurbatov D R 1975 MHD electrical power generation, Proc. Sixth Int. Conf., Washington DC, Vol IV, p 65

Shiendlin A Ya, Kirillov V V, Shumyatsky B Ya 1977 IVTAN Technical Report 477/7 Moscow

Sheindlin A E 1973 Experimental investigation on the model MHD power installation, IVTAN Research Report, M 17/73 Moscow

Simons T D, Eustis R H, Mitchner M 1982 Symposium on Engineering Aspects of MHD, Irvine, California

Sluyter M M 1980 MHD electrical power generation, Private Communication 16th Meeting of the Int. Liaison Group, Butte, Montana

Sluyter M M, Liccardi A L, Sacks S, Sens P F, Vander Laken R A, Blom J, Rietjens L H Th, Dellinger T C, Cook C S, Marston C H, Zauderer B, Copper A P, Tate E 1980 MHD electrical power generation, Proc. Seventh Int. Conf., MIT, Cambridge, Mass., USA, Vol. I, p 34

Status Report (1972) on MHD power generation, At. Energy Rev. 10: 301

Status Report 1977 Joint NEA/IAEA International Liaison Group

Status Report on MHD 1977 OECD

Status Report 1980 Joint IAEA/UNESCO International Liaison Group (under print)

Staiger, Peter J, Abbott, John M 1980 MHD electrical power generation, Proc. Seventh Int. Conf., MIT, Cambridge, Mass., USA, Vol II, p 621

Stekly Z J J, Pittsburg R D, Mushnick S 1980 MHD electrical power generation, Proc. Seventh Int. Conf., MIT, Cambridge, Mass., USA, Vol. II, p 440

Stevenson W J 1980 AICHE Symposium series 196 (76) 117

Stickler D B 1980 MHD electrical power generation, Proc. Seventh Int. Conf., MIT, Cambridge, Mass., Vol III, p 97

Springmann H, Greenburg R, Juhasz A J 1980 MHD electrical power generation, Proc. Seventh Int. Conf., MIT, Cambridge, Mass, USA, Vol I, p 403

Sutton G W, Sherman A 1965 Engineering magnetohydrodynamics (New York: McGraw-Hill)

Swift J D, Schwar M J R 1970 Electrical probes for plasma diagnostics (London: ILIFFE Books Limited)

Symposia on Engineering aspects of MHD-1960, Pennsylvania; 1961 Pennsylvania; 1962 Rochester; 1963 California; 1964 Massachusetts; 1965 Pittsburgh; 1966 Princeton; 1967 Stanford; 1968 Tennessee; 1969 Massachusetts; 1970 California; 1971 Argonne; 1973 Stanford; 1974 Tennessee; 1975 Pennsylvania; 1976 Pittsburgh; 1978 Stanford; 1979 Montana; 1981 Tennessee; 1982 California; 1983 Argonne; 1984 Mississippi

Teare J D, Loubsky W J, Lytle J D, Louis J F 1980 MHD electrical power generation, Proc. Seventh Int. Conf., MIT, Cambridge, Mass., USA, Vol II, p 644

Telegin G P, Romonov A I, Akopov F A, Schneider A, Negas T 1976 High Temp. High Press. 8: 199

Tempelmeyer K E, Sokolov Yu N 1978 Initial test results of the U258 facility, Shakedown Test (No. 1) and MHD generation test (No. 2), DOE/IVTAN MHD

Trung D T, Messerle H K 1981 IEEE Proc. 128: 28

Trung D T, Messerle H K, Ramakrishnan S, Murty S 1980 MHD electrical power generation, Proc. Seventh Int. Conf., MIT, Cambridge, Mass, USA, Vol I, p 426

Unkel W $1980 \mathrm{~J}$. Energy 4: 245

Unkel W, Kruger C H 1983 J. Energy 7: 97 
Unikel W, Kruger C H, Kossler J 1983 J. Energy 7: 10

Velikov Ya P, Volkov Yu M, Zotov A V, Matveyenko O G, Yakyushev A A 1975 MHD electrical power generation, Proc. Sixth Int. Conf., Washington D C, Vol VII, p 141

Vendell E M 1976 Engineering aspects of MHD, Fifteenth Symp., Philadelphia, PA

Venkatramani N, Das A K 1975 Plasma physics and MHD, Proc. Symp., BARC, Bombay, p 218

Vetler A A, Maxwell C D, Demetriades S T 1980 MHD electrical power generation, Proc. Seventh Int. Conf., MIT, Cambridge, Mass, USA, Vol I, p 110

Vorres K S 1980 Int. J. Eng. Res. 4: 109

Wallet A, Gruber A 1970 Proc. Second Int, Clean Air Congress, Washington DC

Walter F E, Ike L J 1982 17th Intersociety Energy Conversion Engineering Conference, Los Angeles, California

Wang S T, Genens L, Gonczy J, Ludwig H, Hoffman J, Mataya K, Lieberg M, Huang Y C, Chen C J, Turner L K, Niemann R C, Kraft E, Gacek D, Johanson E 1980 MHD electrical power generation, Proc. Seventh Int. Conf., MIT, Cambridge, Mass., Vol II, p 442

Way S 1971 Encyclopaedia of chemical technology (New York: John Wiley) p 217

Way $S 1974$ Combustion technology (eds) H B Palmer, J M Beer, (New York: Academic Press)

Womack G J 1969 MHD power generation (Chapman and Hall)

Yoshikawa K, Hattori Y 1975 MHD electrical power generation, Proc. Sixth Int. Conf., Washington DC, Vol I, p 317

Yoshikawa K, Ozawa J, Hattori Y 1979 J. Nucl. Sci. Tech. 16: 316

Zalkind V I, Kirillov V V, Markina A I 1983 High Temp. 20: 941

Zalkind V I, Kirillov V V, Tikhotskii A S, Uspenskaya G L, Burenkov D K, Strekalov N V 1982 High. Temp. 19: 766 